ESCOLA DE ENFERMAGEM

MARYANA DA SILVA FURLAN

CUSTO DIRETO DA OCORRÊNCIA DO EVENTO ADVERSO FLEBITE EM UMA UNIDADE DE INTERNAÇÃO CLÍNICA

SÃO PAULO

2019 
ESCOLA DE ENFERMAGEM

MARYANA DA SILVA FURLAN

\section{CUSTO DIRETO DA OCORRÊNCIA DO EVENTO ADVERSO FLEBITE EM UMA UNIDADE DE INTERNAÇÃO CLÍNICA}

Dissertação apresentada ao Programa de Pósgraduação em Gerenciamento em Enfermagem da Escola de Enfermagem da Universidade de São Paulo, para obtenção do título de Mestre em Ciências

Área de concentração: Fundamentos e Práticas de Gerenciamento em Enfermagem e em Saúde

Orientador: Prof. Dr. Antônio Fernandes Costa Lima

\section{SÃO PAULO}


AUTORIZO A REPRODUÇÃO E DIVULGAÇÃO TOTAL OU PARCIAL DESTE TRABALHO, POR QUALQUER MEIO CONVENCIONAL OU ELETRÔNICO, PARA FINS DE ESTUDO E PESQUISA, DESDE QUE CITADA A FONTE.

Assinatura:

Data:

\section{Catalogação na Publicação (CIP)}

Biblioteca "Wanda de Aguiar Horta"

Escola de Enfermagem da Universidade de São Paulo

Furlan, Maryana da Silva

Custo direto da ocorrência do evento adverso flebite em uma unidade de internação clínica / Maryana da Silva Furlan. São Paulo, 2019.

$150 \mathrm{p}$.

Dissertação (Mestrado) - Escola de Enfermagem da Universidade de São Paulo.

Orientador: Prof. Dr. Antônio Fernandes Costa Lima

Área de concentração: Fundamentos e Práticas de Gerenciamento em Enfermagem e em Saúde

1. Pacientes internados. 2. Cateterismo venoso periférico. 3. Flebite. 4. Enfermagem médica. 5. Cuidados de enfermagem. 6. Custos em enfermagem. I. Título.

Ficha catalográfica elaborada por Fabiana Gulin Longhi Palacio (CRB-8: 7257) 
Maryana da Silva Furlan

Custo direto da ocorrência do evento adverso flebite em uma Unidade de Internação Clínica

Dissertação apresentada ao Programa de Pós-graduação em Gerenciamento em Enfermagem da Escola de Enfermagem da Universidade de São Paulo para obtenção do título de Mestre em Ciências.

Aprovado em:

\section{Banca Examinadora}

Orientador: Prof. Dr. Antônio Fernandes Costa Lima

Instituição: EEUSP

Assinatura:

Prof. Dr. Instituição:

Julgamento:

Assinatura:

Prof. Dr. Instituição:

Julgamento:

Assinatura:

Prof. Dr. Instituição:

Julgamento: Assinatura: 


\section{DEDICATÓRIA}

A Deus e à Nossa Senhora Aparecida, minha luz e fonte inesgotável, que me protegem diariamente.

Aos meus pais, Natal Furlan e Eliane Ferreira da Silva Furlan.

À minha irmã, Fernanda Furlan Santoro.

À minha sobrinha/afilhada, Mirela Furlan Santoro.

À minha avó, Durcinéia Mendes da Silva.

À minha madrinha, Deuzelita Ferreira da Silva. 


\section{AGRADECIMENTOS}

Agradeço a Deus que me deu força, sabedoria e fé durante toda a minha caminhada. Obrigada por me permitir chegar até aqui e ser a minha fortaleza diária.

Agradeço à Nossa Senhora Aparecida, mãe e protetora que me abençoa e ilumina o meu caminho.

À minha amada família que sempre esteve ao meu lado em todos os momentos. Aos meus pais, Natal Furlan e Eliane Ferreira da Silva Furlan, que são a minha inspiração. Obrigada por me incentivarem diariamente a perseguir os meus sonhos, por todo o apoio durante a minha vida. Vocês que sempre colocaram a educação em primeiro lugar e levo isso como exemplo, tudo que construí e sou hoje devo a vocês que, mesmo morando longe, preenchem o meu coração de amor e me dão forças para continuar na caminhada. Vocês são luz na minha vida.

Ao meu querido orientador, Professor Dr. Antônio Fernandes Costa Lima, muito obrigada pelo conhecimento transferido, paciência, orientação e compreensão durante esta trajetória. Agradeço a Deus pela sua vida, obrigada pelos ensinamentos, admiro muito a sua ética e o amor que você tem no exercício da docência.

À minha irmã, Fernanda Furlan Santoro, que sempre torce por mim e me incentiva a enfrentar novos desafios, obrigada por todo o carinho e pelo presente lindo que é a minha afilhada Mirela.

À minha avó, Durcinéia Mendes da Silva, e à minha madrinha, Deuzelita Ferreira da Silva, que estão presentes em todas as minhas batalhas e vitórias, obrigada por todas as orações.

A todos do Hospital Campo de Estudo (HCE), lugar onde realizei a minha residência e comecei a minha vida profissional, obrigada por ser uma instituição que apoia os colaboradores no desenvolvimento e pela oportunidade de crescer a cada dia. 
Aos profissionais da Unidade de Internação Clínica do HCE que são pessoas especiais que moram no meu coração, vocês me deram muito apoio nesta caminhada. Obrigada por tudo!

Aos docentes e colegas do Programa de Pós-graduação em Gerenciamento em Enfermagem - PPGEn -, pelo convívio enriquecedor que muito acrescentou à minha prática profissional e por transformarem a minha forma de ver o mundo.

Às Professoras Valéria Castilho, Marli de Carvalho Jericó, Daisy Maria Rizatto Tronchin e Marta Maria Melleiro, que contribuíram para este trabalho no meu exame de qualificação.

Às minhas amigas, Jéssica Batistela Vicente, Beatriz Castanheira Facio, Marielli Terassi, Mariana Ferreira, Mayara Caroline Barbieri e Renata Hermógenes da Silva, vocês são presentes que a Universidade Estadual de Maringá me deu, obrigada pelo incentivo para ingressar neste desafio e por todo o apoio.

À minha amiga Andrea Penha Santana, que está presente em todos os momentos da minha vida aqui em São Paulo, obrigada pela força e por sempre me acolher.

A todos que me incentivaram, estiveram ao meu lado e acreditaram em mim. Obrigada pela conversa, palavras de apoio. Deixo o meu agradecimento a todos que não citei, mas que não deixaram de se fazer presentes em minha vida. 
"Desistir? Eu já pensei seriamente nisso, mas nunca me levei realmente a sério. É que tem mais chão nos meus olhos do que cansaço nas minhas pernas, mais esperança nos meus passos do que tristeza nos meus ombros, mais estrada no meu coração do que medo na minha cabeça".

(Cora Coralina) 
Furlan MS. Custo direto da ocorrência do evento adverso flebite em uma Unidade de Internação Clínica [dissertação]. São Paulo: Escola de Enfermagem, Universidade de São Paulo; 2019.

\section{RESUMO}

Introdução: Nas organizações hospitalares, estudos sobre os custos do evento adverso (EA) flebite ainda são escassos. Portanto, conhecer as causas desse EA e o impacto financeiro associado ao seu manejo pode consistir em importante fonte de informação visando à melhoria dos processos assistenciais e gerenciais. Objetivos: Analisar a ocorrência e as causas do EA flebite em pacientes da Unidade de Internação Clínica de um hospital privado no município de São Paulo; identificar o custo direto médio (CDM) dos procedimentos realizados para o tratamento do EA flebite em pacientes da Unidade de Internação Clínica; e estimar o CDM dos procedimentos realizados para o tratamento do EA flebite em pacientes da Unidade de Internação Clínica no ano de 2017. Método: Pesquisa quantitativa, exploratório-descritiva, do tipo estudo de caso único. A partir da análise dos formulários eletrônicos de notificação da ocorrência do EA flebite, em 2017, foram identificados os registros dos procedimentos realizados para o seu manejo. A amostra constituiu-se de cinco observações não participantes de cada procedimento para os diferentes graus de flebite a fim de subsidiar a aferição dos custos e, posteriormente, a estimativa de custos em 2017. Calculou-se o CDM, multiplicando-se o tempo (cronometrado) despendido por técnicos de enfermagem pelo custo unitário da mão de obra direta (MOB), somando-se ao custo dos materiais. Os valores obtidos foram convertidos para o dólar norte-americano (US\$). Resultados: Em 2017, foram notificadas 107 flebites associadas a 96 pacientes, a maioria com registro de uma ocorrência $(91,7 \%)$, do sexo masculino $(53,1 \%)$, na faixa etária de $60-69$ anos $(23 \%)$ e com tempo de permanência inferior a quatro dias (30,2\%). Quanto às doenças pré-existentes, destacaram-se hipertensão arterial sistêmica $(22,9 \%)$, diabetes mellitus (15,6\%) e dislipidemia (12,5\%); 68 pacientes apresentaram hipóteses diagnósticas médicas relativas a afecções infecciosas. Prevaleceu a ocorrência de flebite em pacientes com acesso venoso periférico (AVP) com cateter Jelco® $(52,3 \%)$, o tempo de permanência do dispositivo de 24 h (38,3\%); a classificação em grau 2 (45,8\%); a infusão de antibióticos (46,7\%); a localização do leito distante do posto de enfermagem (52,3\%); e a presença de acompanhante $(82,2 \%)$. Houve diferença estatística significante entre a ocorrência de flebite grau 2 e as doenças pré-existentes hipertensão arterial sistêmica $(p=0,020)$, transtornos mentais e comportamentais $(p=0,020)$ e neuropatia $(p=0,005)$; a flebite grau 2 e a notificação realizada pelo enfermeiro e a notificação de forma anônima ( $p=0,007)$; o baixo risco de desenvolvimento de flebite associado ao uso de solução eletrolítica $(p=0,003)$ e antiviral $(p=0,018)$; a classificação de dano leve e a infusão do fármaco Oxacilina $(p=0,007)$; o dano causado pela 
flebite e as doenças pré-existentes transtorno mental e de comportamento $(p=0,014)$ e hipotireoidismo $(p=0,042)$ e a hipótese diagnóstica médica de Sepse $(p=0,023)$. Para o tratamento dos diferentes graus de flebite, notificadas no ano de 2017, foram realizados três procedimentos: "aplicação de pomada de extrato de flor de camomila"; "aplicação de compressas" e "instalação de AVP", em consonância com o protocolo vigente no hospital campo de estudo. O CDM total do procedimento "aplicação de pomada de extrato de flor de camomila" correspondeu a US\$ 0.55 (DP=0.06), sendo US\$ $0.40(\mathrm{DP}=0.06)$ com a MOB de técnico de enfermagem e o CDM total do procedimento "aplicação de compressas" a US\$ 0.51 ( $\mathrm{DP}=0.00)$, sendo US\$ $0.36(\mathrm{DP}=0.00)$ com a MOB de técnico de enfermagem. O CDM total do procedimento "instalação de AVP com cateter jelco®" foi de US\$3.85 (DP=0.08), sendo US\$ 2.91 ( $\mathrm{DP}=0.00)$ correspondente ao custo do material, e do procedimento "instalação de AVP com cateter íntima ${ }^{\circledR}$ " foi de US\$ 8.90 (DP=0.06), sendo US\$ 7.94 (DP=0.00) correspondentes ao custo do material. Em 2017, verificou-se o registro da realização de 656 (100\%) procedimentos, sendo a maioria $(49,7 \%)$ para o tratamento de flebite grau 2 e para flebite grau $3(26,2 \%)$, e os procedimentos mais realizados foram "aplicação da pomada de extrato de flor de camomila" $(72,1 \%)$ e "aplicação de compressas" $(14,1 \%)$. A estimativa do CDM total dos 656 (100\%) procedimentos correspondeu a US\$ 866.18, com forte impacto do CDM do quantitativo da "instalação de acesso venoso periférico com cateter íntima ${ }^{\circledR}$ ( 42 procedimentos - 6,4\%), com CDM estimado em US $\$ 373.80$, e da "aplicação de pomada de extrato de flor de camomila" (473 procedimentos - 72.1\%), CDM estimado em US\$260.15. A "instalação de AVP", considerando-se a somatória dos custos com cateter jelco $\AA$ e cateter íntima $\AA$, foi o procedimento com a estimativa de CDM mais elevado (US\$ 558,60 - 90 procedimentos), correspondendo a 64.5\% do CDM total. Conclusão: A análise das ocorrências e das causas do EA flebite, na Unidade de Internação Clínica, e o conhecimento sobre os custos dos procedimentos preconizados para o seu manejo contribuirão para tomadas de decisão que incrementem a qualidade e a segurança dos cuidados.

Descritores: Pacientes internados, Cateterismo venoso periférico, Flebite, Enfermagem Médica, Cuidados de enfermagem, Custos em enfermagem, Custos e análise de custo. 
Furlan MS. Direct cost associated with the adverse event phlebitis in an Outpatient Clinic Unit [dissertation]. São Paulo: Escola de Enfermagem, Universidade de São Paulo; 2019.

\section{ABSTRACT}

Introduction: Studies about phlebitis adverse event (AE) costs in hospital organizations are still scarce. Therefore, knowing the causes of this $A E$ and its financial impact may be an important source of information for the improvement of care and management processes. Objectives: To analyze the occurrence and the causes of the phlebitis $A E$ among patients in the Outpatient Clinic Unit of a private hospital in the city of São Paulo; to identify the mean direct cost (MDC) of the procedures performed for the treatment of the phlebitis AE in patients from the Outpatient Clinic Unit and to estimate the MDC of the procedures performed for the treatment of the phlebitis AE in patients from the Outpatient Clinic Unit in 2017. Method: Quantitative, exploratory, descriptive, single-case study. The analysis of the electronic forms notifying the occurrence of the phlebitis AE registered in 2017 allowed identifying the clinical procedures performed for the AE management. The sample consisted of five non-participant observations of each procedure performed with the different levels of phlebitis. The observations were aimed at assessing costs, and later, estimating costs for the year 2017 . The MDC was calculated by multiplying the time spent by nursing technicians by the direct labor (DL) hourly rate, and then adding the value obtained to the costs of the material used. The values obtained were converted to US dollars (US\$). Results: In 2017, a total of 107 phlebitis cases, associated with 96 patients were reported. Most cases were of one occurrence (91.7\%), with male patients $(53.1 \%)$, in the age range of $60-69$ years $(23 \%)$ and with a length of stay of less than 4 days $(30.2 \%)$. The most common pre-existing conditions were Arterial Systemic Hypertension (22.9\%), Diabetes Mellitus (15.6\%) and Dyslipidemia (12.5\%); 68 patients presented diagnostic hypothesis of infectious diseases. Phlebitis was more common among patients with peripheral venous catheter (PVC) with a Jelco® catheter $(52.3 \%)$; indwelling time of 24 hours (38.3\%); grade 2 phlebitis $(45,8 \%)$; infusion of antibiotics $(46.7 \%)$; beds located far from the nursing station (52.3\%); and with the presence of a companion (82.2\%). There was statistically significant difference between: grade 2 phlebitis and the pre-existing conditions Systemic Arterial Hypertension $(\mathrm{p}=0.020)$, mental and behavioral disorders $(p=0.020)$ and Neuropathy $(p=0.005)$; grade 2 phlebitis and notifications registered by the nurse and anonymous notifications ( $p=0.007)$; low risk of developing phlebitis and use of electrolytic $(p=0.003)$ and antiviral $(p=0.018)$ solutions; classification of mild damage and infusion of the drug Oxacillin ( $p=0,007)$; the harm caused by phlebitis and the pre-existing conditions mental and behavioral disorders $(p=0.014)$, hypothyroidism $(p=0.042)$ and diagnostic hypothesis of sepsis $(p=0,023)$. Three procedures were performed for the treatment 
of the different degrees of phlebitis reported in 2017: "application of chamomile extract ointment"; "application of compresses" and "insertion of PVC", according to the hospital protocol. The MDC of the procedure "application of chamomile extract ointment" was US $\$ 0.55$ $(S D=0.06)$, of which US $\$ .40(D P=0.06)$ corresponded to the $D L$ of the nursing technician. The MDC of the procedure "application of compresses" was US\$ 0.51 (SD=0.00), of which US\$ $0.36(S D=0.00)$ corresponded to the $\mathrm{DL}$ of the nursing technician. The MDC of the procedure "insertion of PVC with jelco® catheter" was US\$ $3.85(\mathrm{SD}=0.08)$, of which US $\$ 2.91$ $(S D=0.00)$ corresponded to the cost of the material. The MDC of the procedure "insertion of PVC with íntima ${ }^{\circledR}$ catheter" was US\$ 8.90 ( $\left.S D=0.06\right)$, of which US\$ $7.94(S D=0.00)$ corresponded to the cost of the material. In 2017, a total of 656 (100\%) procedures were performed, most of them associated with grade $2(49.7 \%)$ and grade 3 phlebitis (26.2\%). The most common procedures were "application of chamomile extract ointment" $(72.1 \%)$ and "application of compresses" (14.1\%). The estimated MDC of the $656(100 \%)$ procedures was US\$ 866.18, with a strong impact of the procedures "insertion of peripheral venous catheter with intíma ${ }^{\circledR}$ catheter" (42 procedures - 6.4\%), with an MDC estimated at US\$373.80, and "application of chamomile extract ointment" (473 procedures - $72.1 \%$ ), with an MDC estimated at US\$ 260.15. The procedure "insertion of PVC", considering both the jelco $₫$ and intima $₫$ catheters, had the highest estimated MDC (US\$ 558.60 - 90 procedures), corresponding to $64.5 \%$ of the total MDC. Conclusion: The analysis of the occurrence and causes of the phlebitis $A E$ in the Outpatient Clinic Unit and the knowledge about the costs associated with the procedures recommended for its management will contribute to decisions that increase the quality and safety of care.

Descriptors: Inpatient, Catheterization, Peripheral, Phlebitis, Nursing, Nursing Care, Health Care Costs, Costs and Cost Analysis 


\section{LISTA DE TABELAS}

Tabela 1 - Distribuição dos pacientes acometidos por flebite na Unidade de Internação Clínica conforme sexo, faixa etária e tempo de permanência. São Paulo-SP, Brasil, 2019 ( $N=96)$

Tabela 2 - Distribuição das notificações de flebites, no período de janeiro a dezembro de 2017, segundo o mês, turno e categoria profissional do relator - São Paulo-SP, Brasil, $2019(\mathrm{~N}=107)$

Tabela 3 - Caracterização das flebites notificadas $(\mathrm{N}=107)$ quanto ao tipo de dispositivo, tempo de permanência do dispositivo, grau da flebite, categoria do fármaco infundido - São PauloSP, Brasil, 2019

Tabela 4 - Distribuição do grau das flebites notificadas segundo as variáveis sexo, faixa etária e tempo de permanência dos pacientes - São Paulo-SP, Brasil, 2019 (N=107)

Tabela 5 - Distribuição do grau das flebites notificadas segundo as variáveis doenças pré-existentes e agrupamento das hipóteses diagnósticas médicas - São Paulo-SP, Brasil, $2019(\mathrm{~N}=107)$

Tabela 6 - Distribuição do grau das flebites notificadas $(\mathrm{N}=107)$ segundo as variáveis: mês da ocorrência, turno e categoria profissional do relator - São Paulo-SP, Brasil, 2017.

Tabela 7 - Distribuição do grau das flebites notificadas segundo as variáveis tipo de dispositivo, classe do fármaco, localização do leito em relação ao posto de enfermagem e presença de acompanhante - São Paulo-SP, Brasil, 2019 (N=107) ...

Tabela 8 - Distribuição da avaliação de risco para desenvolvimento de flebite segundo as variáveis sexo, faixa etária e tempo de permanência dos pacientes - São Paulo-SP, Brasil, 2017.

Tabela 9 - Distribuição da avaliação de risco para desenvolvimento de flebite segundo as variáveis doenças pré-existentes e agrupamento das hipóteses diagnósticas médicas - São Paulo-SP, Brasil, 2017

Tabela 10 - Distribuição da avaliação de risco para desenvolvimento de flebite segundo as variáveis: mês da ocorrência, turno e categoria profissional do relator - São Paulo-SP, Brasil, 2017 
Tabela 11 - Distribuição da avaliação de risco para desenvolvimento de flebite segundo as variáveis tipo de dispositivo, classe do fármaco, localização do leito em relação ao posto de enfermagem e presença de acompanhante - São PauloSP, Brasil, 2017.

Tabela 12 - Distribuição da classificação do dano ocasionado pelo EA flebite segundo as variáveis sexo, faixa etária e tempo de permanência dos pacientes - São Paulo-SP, Brasil, 2017

Tabela 13 - Distribuição da classificação do dano ocasionado pelo EA flebite segundo as variáveis doenças pré-existentes e agrupamento das hipóteses diagnósticas médicas - São Paulo-SP, Brasil, 2017

Tabela 14 - Distribuição da classificação do dano ocasionado pelo EA flebite segundo as variáveis mês da ocorrência, turno e categoria profissional do relator - São Paulo-SP, Brasil, 2017

Tabela 15 - Distribuição da classificação do dano ocasionado pelo EA flebite segundo as variáveis tipo de dispositivo, tempo de permanência do dispositivo, classe do fármaco, localização do leito em relação ao posto de enfermagem e presença de acompanhante - São Paulo-SP, Brasil, 2017.

Tabela 16 - Distribuição do tempo de permanência do cateter segundo as variáveis grau de flebite, classificação do dano e avaliação de risco - São Paulo-SP, Brasil, 2019

Tabela 17 - Distribuição das observações do procedimento "aplicação de pomada de extrato de flor de camomila", segundo o custo com MOB de técnico de enfermagem, custo com material e custo direto médio total - São Paulo - SP, 2019

Tabela 18 - Distribuição das observações do procedimento "aplicação de compressas", segundo o custo com MOB de técnico de enfermagem, custo com material e custo direto médio - São Paulo - SP, 2019

Tabela 19 - Distribuição das observações do procedimento "instalação de acesso venoso periférico com cateter jelcoß", segundo o custo com MOB de técnico de enfermagem, custo com material e custo direto médio - São Paulo - SP, 2019. .89

Tabela 20 - Distribuição das observações do procedimento "instalação de acesso venoso periférico com cateter íntima®", segundo o custo com MOB de técnico de enfermagem, custo com material e custo direto médio - São Paulo - SP, 2019. 
Tabela 21 - Distribuição dos procedimentos realizados para o tratamento de flebite em pacientes da Unidade de Internação Clínica, no ano de 2017, segundo o grau da flebite, tipo de procedimento e quantitativo - São Paulo SP, 2019

Tabela 22 - Distribuição dos procedimentos realizados para o tratamento de flebite em pacientes da Unidade de Internação Clínica, no ano de 2017, segundo o grau da flebite, tipo de procedimento e quantitativo e estimativa do custo direto médio - São Paulo - SP, 2019 


\section{LISTA DE QUADROS}

Quadro 1 - Protocolo para condução de estudo de caso único sobre custo da ocorrência do EA flebite em pacientes internados na

Unidade de Internação Clínica. São Paulo, 2018

Quadro 2 - Cálculo do custo e do custo estimado, a partir do consumo observado, em reais e dólares norte-americanos. São PauloSP, Brasil, 2018.

Quadro 3 - Distribuição das doenças pré-existentes e do agrupamento, em categorias, das hipóteses diagnósticas médicas dos pacientes $(\mathrm{N}=96)$ acometidos por flebite na Unidade de Internação Clínica. São Paulo-SP, Brasil, 2019. 


\section{LISTA DE SIGLAS}

\begin{tabular}{|c|c|}
\hline ANVISA & Agência Nacional de Vigilância Sanitária \\
\hline CCIP & Cateter Central de Inserção Periférica \\
\hline CDM & Custo Direto Médio \\
\hline CEP & Comitê de Ética em Pesquisa \\
\hline CONASS & Conselho Nacional de Secretários de Saúde \\
\hline COREN-SP & Conselho Regional de Enfermagem de São Paulo \\
\hline EA & Eventos Adversos \\
\hline EUA & Estados Unidos da América \\
\hline HAS & Hipertensão Arterial Sistêmica \\
\hline HCE & Hospital Campo de Estudo \\
\hline HC-FMUSP & $\begin{array}{l}\text { Hospital das Clínicas da Faculdade de Medicina da } \\
\text { Universidade de São Paulo }\end{array}$ \\
\hline HMPS & The Harvard Medical Practice Study \\
\hline ICPS & International Classification for Patient Safety \\
\hline INS & Infusion Nursing Society \\
\hline IQG & Qmentum International \\
\hline $\mathrm{JCl}$ & Joint Commission International \\
\hline MOB & Mão de obra direta \\
\hline MS & Ministério da Saúde \\
\hline OECD & Organization for Economic Co-operation and Development \\
\hline OMS & Organização Mundial da Saúde \\
\hline OPAS & Organização Pan-Americana da Saúde \\
\hline PNSP & Programa Nacional de Segurança do Paciente \\
\hline RDC & Resolução da Diretoria Colegiada \\
\hline ROPs & Required Organizational Pratices \\
\hline SAE & Sistematização da Assistência de Enfermagem \\
\hline SAME & Serviço de Arquivo Médico e Estatística \\
\hline SUS & Sistema Único de Saúde \\
\hline TIV & Terapia intravenosa \\
\hline
\end{tabular}




\section{SUMÁRIO}

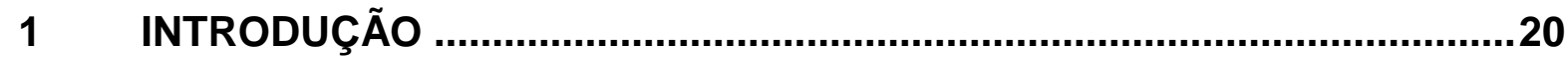

1.1 JUSTIFICATIVA PARA A REALIZAÇÃO DO ESTUDO …............................21

1.2 A SEGURANÇA DO PACIENTE E OS CUSTOS PARA OS

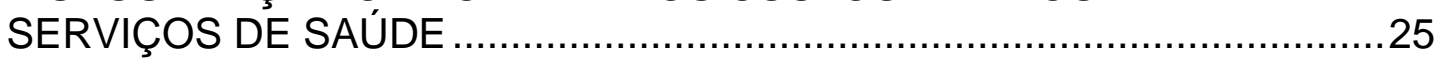

2 OBJETIVOS

3 MÉTODO

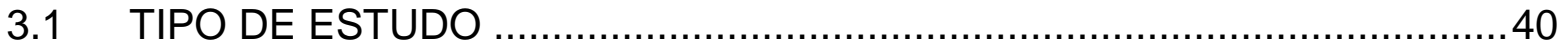

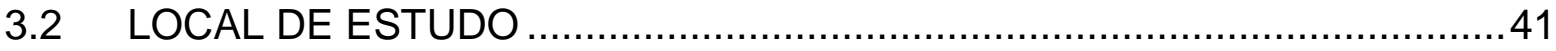

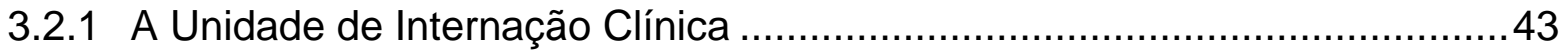

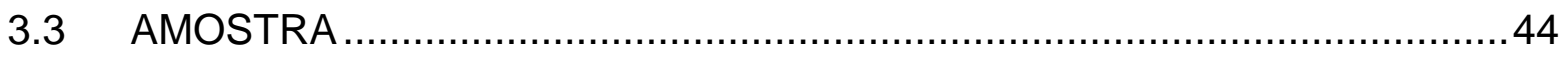

3.4 PROCEDIMENTOS PARA A COLETA DE DADOS E AFERIÇÃO DE

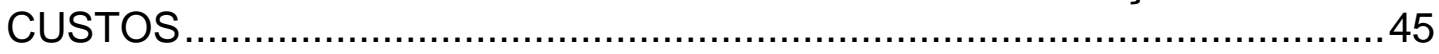

3.4.1 Protocolo para realização do estudo de caso …….....................................45

3.4.2 Cálculo do custo da mão de obra direta (MOD) ......................................48

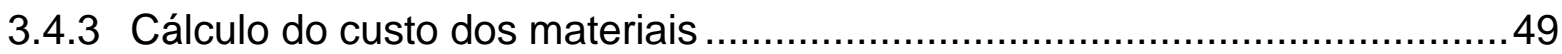

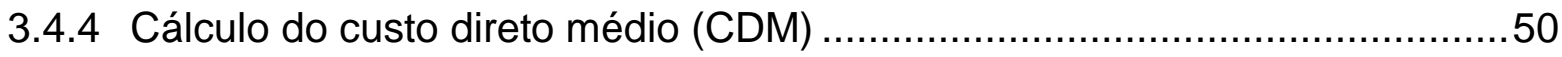

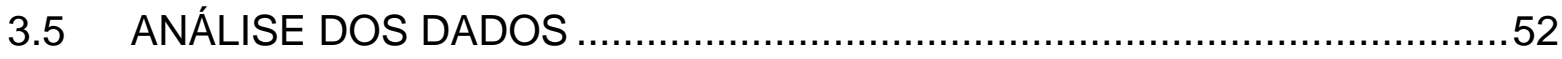

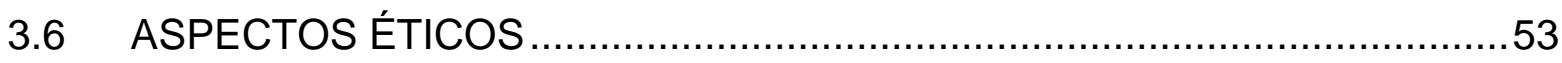

$4 \quad$ APRESENTAÇÃO DOS RESULTADOS ...........................................54

4.1 PERFIL DOS PACIENTES ACOMETIDOS POR FLEBITE EM UMA UNIDADE DE INTERNAÇÃO CLÍNICA ……………….............................55

4.2 CARACTERIZAÇÃO DAS NOTIFICAÇÕES DA OCORRÊNCIA DE FLEBITES EM UMA UNIDADE DE INTERNAÇÃO CLÍNICA .....

4.3 IDENTIFICAÇÃO DO CDM DOS PROCEDIMENTOS REALIZADOS PARA O TRATAMENTO DO EA FLEBITE.

4.4 ESTIMATIVA DO CDM DOS PROCEDIMENTOS REALIZADOS PARA O TRATAMENTO DO EA FLEBITE NA UNIDADE DE INTERNAÇÃO CLÍNICA EM 2017 …........................................................90

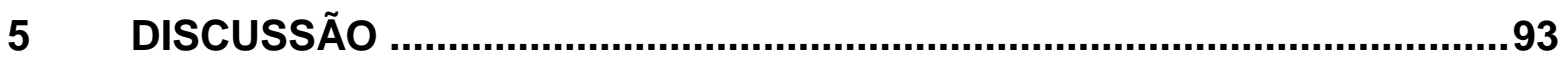

6 CONCLUSÃO

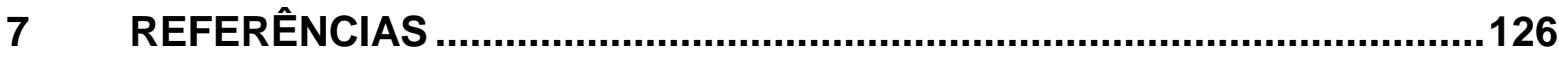

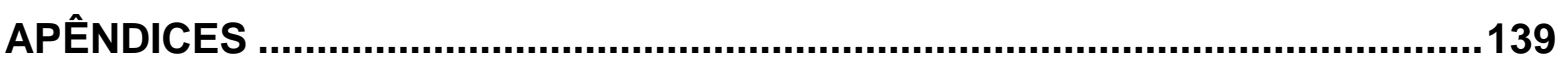




\section{INTRODUÇÃO}

\subsection{JUSTIFICATIVA PARA A REALIZAÇÃO DO ESTUDO}

Durante a internação hospitalar aproximadamente $80 \%$ dos pacientes recebem terapia intravenosa (TIV) e, destes, $20 \%$ a $70 \%$ desenvolvem flebite ${ }^{1}$, uma das principais razões para a remoção do cateter ${ }^{2}$. Considerando-se que a taxa aceitável da ocorrência de flebite é de $5 \%$ ou menos ${ }^{3}$, torna-se imprescindível investigar as causas da ocorrência desse evento adverso (EA) e mensurar o seu custo para as instituições de saúde.

Estudo realizado em uma unidade de internação clínica, em 2014, por meio de observação não participante guiada por um questionário, identificou a presença de flebite em $60 \%$ dos pacientes e em $55,6 \%$ dos acessos venosos periféricos. A flebite foi associada a maior tempo de internação na unidade e a maior quantidade de acessos por paciente ${ }^{4}$.

A internação hospitalar prolongada é um indicador indireto da qualidade do cuidado prestado aos pacientes, aumenta os custos e diminui a oportunidade de outro paciente receber os cuidados necessários em nível terciário, uma vez que os recursos disponíveis para este nível de atendimento são limitados ${ }^{5}$.

Segundo a Organization for Economic Co-operation and Development (OECD), que tem como missão promover políticas que melhorem o bem-estar econômico e social das pessoas em todo o mundo, a crescente complexidade e uso de novas tecnologias nos cuidados de saúde significam maior risco de danos, exigindo maior vigilância e investimento para assegurar que a assistência seja segura. $O$ impacto financeiro da falha de segurança é significativo, e as evidências disponíveis sugerem que aproximadamente $15 \%$ da despesa hospitalar total sejam decorrentes dos EA, muitos desses considerados evitáveis ${ }^{6}$.

A OECD afirma que os estudos que calculam a incidência de EA, particularmente os evitáveis, subestimam a verdadeira magnitude do dano ao paciente e, como constituem a base para os estudos de custos, estes também seriam subestimados, sugerindo que o verdadeiro impacto financeiro e os danos para os 
pacientes são, consideravelmente, maiores. Além do mais, os casos em que o dano ao paciente resulta em sequelas, temporárias ou permanentes, dificilmente são reconhecidos e contabilizados ${ }^{6}$.

Os gastos em saúde crescem devido à transição demográfica e epidemiológica, com o envelhecimento da população, aumento da longevidade e das doenças crônicas. O uso de novas tecnologias na área de equipamentos e de medicação aumenta também os custos, e, a partir dessas inovações, a população e os profissionais de saúde buscam novas soluções para os problemas de saúde ${ }^{7,8}$. Além disso, as incorporações de novas tecnologias em saúde aumentam a demanda de mão de obra cada vez mais complexa e especializada ${ }^{9}$.

Os serviços de saúde são $\operatorname{caros}^{10}$ e a elevação dos custos tem recebido atenção crescente dos gestores, profissionais da saúde e agências pagadoras do cuidado em saúde ${ }^{11}$. Pelo cenário atual, é vital a busca de estratégias gerenciais que possam adequar a restrição no orçamento com a melhoria e a qualidade dos serviços prestados à população ${ }^{10}$.

O Conselho Nacional de Secretários de Saúde (CONASS), ao discorrer sobre os avanços e desafios do Sistema Único de Saúde (SUS), indica que o maior desafio é a insuficiência dos recursos financeiros para se construir um sistema público acessível a todos que dele necessitem. Segundo o CONASS, realmente se gasta pouco em saúde no Brasil, no entanto há que se investir na melhoria da qualidade do gasto ${ }^{8}$.

Os hospitais brasileiros, conforme relatório publicado em 2009, respondiam por $70 \%$ dos atendimentos de emergência, $27 \%$ dos atendimentos ambulatoriais e grande parte das internações. Por isso, recebiam $70 \%$ dos gastos públicos na área da saúde e $67 \%$ de todo o gasto total com saúde. Na produção de serviços de saúde, a forma como o hospital utiliza os recursos disponíveis é determinante, pois, quando estes não são aplicados corretamente, há prejuízos ao cuidado eficiente, comprometimento da qualidade e elevação dos custos $^{12}$.

Os hospitais vêm sendo forçados a realizar mudanças nas suas políticas de gestão com o intuito de assegurar sua própria sobrevivência, com isso o controle dos custos caracteriza-se como um componente fundamental. O campo de controle de 
custos na área hospitalar é crescente, uma vez que os gastos neste setor têm aumentado, somando-se à escassez de recursos financeiros ${ }^{13}$.

Nas organizações hospitalares, públicas e privadas, e à frente do gerenciamento dos serviços de enfermagem, os enfermeiros precisam tomar decisões referentes à estrutura, processos e resultados, sendo necessário que dominem conhecimentos e habilidades de diferentes áreas. Assim, a aquisição de conhecimentos e o desenvolvimento de habilidades sobre custos são elementos adicionais a serem utilizados nos processos decisórios ${ }^{7}$.

Os enfermeiros são responsáveis pela administração de setores e gerenciam recursos humanos e materiais que consomem grande parte dos recursos financeiros disponíveis. A enfermagem representa grande parte dos profissionais que estão no ambiente hospitalar e o uso de materiais em suas unidades é um fator contribuinte para os custos das organizações de saúde?.

Segundo o Ministério da Saúde (MS) e a Organização Pan-Americana de Saúde (OPAS), a gestão de custos auxilia na identificação de quais recursos (humanos, materiais, tecnologia e outros) foram consumidos e como estes foram utilizados, contribuindo para a construção de informações que colaboram na compreensão dos processos gerenciais internos, planejamento e controle dos serviços prestados ${ }^{14}$.

O Gerenciamento de Custos na Enfermagem é um processo administrativo que tem como propósitos o controle de custos e a tomada de decisão dos enfermeiros para eficiente racionalização dos recursos disponíveis e limitados. Objetiva alcançar os resultados de acordo com a demanda da população e, com esse propósito, tornase essencial a compreensão de um conjunto de princípios e conhecimentos de análise econômica que fundamente o processo decisório mais conveniente ${ }^{10}$.

Por sua formação e experiência gerencial, os enfermeiros têm participado, em instituições de saúde públicas e privadas, do processo de aferição, controle e contenção/minimização de custos, contribuindo com a alocação racional de recursos humanos, materiais e estruturais com os propósitos de aumentar a qualidade da assistência, evitar desperdícios e assegurar a acessibilidade aos pacientes/usuários ${ }^{15}$. Portanto, reafirma-se que o conhecimento dos custos incorridos na prestação dos serviços de enfermagem tem potencial para fundamentar a 
redefinição de prioridades institucionais, o uso eficiente de recursos limitados e o acompanhamento da produtividade ${ }^{16}$.

Além disso, administrar com eficiência e eficácia as organizações complexas e as atividades exercidas nesses locais é também um dever moral e ético do profissional que está à frente desses lugares, exercendo o cargo de gestor?

$\mathrm{Na}$ área da segurança do paciente, prevenir danos é o desafio mais importante. Nessa direção, a flebite é um EA evitável e há estratégias e cuidados que podem ser realizados para promover a assistência segura, diminuindo a sua incidência, e reduzir, assim, os custos assistenciais ao não ser necessário o uso adicional de recursos.

A avaliação sistemática da ocorrência da flebite fornece informações que podem incrementar as estratégias de prevenção e de notificação deste EA. No hospital em que a pesquisadora deste estudo atua, o indicador institucional de incidência de notificação de flebite evidenciou que o quantitativo de eventos ultrapassou a meta institucional, tendo sido desenvolvidas estratégias educativas para diminuir a sua ocorrência. Em 2016, foi estabelecida uma diretriz assistencial de cuidados na administração de medicamentos vesicantes e irritantes não antineoplásicos em acesso venoso periférico, para qualificar a prática assistencial e diminuir a incidência de flebites, e realizaram-se auditorias pelo Centro de Controle de Infecção Hospitalar a fim de avaliar os dispositivos e identificar situações de risco para flebite.

Nesse hospital, as unidades de oncologia, terapia intensiva e transplante de medula óssea utilizam, em maior frequência, o acesso venoso central para o uso de fármacos durante a hospitalização. Entretanto, a Unidade de Internação Clínica tem grande número de pacientes que requerem a utilização de cateter venoso periférico, cujo perfil (idosos com alterações tegumentares e vasculares, indivíduos com doenças crônicas) apresenta fatores de riscos não modificáveis para flebite. A Unidade de Internação Clínica recebe pacientes que permanecem por um longo período em uso de acesso venoso periférico para a administração de antimicrobianos, corticosteroides e infusão de soluções.

Estudo italiano mostrou que a permanência dos pacientes em unidades ortopédicas e cirúrgicas reduz os riscos de apresentar flebite, quando comparados 
aos que estavam em unidades de internações clínicas. O tempo de internação prolongado, a utilização de antimicrobianos, a infusão de soluções, o uso de medicamentos vesicantes e eletrólitos, a presença de processo infeccioso no paciente, o uso de corticosteroides e o período de permanência do cateter superior a $72 \mathrm{~h}$ foram fatores associados ao desenvolvimento de flebite ${ }^{17}$. Tais fatores são comuns nos pacientes internados na Unidade de Internação Clínica do hospital campo de estudo (HCE) que, no período entre janeiro e setembro de 2017 , tinha contabilizado a notificação de 79 ocorrências de flebite.

\subsection{A SEGURANÇA DO PACIENTE E OS CUSTOS PARA OS SERVIÇOS DE SAÚDE}

O Harvard Medical Practice Study (HMPS) avaliou, em 1984, a incidência de EA a partir da análise de 30.121 prontuários em 51 hospitais no Estado de Nova York. Após a avaliação, observou-se que 3,7\% dos pacientes hospitalizados sofreram EA, destes, 2,6\% causaram lesões incapacitantes permanentes e 13,6\% levaram ao óbito $^{18}$. Esse estudo contribuiu para a publicação do livro To err is human, que apresentou grande impacto mundial sobre a segurança do paciente e estimou que cerca de 44.000 a 98.000 mortes anuais nos Estados Unidos da América (EUA) ocorriam por falhas da assistência à saúde ${ }^{19}$.

A Organização Mundial da Saúde (OMS), reconhecendo a extensão do problema no mundo todo, estabeleceu, em 2004, a World Alliance for Patient Safety 20 objetivando definir e identificar prioridades na área da segurança do paciente, propor medidas para reduzir os riscos e a ocorrência de $E A^{21,22}$ e contribuir para 0 desenvolvimento de pesquisas na área ${ }^{23}$. Para tanto, delinearam-se seis áreas de ação 20 :

1. desafio global para a segurança do paciente: prevenção de infecções relacionadas com a assistência à saúde;

2. mobilização de pacientes e seu envolvimento, visando à atuação para a segurança do paciente no mundo todo; 
3. desenvolvimento de uma taxonomia para a segurança do paciente com padrões internacionais para coleta e classificação dos EA e near miss (quase erro);

4. desenvolvimento de pesquisas na área de segurança do paciente;

5. disseminação de soluções para reduzir o risco na assistência à saúde e melhorar a segurança do paciente no âmbito mundial;

6. produção de ferramentas para notificação de ocorrências e aprendizagem com os resultados gerados nesses relatórios.

Além dessas áreas de ação, a World Alliance for Patient Safety tem como missão coordenar e acelerar as melhorias de segurança do paciente, atuando como líder nessa mudança, gerando e compartilhando conhecimento e experiência e apoiando os países membros para implementar as ações estabelecidas ${ }^{24}$.

A fim de facilitar a comparação, medição, análise e interpretação de informações para melhorar o cuidado do paciente, a OMS desenvolveu a International Classification for Patient Safety - ICPS. A tradução da ICPS para a língua portuguesa foi realizada pelo Centro Colaborador para a Qualidade do Cuidado e a Segurança do Paciente (Proqualis), em 2010, cujas principais definições são apresentadas a seguir $25-26$.

1) Erro: consiste em uma falha em se executar um plano de ação como desejado. Erros são, por definição, não intencionais, enquanto violações são atos intencionais;

2) incidente: evento ou circunstância que poderia ter resultado, ou resultou, em dano desnecessário ao paciente;

3) near miss (quase erro): incidente que não atingiu o paciente;

4) incidente sem dano: evento que atingiu o paciente, mas não causou dano;

5) incidente com dano EA: incidente que resulta em dano ao paciente. Este é classificado em EA evitável, quando é decorrente de erros, e EA não evitável, quando acontece um dano ao paciente sem que o erro tenha ocorrido. 
No Brasil, destaca-se a portaria ํㅡㄴ 529, de $1^{\circ}$ de abril de 2013, do Ministério da Saúde (MS), que instituiu o Programa Nacional de Segurança do Paciente (PNSP) objetivando contribuir para a assistência à saúde de qualidade em todos os serviços no contexto nacional, assim como promover iniciativas voltadas ao tema em diversos setores de atenção à saúde, por meio da gestão de risco e implantação dos Núcleos de Segurança do Paciente (NSP). O PNSP tem como finalidades promover informações sobre segurança do paciente, envolver pacientes e familiares nas ações, produzir estudos na área e estimular a inclusão do tema na grade curricular no ensino em saúde. Constituem estratégias de implementação do PNSP a formulação e suporte na execução dos protocolos de segurança do paciente; capacitação de gestores e profissionais de saúde sobre o conteúdo; promoção da cultura de segurança; envolvimento de profissionais e pacientes na prevenção de incidentes ${ }^{27}$.

A Resolução da Diretoria Colegiada (RDC) 36 28 , de 25 de julho de 2013, estabelece as ações para a promoção da segurança do paciente e a melhoria da qualidade nos serviços de saúde e descreve os princípios e diretrizes dos NSP que são "A melhoria contínua dos processos de cuidado e do uso de tecnologias da saúde; a disseminação sistemática da cultura de segurança; a articulação e a integração dos processos de gestão de risco e a garantia das boas práticas de funcionamento do serviço de saúde" (ANVISA, 2013, p. 3).

Compete aos NSP desenvolver ações para integrar a equipe multiprofissional no serviço de saúde; analisar e avaliar os relatórios gerados sobre EA e notificar ao Sistema Nacional de Vigilância Sanitária; identificar e avaliar as não conformidades e propor ações de prevenção e correção; instituir os protocolos de segurança do paciente e acompanhar os indicadores; promover programas de capacitação em segurança do paciente e qualidade em serviços de saúde ${ }^{28}$.

As portarias do MS no 1.377 e no 2.095, de 2013 aprovam os protocolos de segurança do paciente que foram criados para minimizar a ocorrência de EA durante os cuidados ao paciente, sendo eles identificação do paciente, prevenção de lesão por pressão, cirurgia segura, prática de higiene das mãos em serviços de saúde, prevenção de quedas e segurança na prescrição, uso de administração de medicamentos $29-30$.

Reitera-se que, no ambiente de assistência à saúde, a segurança do paciente é um componente essencial da qualidade do cuidado, abrange todos os processos 
inerentes à prestação de serviços de saúde, ambulatoriais e hospitalares, e adquire, cada vez mais, espaço no cenário científico. Nessa direção, a ocorrência de EA, incidentes que resultam em danos à saúde do paciente, constitui grande preocupação às organizações de saúde por representar alta morbidade e mortalidade ${ }^{21}$.

Prevenir danos é o desafio mais importante no campo da segurança do paciente. Estima-se que o custo com a mortalidade, perda de capacidade e produtividade dos pacientes e familiares afetados com os EA equivale a trilhões de dólares nos EUA anualmente, além do dano psicológico que é mais difícil de se mensurar. Em alguns países o custo anual com cuidados precários e infecção adquirida no ambiente hospitalar está entre 6 bilhões e 29 bilhões de dólares, na Europa cerca de $15 \%$ das despesas hospitalares estão ligadas ao tratamento de $E A^{31}$.

Mesmo com todo o avanço relativo à segurança do paciente, a falha humana que envolve os profissionais da saúde ${ }^{32}$ está presente no processo de cuidar, podendo ser analisada por diversas perspectivas. A ocorrência de EA é um problema de preocupação mundial, pois, além de acarretar danos irreversíveis ao paciente e sua família, impacta nos custos hospitalares ${ }^{33}$.

Estudo que identificou o custo dos EA nos países membros da Joint Action European Union Network for Patient Safety and Quality of Care, a partir da análise de artigos publicados no período de janeiro de 2000 a março de 2016, obtidos nas bases de dados MEDLINE, EMBASE e CINAHL, evidenciou custo anual com os EA evitáveis entre 17 e 38 bilhões de euros ${ }^{34}$.

Em Portugal, pesquisa realizada em 2010 estimou a incidência e impacto de EA nos hospitais desse país. Foi realizada a revisão de 1.669 prontuários de pacientes, de forma aleatória, tendo sido encontrada a incidência de 11,1\% de EA, dos quais, cerca de 53,2\% foram considerados evitáveis. Os eventos relatados estiveram associados a procedimentos cirúrgicos (27\%), medicação (18,3\%) e infecções hospitalares (12,2\%). Em 58,6\% dos EA o período de internação hospitalar prolongou-se em média 10,7 dias e os custos diretos adicionais ultrapassaram 470 mil euros 35 .

Relatório divulgado no ano de 2017 pela Universidade Federal de Minas Gerais e o Instituto de Estudos em Saúde Suplementar indicou que os EA assistenciais 
hospitalares consumiram entre $R \$ 5,2$ bilhões e $R \$ 15,6$ bilhões da saúde privada no Brasili6.

Levantamento realizado a partir das informações financeiras disponíveis no Sistema de Informações Hospitalares do Sistema Único de Saúde (SIH-SUS), relativas a pacientes internados em dois hospitais públicos de ensino do Estado do Rio de Janeiro em 2003, evidenciou que, dos pacientes que sofreram EA, 64,1\% foram considerados evitáveis. O valor médio pago pelo atendimento a estes pacientes foi $200,5 \%$ superior ao valor pago aos pacientes que não sofreram EA e apresentaram também tempo médio de permanência no hospital 28,3 dias superior aos demais. $A$ magnitude financeira dos EA correspondeu a $R \$ 1.212 .363,30^{33}$.

Independentemente da natureza jurídica das organizações hospitalares, o fluxo de pacientes precisa ser dinâmico, possibilitando atendimentos de diferentes complexidades, realização de exames, medicamentos e outros serviços necessários para o seu adequado tratamento. Então, a ocorrência de EA, além de aumentar os custos com a internação hospitalar, que pode ser prolongada, e acarretar em custos intangíveis ao paciente, compromete a oferta de serviços de saúde a outros pacientes que podem não receber o tratamento requerido para a sua patologia.

Assim, é fundamental desenvolver estudos que favoreçam conhecer, detalhadamente, as causas e as consequências dos EA, que podem ser vistas como importantes fontes de informação para a melhoria dos processos assistenciais e, consequentemente, aumento da qualidade e da segurança para os pacientes, profissionais e instituições de saúde, bem como o impacto de eventos dessa natureza nos custos hospitalares.

Na Irlanda, foi conduzida uma revisão, no ano de 2009, de 1.574 prontuários de pacientes adultos internados em oito hospitais selecionados aleatoriamente. Foram realizadas duas revisões desses prontuários, a primeira por um grupo de enfermeiros e a segunda por um grupo de médicos, relativos ao período de dezembro de 2013 a janeiro de 2015. Dentre os pacientes internados, 12,2\% sofreram EA, com uma incidência de 10,3 eventos por cada 100 internações, sendo 70\% considerados evitáveis. Os EA aumentaram, em média, 6,1 dias no tempo de internação e tiveram um custo de 5.550 euros por evento. Estimou-se que os EA custaram mais de 194 milhões de euros ${ }^{37}$. 
Estudo de coorte retrospectiva, ao avaliar a ocorrência de EA em uma amostra de 1.103 pacientes adultos internados por mais de 24 horas em três hospitais gerais, públicos e de ensino, localizados no Estado do Rio de Janeiro em 2003, evidenciou a sua expressiva associação com dias adicionais de internação. Os EA foram responsáveis por 373 dias a mais de internação, sendo que as infecções associadas aos cuidados da saúde representaram maior impacto com 226 dias a mais de internação ${ }^{38}$.

Pesquisa conduzida na unidade de internação clínica de um hospital de Goiás analisou, por meio dos registros de enfermagem, a ocorrência de 1.360 EA referentes ao período entre janeiro de 2005 a dezembro de 2014. Dentre os EA documentados, $30 \%$ se referiam a retiradas acidentais de sondas, cateteres e cânulas; $21,2 \%$, a erros de medicação; $11,5 \%$, a erros envolvendo acesso vascular; 9,8\%, a casos de infecção relacionada à assistência à saúde; e 6,7\%, a outros eventos relatados. Constatou-se que os registros desses eventos não estavam completos e detalhados, dificultando a investigação sobre as causas, consequências e condutas adotadas ${ }^{39}$.

Profissionais de enfermagem de um hospital universitário relataram que o sistema de notificação de EA constitui uma ferramenta que auxilia a gestão do cuidado e permite realizar melhorias com o intuito de prevenir novos episódios de EA. Segundo os autores, a visão do enfermeiro, como o responsável pela notificação, afasta os demais profissionais dessa ação. Assim, afirmam haver a necessidade de se estimular e dar oportunidade à participação de todos os membros da equipe de saúde na notificação dos $E A^{40}$.

A notificação de incidentes é uma estratégia implantada por muitos países para a identificação de problemas na área da segurança do paciente. Os eventos notificados são analisados para se verificar a causa raiz do problema e buscar estratégias para se melhorar o processo. Apesar dos investimentos nessa iniciativa, há dificuldades na utilização dessa ferramenta ${ }^{41}$. Um relatório publicado nos EUA, em 2012, constatou que os sistemas de notificação capturaram somente $14 \%$ dos EA, indicando que a subnotificação poderia ser pelo desconhecimento sobre o instrumento e qual o significado do dano ao paciente. Descreveu também que a deficiência de notificação estava relacionada ao medo do profissional envolvido, no EA, em ser culpabilizado pela sua ocorrência, medida que é contrária à cultura de segurança do paciente $^{42}$. 
Em um hospital universitário terciário, da região centro-sul do Estado de São Paulo, verificou-se adesão dos profissionais de enfermagem à utilização de um boletim de notificação de EA. Porém, os autores ponderaram a possibilidade de não se ter atingido o total de EA ocorridos nos setores do hospital pela subnotificação e destacaram serem cruciais o estímulo à notificação bem como a relevância do desenvolvimento de um sistema eletrônico de notificação para auxiliar no processo de comunicação e construção de banco de dados ${ }^{43}$.

É fundamental que os membros da equipe de saúde estejam sensibilizados e tenham conhecimento sobre a importância de realizar a notificação dos EA a fim de identificar as suas causas e elaborar planos de ação para a melhoria dos processos assistenciais nas respectivas instituições de atuação. Tais notificações são indispensáveis para subsidiar a realização de estudos que evidenciem a magnitude dos EA e seus impactos nos sistemas de saúde pelo aumento no tempo de permanência dos pacientes, inclusão de outras modalidades de tratamento e elevação dos custos assistenciais.

O conceito de segurança do paciente destaca, como fatores propícios à ocorrência de EA, as carências do sistema de prestação de cuidados de saúde, a organização e o funcionamento dos serviços ${ }^{3}$. Ambientes movimentados, mudanças e novas informações, situações de estresse, alta tecnologia, ambiente de trabalho com muitas normas e cultura organizacional constituem características do sistema de saúde que predispõem a ocorrência de erros ${ }^{44}$.

A compreensão do caráter multifatorial subjacente às falhas de segurança pode ser explicada por meio da "teoria do queijo suíço", que compara a vulnerabilidade do sistema de saúde aos buracos de um queijo suíço. As múltiplas fatias do queijo suíço são colocadas lado a lado como bloqueio à ocorrência de erros. Em algumas situações os buracos do queijo se alinham, permitindo que um erro passe pelas múltiplas barreiras, causando o dano. Nessa perspectiva, é primordial que os serviços de saúde e os hospitais assumam uma política de gerenciamento de risco e instalem obstáculos de proteção contra possíveis erros, visto que, quanto menos furos houver nos processos e barreiras, mais seguro será o hospital para o paciente ${ }^{45}$.

Revisão sistemática da literatura demonstrou a influência da carga de trabalho de enfermagem na ocorrência de EA nos pacientes internados em Unidade de Terapia Intensiva (UTI). Dos oito estudos que compuseram a amostra, 75\% identificaram 
influência da sobrecarga de trabalho na ocorrência de infecção, lesão por pressão e uso de medicamentos ${ }^{46}$.

Estudo observacional, descritivo e prospectivo, desenvolvido em quatro UTI de um hospital universitário do município de São Paulo, verificou a adequação entre a alocação da equipe de enfermagem e as horas de cuidado solicitadas pelos pacientes e identificou a relação entre a alocação da equipe de enfermagem, por paciente, e a ocorrência de EA e incidentes. A média de EA e de incidentes foi maior nas alocações inadequadas da equipe de enfermagem, e, quanto maior a diferença entre as horas disponíveis e requeridas de cuidado nas alocações de enfermagem, menor a frequência de EA e incidentes ${ }^{47}$.

A partir de estudos dessa natureza é possível se compreender os fatores que influenciam para que os EA ocorram e, com isso, buscar apoio dos gestores, para se elaborar estratégias de melhorias na estrutura dos diferentes serviços de saúde. É imprescindível que outros estudos sejam desenvolvidos para se conhecer quais fatores interferem na qualidade da assistência prestada ao paciente e contribuem para a ocorrência de EA.

Os serviços de saúde vêm introduzindo, constantemente, novas tecnologias como equipamentos, medicamentos e outros insumos, configurando-se, cada vez mais, em ambientes complexos e com riscos maiores para a ocorrência de EA. No entanto, algumas medidas podem ser utilizadas para reduzir riscos e possíveis erros, tais como melhoria da comunicação entre profissionais de saúde, administração segura de medicamentos, prevenção de quedas, identificação do paciente e adesão à higiene das mãos. Utilizar essas medidas com o seguimento de protocolos possibilita prevenir eventos relacionados à assistência à saúde ${ }^{41}$. Portanto, é vital uma mudança na cultura dos profissionais e dos serviços de saúde para que todos sigam as orientações do PNSP28.

Apesar do interesse mundial pela temática segurança do paciente, há pontos vulneráveis que precisam ser discutidos para que haja maior conscientização do problema. Quando um EA ocorre, a tendência, ainda, é a de se procurar um culpado, e constata-se que a falta de registros e de zelo com essas informações prejudica a sua avaliação ${ }^{48}$. 
Na perspectiva de estabelecer medidas para fortalecer e consolidar a cultura de segurança do paciente nos serviços de saúde, cada profissional de saúde precisa compreender a importância da sua participação efetiva, conforme seu nível de governabilidade, na implantação, implementação e manutenção dessas medidas, visando à obtenção de resultados de qualidade para os pacientes/usuários, familiares, profissionais da equipe de saúde, organização e sociedade.

No Brasil, os hospitais são o centro do sistema de saúde, lideram a prestação de serviços, empregam a maior parte dos profissionais de saúde e constituem centros de treinamento e ambiente principal de desenvolvimento e de adoção de novas tecnologias $^{12}$.

Nos estabelecimentos de saúde, notadamente nas organizações hospitalares, os profissionais da equipe de enfermagem representam a principal força de trabalho para a viabilização dos cuidados aos pacientes e familiares e correspondem ao maior quantitativo de recursos humanos em saúde. De acordo com publicação do Conselho Regional de Enfermagem de São Paulo (COREN-SP), em 2013, a equipe de enfermagem era constituída por 1,8 milhão de pessoas, sendo $77 \%$ de técnicos e auxiliares e $23 \%$ de enfermeiros ${ }^{49}$. Além de sua representatividade numérica, os profissionais de enfermagem destacam-se por viabilizar a prestação de cuidados, de complexidades variadas, em unidades/serviços e setores que funcionam, ininterruptamente, nas 24 horas.

Nos hospitais, dentre os cuidados realizados por enfermeiros, técnicos e auxiliares de enfermagem, destaca-se a administração de medicamentos por via intravenosa que demanda o uso de um cateter de acesso vascular, periférico ou central. A inserção e os cuidados com o cateter são procedimentos frequentes na prática assistencial desses profissionais e exige conhecimento científico sobre a técnica para punção e manejo do dispositivo, como os cuidados com curativo e forma correta para se administrar medicamentos.

O uso do cateter venoso periférico pode ocasionar complicações tais como flebite, tromboflebite, infiltração, extravasamento e infecção ${ }^{50}$. Logo, a escolha do dispositivo a ser utilizado é uma importante medida para se prevenir a ocorrência desses eventos. Os cateteres flexíveis, como os de poliuretano, estão associados a menores complicações infecciosas em relação aos de cloreto de polivinil ou polietileno e apresentam menor risco de provocarem flebites. Como os cateteres rígidos podem 
lesar a camada íntima da veia, aumentando o número de flebites e a formação de trombos, recomenda-se ${ }^{51}$

1) higienizar as mãos antes e após a inserção do cateter venoso periférico e durante a sua manipulação;

2) avaliar e escolher o cateter de acordo com o tempo da TIV, condição vascular do paciente e fármaco utilizado;

3) evitar região de flexão, membros comprometidos por lesões, local onde a rede vascular já está comprometida;

4) utilizar um cateter venoso periférico para cada tentativa de punção;

5) remover toda a sujidade no local onde será realizada a punção e utilizar soluções antissépticas adequadas;

6) não tocar o sítio de inserção do cateter após a aplicação do antisséptico e, caso isso seja necessário, calçar luvas estéreis;

7) promover a estabilização do cateter, prevenindo a movimentação e perda do dispositivo: a inserção deve estar visível, a cobertura deve ser estéril, e não utilizar fitas adesivas e suturas para a estabilização. Trocar a cobertura sempre que houver suspeita de contaminação ou presença de sujidade;

8) realizar flushing antes de cada administração de medicamentos e imediatamente após o uso para que não haja interação medicamentosa e prevenir o depósito de medicamentos e formação de fibrina;

9) avaliar, sistematicamente, o local de inserção do cateter e, quando se apresentarem os primeiros sinais flogísticos como rubor, edema e drenagem de secreções, o dispositivo deve ser removido. 
Reitera-se que os profissionais de enfermagem precisam ter o conhecimento técnico-científico a respeito da manipulação do cateter e administração da TIV. Esse conhecimento melhora a qualidade do cuidado, favorece a segurança do paciente e aumenta a satisfação deste com a assistência prestada, sendo possível reduzir o tempo de internação hospitalar e o custo da assistência prestada ${ }^{52}$.

Durante o uso do cateter vascular periférico, a flebite é uma das lesões mais frequentes, caracterizando-se como um EA a ser notificado ${ }^{53}$. A flebite ocorre quando há inflamação do vaso, os sinais e sintomas apresentados são edema, calor local, hiperemia, cordão fibroso no trajeto do vaso, dor e, em casos infecciosos, pode haver presença de secreção purulenta em sítio de inserção do cateter. Segundo a Infusion Nursing Society (INS), é aceitável que no máximo $5 \%$ dos pacientes em uso de dispositivos vasculares desenvolvam flebite. ${ }^{3}$

Sua origem pode ser mecânica, quando há inserção traumática do cateter dentro do vaso ou quando o seu calibre é muito grande para o vaso; química, pela agressividade dos medicamentos e soluções à parede do vaso; bacteriana, pela entrada de bactéria no interior da veia e colonização, que oferece grande risco ao paciente $^{54}$.

A flebite é classificada em quatro graus: grau 1: presença de hiperemia no sítio de inserção do cateter com ou sem dor local; grau 2: dor no sítio de inserção do cateter com hiperemia e/ou edema e endurecimento; grau 3: dor no sítio de inserção do cateter com hiperemia, endurecimento e formação de cordão venoso palpável; grau 4: dor no sítio de inserção do cateter com hiperemia, endurecimento e formação de cordão venoso palpável com drenagem purulenta ${ }^{3}$.

Quando o paciente desenvolve a flebite, ocorre a retirada do cateter venoso periférico e há a necessidade de uma nova punção. Toda essa situação, além de gerar estresse e dor para o paciente, acarreta a interrupção da terapia medicamentosa, aumento do consumo de insumos, inclusive insumos adicionais para o tratamento da flebite, ocasionando aumento dos custos. 
No Brasil, estudos sobre os custos dos EA para as organizações de saúde ainda são escassos, então, conhecer as causas e o impacto financeiro desses eventos na assistência pode ser concebido como uma importante fonte de informação visando à melhoria dos processos, assistenciais e gerenciais, com repercussões favoráveis na qualidade do cuidado e na segurança. Nessa perspectiva, propõe-se a realização do presente estudo a fim de se responder à seguinte questão:

- Quais seriam as causas, os motivos associados e o custo dos procedimentos para o tratamento da ocorrência do EA flebite na Unidade de Internação Clínica de um hospital geral, de grande porte, privado? 
2 OBJETIVOS 


\section{OBJETIVOS}

- Analisar a ocorrência e as causas do evento adverso (EA) flebite em pacientes da Unidade de Internação Clínica de um hospital privado no município de São Paulo;

- $\quad$ identificar o custo direto médio (CDM) dos procedimentos realizados para o tratamento do evento adverso (EA) flebite em pacientes da Unidade de Internação Clínica de um hospital privado no município de São Paulo;

- $\quad$ estimar o custo direto médio (CDM) dos procedimentos realizados para o tratamento do evento adverso (EA) flebite em pacientes da Unidade de Internação Clínica de um hospital privado no município de São Paulo no ano de 2017. 
3 MÉTODO 


\section{MÉTODO}

\subsection{TIPO DE ESTUDO}

Trata-se de um estudo quantitativo, exploratório-descritivo, retrospectivo, documental, do tipo estudo de caso único ${ }^{55}$, relativo à ocorrência do EA flebite na Unidade de Internação Clínica de um hospital geral, de porte especial, privado, localizado na cidade de São Paulo.

O estudo exploratório tem como objetivos analisar um tema pouco estudado bem como fenômenos desconhecidos ou novos, pesquisar novos problemas, identificar conceitos e estabelecer prioridades para novos estudos que serão realizados. A pesquisa descritiva busca observar, registrar e especificar as características do fenômeno que será analisado e mostrar, com precisão, as dimensões de um contexto ou situação. O pesquisador deve definir o que será medido e quais dados serão coletados; nesse tipo de pesquisa não há interferência do pesquisador, que deverá apenas descobrir a frequência com que o fenômeno ocorre ${ }^{56}$.

A pesquisa documental é realizada por intermédio da análise de materiais de natureza diversa, que ainda não receberam tratamento analítico, estes também podem ser reexaminados em busca de novas interpretações ${ }^{56}$.

O estudo de caso propicia a investigação de um fenômeno em profundidade, no local onde ocorre, sendo utilizado quando se pretende investigar o como e o porquê de um conjunto de eventos contemporâneos. A partir da observação direta dos eventos que serão analisados, o estudo de caso possibilita responder a questionamentos sobre os quais o pesquisador não tem muito controle, conta com um método abrangente com planejamento da coleta e da análise de dados ${ }^{55}$. 


\subsection{LOCAL DE ESTUDO}

O HCE integra uma rede, com unidades de atendimento localizadas no município de São Paulo e em Brasília, é acreditado pela Joint Commission International (JCl), desde 2007, e Qmentum International (IQG) - Acreditação Canadense -, desde 2015, e segue os padrões internacionais de qualidade.

Atende a mais de 40 especialidades, possui 512 leitos de internação, Pronto Atendimento, Centro Cirúrgico, Unidades Críticas e Centros de Medicina Avançada. Dispõe de um Instituto de Ensino e Pesquisa, atuando na geração de conhecimento relacionado às boas práticas e à gestão na área da saúde, por intermédio de programas de residência, pós-graduações lato e stricto sensu e eventos na área da saúde.

No HCE, a equipe multiprofissional é estimulada a participar da investigação dos EA e dos processos de melhoria para garantir assistência segura aos pacientes. Os profissionais são constantemente orientados, pelos gestores das unidades que se fundamentam em processos de auditoria interna, a realizarem a notificação de erros ocorridos durante a prestação da assistência. Para tanto, é indicado que qualquer membro da equipe multiprofissional que tenha identificado, participado ou presenciado a ocorrência preencha um instrumento de notificação.

O instrumento consiste em um formulário eletrônico, disponível na intranet ou no Sistema de informação Hospitalar (Tasy), específico para cada tipo de EA, que compõe um banco de notificações cujo processo de análise e consolidação mensal é realizado pela Segurança Assistencial. Posteriormente, essas informações são analisadas pela enfermeira da Gerência de Risco, e, quando o EA é classificado como grave, é encaminhado para o Comitê de Segurança Assistencial do HCE. Este comitê é composto por uma equipe multidisciplinar (membros das áreas de governança clínica, práticas médicas, pacientes críticos, qualidade, enfermagem, nutrição, farmácia, saúde e segurança do trabalhador, controle de infecção, tecnologia da informação, engenharia hospitalar, engenharia clínica, jurídico, ouvidoria, epidemiologia clínica e hotelaria) e compõe o Núcleo de Segurança do Paciente. 
A cada tipo de ocorrência são designados um ou mais profissionais para acompanhamento, análise e investigação do EA. Os relatórios gerados a partir das notificações são encaminhados, mensalmente, para os gestores e compartilhados com as equipes nas áreas assistenciais. As ocorrências são investigadas em três níveis:

- nível 1: incidentes sem danos, near miss e EA com dano leve ao paciente. As informações são fornecidas exclusivamente pelo notificador, é realizada a identificação de falhas nas barreiras de segurança e são promovidas ações baseadas no conjunto de ocorrências;

- nível 2: EA com dano moderado e potencial para dano grave. As informações são fornecidas pelo notificador e por outras fontes (revisão de prontuário, comissão, entre outros), e a análise, baseada na frequência e gravidade, realimenta os protocolos institucionais;

- nível 3: EA com dano grave ou EA sentinela, as informações são fornecidas pelo notificador e outras fontes (revisão de prontuário, comissão, entre outros), há a identificação e a análise da causa raiz e dos fatores que contribuíram para sua ocorrência, podendo ser solicitado o parecer de um especialista. Disclosure, caso necessário.

Todos os procedimentos realizados no HCE têm protocolos (descrição da técnica, dos materiais utilizados e indicação de qual profissional é responsável pela sua execução) que estão disponíveis, para consulta no caso de dúvidas, na intranet do hospital. No período de admissão, os profissionais da equipe de saúde são orientados e treinados em relação aos diferentes processos assistenciais, bem como quanto aos procedimentos específicos, e são acompanhados por um preceptor, da sua categoria profissional, na unidade de atuação. Durante a realização sistemática das auditorias internas de qualidade, os profissionais de saúde são questionados sobre seu conhecimento a respeito dos EA, como estes podem ser notificados, como podem participar na investigação de sua ocorrência e na proposição de melhorias nos processos.

No caso da ocorrência do EA flebite, o formulário eletrônico contém as seguintes informações: autor da notificação (dado opcional), departamento/setor, data, ocorrência, descrição da ocorrência, unidade da ocorrência, número do 
atendimento e nome do paciente envolvido, data do atendimento, nome do médico, número de atendimento do Serviço de Arquivo Médico e Estatística (SAME), idade, leito, data da ocorrência, período da ocorrência (manhã, tarde ou noite), setor da ocorrência, grau de flebite (grau 1: hiperemia, grau 2: hiperemia e dor local, grau 3: hiperemia, dor local, cordão palpável e grau 4: hiperemia, dor local, cordão palpável e drenagem purulenta), nome do fármaco envolvido, tempo que está com o cateter (1 dia, 2 dias, 3 dias, 4 dias, 5 dias, 6 dias, 7 dias ou pós-retirada), classificação do dano (grave, moderado, leve, nenhum), avaliação risco para o desenvolvimento de flebite (alto, moderado, baixo, sem risco) e anexos (informações adicionais, como exemplos, print da prescrição, fotografia do local).

Como há a padronização sobre a técnica de punção do acesso venoso periférico e os cuidados com o dispositivo, quando ocorre a flebite, preconiza-se a retirar imediatamente o cateter, evitar puncionar novo acesso no membro acometido, elevar o membro acometido para diminuir o edema (24-48 h), realizar compressa gelada nas primeiras 24 h para alívio da dor (utilizar gelo ou bolsa gel por 10 a 15 min. de 6/6 h), após esse período, realizar compressa morna (20 a $30 \mathrm{~min}$. de 8/8 h) até o alívio dos sintomas, para aliviar o edema pela vasodilatação, e utilizar pomada com extrato de flor de camomila de 6/6 h.

Caso o paciente esteja recebendo tratamento com medicação endovenosa e não haja possibilidade de alterar a via de administração, outro acesso venoso periférico é puncionado, porém, dependendo da intensidade da flebite, é necessária a indicação de anti-inflamatórios e antibióticos sistêmicos e local. Nessas situações, devem constar os registros, médicos e de enfermagem, no prontuário do paciente, relativos ao tratamento da flebite.

\subsubsection{A Unidade de Internação Clínica}

A Unidade de Internação Clínica está dividida em dois pavimentos do HCE, recebendo a denominação de Unidade de Internação Clínica 1 e Unidade de Internação Clínica 2, ambas com capacidade para 19 leitos, totalizando 38 leitos de internação. Cada andar tem uma sala de estar, com televisão e computador, e dois banheiros para uso de pacientes e acompanhantes, sala para preparo de medicação, sala para armazenamento de materiais na qual se localiza uma pyxis, abastecida com 
medicamentos e materiais que serão dispensados em nome do paciente e com o login do profissional, sala de expurgo, copa, dois banheiros para uso dos profissionais, sala para descarte de resíduos, sala para descarte de roupas, rouparia e sala de equipamentos.

A estrutura física de cada pavimento é composta por duas alas, ligadas por um corredor no qual estão distribuídos oito computadores para uso da equipe multiprofissional. Uma das alas possui dez leitos e um posto de enfermagem, e a outra, nove leitos (02 quartos destinados a pacientes em isolamento de aerossóis com pressão negativa) e um posto de enfermagem.

O quadro total de profissionais de enfermagem da Unidade de Internação Clínica compreende uma enfermeira coordenadora, uma enfermeira líder, 27 enfermeiros assistenciais e 47 técnicos de enfermagem. A enfermeira coordenadora atua das 8 às 17 h e a enfermeira líder, das 6 h 30 min. às 15 h 06 min., ambas são responsáveis pelo gerenciamento das Unidades de Internação Clínica 1 e 2 . Na Unidade de Internação Clínica 1 estão distribuídos quatro enfermeiros, oito técnicos pela manhã (7-13 h), três enfermeiros, seis técnicos à tarde $(13-19 \mathrm{~h})$ e dois enfermeiros, seis técnicos nos noturnos par e ímpar (19-07 h); na Unidade de Internação Clínica 2 três enfermeiros, seis técnicos pela manhã (7-13 h), três enfermeiros, seis técnicos à tarde pela manhã $(13$ - 19 h) e dois enfermeiros, seis técnicos nos noturnos par e ímpar (19-07 h). Em cada período um técnico de enfermagem é designado para realizar, exclusivamente, o preparo das medicações.

\subsection{AMOSTRA}

Na primeira etapa do estudo, foram inclusos todos os formulários eletrônicos relativos à notificação da ocorrência do EA flebite, em pacientes da Unidade de Internação Clínica, no período de janeiro a dezembro de 2017. Após a análise desses formulários, solicitaram-se os prontuários dos pacientes portadores de flebite ao SAME do HCE, nos quais se verificou que foram realizados os procedimentos "aplicação de pomada de extrato de flor de camomila"; "aplicação de compressas" e “instalação de AVP”.

Considerando que esses três procedimentos estão devidamente padronizados no HCE, bem como a experiência clínica da pesquisadora que observa, 
na sua prática assistencial, que eles são executados exatamente conforme preconizado no protocolo assistencial do HCE, um profissional estatístico orientou que fossem realizadas cinco observações de cada um deles para os diferentes graus de flebite (1, 2, 3 e 4), totalizando 20 observações por procedimento, para aferição do CDM (segunda etapa do estudo) e, posteriormente, estimativa dos custos dos procedimentos documentados em prontuário, no ano de 2017, para o tratamento das flebites notificadas (terceira etapa do estudo).

\subsection{PROCEDIMENTOS PARA A COLETA DE DADOS E AFERIÇÃO DE CUSTOS}

\subsubsection{Protocolo para realização do estudo de caso}

Para se nortear a coleta de dados, foi construído um protocolo (Quadro 1), fundamentado no referencial proposto por $\mathrm{Yin}^{55}$, abrangendo as etapas da pesquisa, os seus objetivos e as atividades relacionadas.

Quadro 1 - Protocolo para condução de estudo de caso único sobre custo da ocorrência do EA flebite em pacientes internados na Unidade de Internação Clínica. São Paulo, 2018

\section{ETAPA: COLETA DE DADOS}

\begin{tabular}{|c|c|}
\hline \multicolumn{1}{|c|}{ Objetivo } & Atividade \\
\hline - Identificar a ocorrência & - Obter a autorização do Comitê de Ética em Pesquisa do \\
do EA flebite, relativa ao & HCE para iniciar os procedimentos de coleta dos dados; \\
período em estudo, no & - Realizar coleta das informações relativas às notificações do \\
banco de notificação. & EA flebite na Segurança Assistencial do HCE (Apêndice A); \\
& - Elaborar uma lista dos pacientes que apresentaram o EA \\
& flebite e solicitar os respectivos prontuários ao SAME.
\end{tabular}


Quadro 1 - Protocolo para condução de estudo de caso único sobre custo da ocorrência do EA flebite em pacientes internados na Unidade de Internação Clínica. São Paulo, 2018

(continuação)

\begin{tabular}{|c|c|}
\hline \multicolumn{2}{|r|}{ ETAPA: COLETA DE DADOS } \\
\hline Objetivo & Atividade \\
\hline $\begin{array}{l}\text { - Verificar, nos prontuários } \\
\text { dos pacientes, os } \\
\text { procedimentos } \\
\text { decorrentes da } \\
\text { ocorrência do EA flebite. }\end{array}$ & $\begin{array}{l}\text { - Levantar, nos prontuários dos pacientes, os procedimentos } \\
\text { decorrentes da ocorrência do EA flebite (intervenção } \\
\text { medicamentosa e/ou outras modalidades terapêuticas e } \\
\text { diagnósticas); } \\
\text { - Solicitar, a um profissional estatístico, o cálculo amostral do } \\
\text { quantitativo de observações a serem realizadas, a partir do } \\
\text { levantamento dos procedimentos evidenciados nos } \\
\text { prontuários dos pacientes. }\end{array}$ \\
\hline $\begin{array}{l}\text { - Coletar os dados } \\
\text { necessários à estimativa } \\
\text { dos custos relativos aos } \\
\text { procedimentos } \\
\text { decorrentes do EA flebite } \\
\text { em pacientes internados } \\
\text { na Unidade de } \\
\text { Internação Clínica }\end{array}$ & $\begin{array}{l}\text { - Elaborar, de acordo com os procedimentos padronizados no } \\
\text { HCE, os instrumentos (Apêndices B, C e D) para o registro } \\
\text { do consumo de materiais utilizados, quantidade de } \\
\text { profissionais de enfermagem envolvidos e tempo } \\
\text { despendido (cronometrado) na execução dos } \\
\text { procedimentos decorrentes do EA flebite. } \\
\text { - Convidar os profissionais da equipe de enfermagem a } \\
\text { participarem da pesquisa concedendo a autorização para } \\
\text { serem observados durante a execução desses } \\
\text { procedimentos; } \\
\text { - Realizar a observação não participante da execução dos } \\
\text { procedimentos decorrentes do EA flebite. }\end{array}$ \\
\hline $\begin{array}{l}\text { - Calcular o custo unitário } \\
\text { da mão de obra direta } \\
\text { (MOB) dos profissionais } \\
\text { da equipe de } \\
\text { enfermagem da Unidade } \\
\text { de Internação Clínica }\end{array}$ & $\begin{array}{l}\text { - Calcular a MOB dos enfermeiros e técnicos de enfermagem } \\
\text { a partir dos salários médios (salários, benefícios, } \\
\text { gratificações e encargos sociais) fornecidos pela Gestão de } \\
\text { Pessoas. }\end{array}$ \\
\hline
\end{tabular}


Quadro 1 - Protocolo para condução de estudo de caso único sobre custo da ocorrência do EA flebite em pacientes internados na Unidade de Internação Clínica. São Paulo, 2018

(continuação)

\begin{tabular}{|c|c|}
\hline \multicolumn{2}{|r|}{ ETAPA: COLETA DE DADOS } \\
\hline Objetivo & Atividade \\
\hline $\begin{array}{l}\text { - Levantar os custos dos } \\
\text { materiais/medicamentos/ } \\
\text { soluções utilizados para } \\
\text { se viabilizar os } \\
\text { procedimentos. }\end{array}$ & $\begin{array}{l}\text { - Obter os custos dos materiais, medicamentos e soluções } \\
\text { consumidos junto aos Setores de Compras e Planejamento, } \\
\text { Farmácia e Almoxarifado do HCE. }\end{array}$ \\
\hline $\begin{array}{lr}\text { - Elaborar planilhas } \\
\text { eletrônicas } \\
\text { armazenamento dos } \\
\text { dados. }\end{array}$ & $\begin{array}{l}\text { - Transportar todos os dados obtidos para planilhas } \\
\text { eletrônicas. }\end{array}$ \\
\hline \multicolumn{2}{|c|}{ ETAPA: ESTIMATIVA DO CDM E ANÁLISE DOS DADOS } \\
\hline Objetivo & Atividade \\
\hline $\begin{array}{l}\text { - Estimar o CDM dos } \\
\text { procedimentos } \\
\text { decorrentes do EA flebite } \\
\text { em pacientes internados } \\
\text { na Unidade de } \\
\text { Internação Clínica. }\end{array}$ & $\begin{array}{l}\text { - Multiplicar o tempo despendido (cronometrado) por } \\
\text { enfermeiros e técnicos pelo custo unitário da MOB e somá- } \\
\text { lo ao custo dos insumos utilizados; } \\
\text { - Multiplicar o CDM estimado para cada procedimento pelo } \\
\text { quantitativo realizado no período de janeiro a dezembro de } \\
2017 ; \\
\text { - Submeter, se pertinente, os dados a testes estatísticos; } \\
\text { - Analisar as variáveis categóricas pelo número absoluto e } \\
\text { relativo das respostas; } \\
\text { - Demonstrar as variáveis categóricas por meio de tabelas e } \\
\text { gráficos; } \\
\text { - Discutir os dados nas perspectivas da segurança do } \\
\text { paciente e do gerenciamento de custos. }\end{array}$ \\
\hline
\end{tabular}


Quadro 1 - Protocolo para condução de estudo de caso único sobre custo da ocorrência do EA flebite em pacientes internados na Unidade de Internação Clínica. São Paulo, 2018

(conclusão)

\begin{tabular}{|c|c|}
\hline \multicolumn{2}{|r|}{ ETAPA: CONCLUSÃO } \\
\hline Objetivo & Atividades \\
\hline $\begin{array}{l}\text { - Apresentar as } \\
\text { conclusões sobre a } \\
\text { análise da ocorrência e } \\
\text { estimativa do CDM dos } \\
\text { procedimentos } \\
\text { decorrentes do EA flebite } \\
\text { em pacientes internados } \\
\text { na Unidade de } \\
\text { Internação Clínica. }\end{array}$ & $\begin{array}{l}\text { - Realizar a síntese dos resultados obtidos e divulgá-la no } \\
\text { HCE. }\end{array}$ \\
\hline
\end{tabular}

Fonte: Adaptado Jericó 57

Fundamentou-se a condução deste estudo por intermédio da utilização dos custos diretos, considerados todos aqueles que podem ser identificados e claramente quantificados. Custos diretos referem-se a um dispêndio monetário, aplicado na produção de um produto ou de um serviço em que há possibilidade de identificação com o produto ou departamento ${ }^{58}$. Nas organizações hospitalares, compõem-se de mão de obra, insumos e equipamentos utilizados, diretamente, no processo assistencial ${ }^{7}$.

\subsubsection{Cálculo do custo da mão de obra direta (MOD)}

A MOB diz respeito ao pessoal que trabalha diretamente sobre um produto ou serviço prestado, desde que seja possível mensurar o tempo despendido e a identificação de quem executou o trabalho. É composta dos salários, encargos sociais, provisões para férias e $13^{\circ}$ salário ${ }^{58}$.

Ao término do levantamento dos procedimentos para tratamento da flebite, constatou-se que as mesmas foram realizadas exclusivamente por técnicos de enfermagem mediante protocolo institucional. 
A Gestão de Pessoas do HCE forneceu os salários médios dos técnicos de enfermagem da Unidade de Internação Clínica que subsidiaram o cálculo do custo unitário da $\mathrm{MOB}$ desta categoria profissional que cumpria carga de trabalho de 180 $\mathrm{h} / \mathrm{mês}$. Os valores em reais $(\mathrm{R} \$)$ foram convertidos para o dólar norte-americano (US\$) pela taxa de US\$ 0.26/R \$, com base na cotação de 08/06/2018, fornecida pelo Banco Central do Brasil. Assim, obtiveram-se os custos médios mensal, hora e minuto que corresponderam a US\$ 1.340,41 (remuneração/180 h), US\$ 7,44 (remuneração/h) e US $\$ 0,12$ (remuneração/minuto), respectivamente.

\subsubsection{Cálculo do custo dos materiais}

Os custos unitários dos materiais, medicamentos e soluções, relativos à reposição das últimas três aquisições e/ou à reposição do último ano, foram disponibilizados pelo Setor de Compras, Farmácia e Almoxarifado do Hospital. Para alguns itens, foi calculado o custo estimado, a partir do consumo observado na prática clínica, conforme ilustrado no Quadro 2: 
Quadro 2 - Cálculo do custo e do custo estimado, a partir do consumo observado, em reais e dólares norte-americanos. São Paulo-SP, Brasil, 2018.

\begin{tabular}{|c|c|c|}
\hline $\begin{array}{c}\text { MATERIAL } \\
\text { (APRESENTAÇÃO) }\end{array}$ & $\begin{array}{l}\text { CUSTO } \\
\text { EM R\$ }\end{array}$ & $\begin{array}{c}\text { CUSTO E CUSTO ESTIMADO* } \\
\text { EM US } \$^{* *}\end{array}$ \\
\hline $\begin{array}{l}\text { Pomada de extrato de flor de camomila } \\
\text { (20 gramas) }\end{array}$ & 4,00 & $\begin{array}{c}1,06 / 20 \text { gramas } \\
0,01 / 0,2 \text { gramas/ procedimento* }\end{array}$ \\
\hline Máscara (unidade) & 0,49 & $0,13 /$ unidade \\
\hline $\begin{array}{l}\text { Seringa de } 10 \mathrm{~mL} \text { com SF } 0,9 \% \text { - } \\
\text { Posiflush } \AA \text { (unidade) }\end{array}$ & 1,40 & 0,37/unidade \\
\hline Swab de álcool a $70 \%$ (unidade) & 0,04 & 0,01/unidade \\
\hline Bolsa gel $300 \mathrm{~mL}$ (unidade) & 4,31 & $\begin{array}{c}1,14 / \text { unidade } \\
\begin{array}{c}0,15 / \text { estimativa de } \\
\text { paciente }^{*}\end{array}\end{array}$ \\
\hline $\begin{array}{l}\text { Película transparente com fenda }(7 \times 7 \\
\mathrm{cm} \text { ) (unidade) }\end{array}$ & 3,82 & $1,01 /$ unidade \\
\hline Cateter periférico íntima $\AA^{\circledR}$ (unidade) & 18,24 & $4,82 /$ unidade \\
\hline Cateter periférico Jelco® (unidade) & 1,21 & $0,32 /$ unidade \\
\hline Conector de sistema fechado (unidade) & 2,00 & 0,53/unidade \\
\hline $\begin{array}{l}\text { Luva de procedimento não estéril } \\
\text { (unidade) }\end{array}$ & 0,28 & 0,07/unidade \\
\hline
\end{tabular}

*Taxa de conversão: US\$ 0.26/R\$, com base na cotação de 08/06/2018, fornecida pelo Banco Central do Brasil.

\subsubsection{Cálculo do custo direto médio (CDM)}

A realização de determinado procedimento prevê o consumo de quantidades variadas de insumos, sendo possível estabelecer o valor do seu CDM $\left[\overline{C\left(P_{1}\right)}\right]$ por intermédio da soma do CDM dos materiais $\left[\overline{C\left(P_{2}\right)_{\text {mat }}}\right]$, do CDM das soluções/medicamentos [ $\left.\overline{C\left(P_{\imath}\right)_{s o l}}\right]$ e do CDM da MOD [ $\overline{C\left(P_{1}\right)_{m o b}}$, (equação 1$)^{59}$ :

$$
\overline{C\left(P_{2}\right)}=\overline{C\left(P_{2}\right)_{\text {mat }}}+\overline{C\left(P_{2}\right)_{s o l}}+\overline{C\left(P_{\imath}\right)_{\operatorname{mob}}(1)}
$$

Obtém-se o $\overline{C\left(P_{2}\right)_{\text {mat }}}$ pela soma dos custos médios [ $\overline{C m_{k}}$ ] de cada um dos materiais $[k]$ utilizados no procedimento (equação 2$)^{59}$ :

$$
\overline{C\left(P_{\imath}\right)_{\operatorname{mat}}}=\sum_{k=1}^{n} \overline{C m_{k}}(2)
$$


De acordo com a equação 3, o CDM de cada material é obtido pelo produto da quantidade média desse material $\left[\overline{q m_{k}}\right]$ pelo preço unitário médio $\left[\overline{P m u_{k}}\right]$ do mesmo:

$$
\overline{C m_{k}}=\overline{q m_{k}} \times \overline{P m u_{k}} \overline{C m_{k}}=\overline{q m_{k}} \times \overline{P m u_{k}}
$$

Substituindo-se a equação (3) na equação (2), obtém-se uma equação mais detalhada para o $\overline{C\left(P_{2}\right)_{\text {mat }}}$ (equação 4$)^{59}$ :

$$
\overline{C\left(P_{\imath}\right)_{\text {mat }}}=\sum_{k=1}^{n}\left(\overline{q_{m k}} \times \overline{P m u_{k}}\right) \overline{C\left(P_{n}\right)_{m a t}}=\sum_{k=1}^{n}\left(\overline{q_{m k}} \times \overline{P m u_{k}}\right)
$$

Obtém-se o $\overline{C\left(P_{2}\right)_{\text {sol }}}$ pela soma dos custos médios [ $\overline{C s_{k}}$ de cada uma das soluções/medicamentos consumidas no procedimento (equação 5) ${ }^{59}$ :

$$
\overline{C\left(P_{2}\right)_{s o l}}=\sum_{k=1}^{n} \overline{C s_{k}} \overline{C\left(P_{\imath}\right)_{s o l}}=\sum_{k=1}^{n} \overline{C s_{k}}(5)
$$

Conforme a equação 6, o CDM de cada solução/medicamento é obtido pelo produto da quantidade média dessa solução/medicamento $\left[\overline{q s_{k}}\right]$ pelo preço unitário médio [ $\left.\overline{P s u_{k}}\right]$ do mesmo:

$$
\overline{C s_{k}}=\overline{q s_{k}} \times \overline{P s u_{k} C s_{k}}=\overline{q s_{k}} \times \overline{P s u_{k}}(6)
$$

Substituindo-se a equação (6) na equação (5), obtém-se uma equação mais detalhada para o $\overline{C\left(P_{2}\right)_{\text {sol }}}$ (equação 7) ${ }^{59}$ :

$$
\overline{C\left(P_{n}\right)_{s o l}}=\sum_{k=1}^{n}\left(\overline{q s_{k}} \times \overline{P s u_{k}}\right) \overline{C\left(P_{\imath}\right)_{s o l}}=\sum_{k=1}^{n}\left(\overline{q s_{k}} \times \overline{P s u_{k}}\right)(7)
$$

Obtém-se o $\overline{C\left(P_{x}\right)_{m o b}}$ pela soma dos custos médios $\left[\overline{C h_{c}}\right]$ de cada categoria profissional envolvida no procedimento (equação 8):

$$
\overline{C\left(P_{1}\right)_{m o b}}=\sum_{c=1}^{n} \overline{C h_{c} C\left(P_{i}\right)_{m o b}}=\sum_{c=1}^{n} \overline{C h_{c}}(8)
$$

O custo médio de cada categoria profissional é obtido pelo produto do tempo médio dedicado pela categoria $[c]$ no procedimento $\left[{ }^{\overline{t_{c}}}\right]$ pelo custo médio unitário da mão de obra [ $\left.\overline{S u_{c}}\right]$ de cada categoria profissional (equação 9) ${ }^{59}$ :

$$
\overline{C h_{c}}=\bar{t}_{c} \times \overline{S u_{c}} \overline{C h_{c}}=\bar{t}_{c} \times \overline{S u_{c}}(9)
$$


Substituindo-se a equação (9) na equação (8), obtém-se uma equação mais detalhada para o $\overline{C\left(P_{2}\right)_{m o b}}$ (equação 10) ${ }^{59}$ :

$$
\overline{C\left(P_{\imath}\right)_{m o b}}=\sum_{c=1}^{n}\left(\bar{t}_{c} \cdot \overline{S u_{c}} \overline{\overline{C\left(P_{\imath}\right)_{m o b}}}=\sum_{c=1}^{n}\left(\overline{t_{c}} \cdot \overline{S u_{c}}\right)\right.
$$

Finalmente, substituindo-se as equações (4), (7) e (10) na equação (1), obtém-se a seguinte equação 11 que permite determinar o $\overline{C\left(P_{2}\right)} 59$ :

$$
\overline{C\left(P_{l}\right)}=\sum_{k=1}^{n}\left(\overline{q_{k}} \times \overline{P u_{k}}\right)+\sum_{k=1}^{n}\left(\overline{q s_{k}} \cdot \overline{P s u_{k}}\right)+\sum_{c=1}^{n}\left(\overline{t_{c}} \cdot \overline{S u_{c}}\right)(11)
$$

Logo, para apuração do $\overline{C\left(P_{2}\right)}$, definem-se como variáveis a quantidade média dos materiais [ $\overline{q m_{k}}$; o preço unitário médio de cada material $\left[\overline{P m u_{k}}\right.$; a quantidade média das soluções/medicamentos $\left[\overline{q s_{k}}\right] ; \quad$ p preço unitário médio de cada solução/medicamento $\left[\overline{P s u_{k}}\right]$; o tempo médio de dedicação de cada categoria profissional $\left[\bar{t}_{c}\right]$; e a massa salarial unitária média da MOD de cada categoria profissional $\left[\overline{S u_{\mathrm{c}}}\right]^{59}$.

Para o cálculo do CDM dos procedimentos, decorrentes do EA flebite, realizados por técnicos de enfermagem da Unidade de Internação Clínica, utilizou-se a moeda brasileira real (R\$) que foi convertida para o dólar americano (US\$) pela taxa de US $\$ 0,26 / R \$$, com base na cotação de 08 de junho de 2018, fornecida pelo Banco Central do Brasil.

\subsection{ANÁLISE DOS DADOS}

Os dados coletados foram inseridos em planilhas eletrônicas, tendo sido utilizado o programa de Estatística SPSS 19.0 da Empresa IBM®. Os dados contínuos e semicontínuos, relativos à ocorrência e às causas do EA flebite, foram inicialmente comparados com a curva de Gauss por meio do teste de distância K-S (KolmogorovSmirnov) e determinados como não paramétricos. Os dados não paramétricos foram expressos por intermédio de mediana e percentis e comparados pelo teste de KrusKal-Wallis com pós-teste de Muller-Dunn na comparação de três ou mais grupos.

Os dados categóricos foram representados por frequência absoluta (n) e 
relativa (\%) sendo as matrizes de contingência analisadas pelo teste de Qui-quadrado de Pearson, ou Teste Exato de Fisher, quando necessário. As matrizes complexas $(2 \times 3,3 \times 4 \ldots)$ foram particionadas em matrizes simples para melhor determinação da causalidade. Foi considerado, para todo o estudo, risco $\alpha \leq 0,05$ de cometer erro tipo I ou de $1^{\mathrm{a}}$ espécie e risco $\beta \leq 0,20$ de cometer erro tipo II ou de $2^{\mathrm{a}}$ espécie.

Para a identificação do CDM dos procedimentos realizados para o tratamento do EA flebite, analisaram-se as variáveis contínuas descritivamente por meio de estatísticas de posição (média, mínimo, máximo) e de escala (desvio padrão - DP).

\subsection{ASPECTOS ÉTICOS}

Iniciou-se a coleta de dados apenas após a anuência do HCE, aprovação do Comitê de Ética em Pesquisa (CEP), parecer consubstanciado número 2.500.262, e aceite de participação dos profissionais de enfermagem e dos pacientes por meio da assinatura do Termo de Consentimento Livre e Esclarecido (Apêndices F e G).

Os dados obtidos na pesquisa foram utilizados exclusivamente para a finalidade prevista no estudo, este atendeu a todas as especificações da resolução 466, de 12 de dezembro de 2012, que aprova as diretrizes e normas regulamentadoras de pesquisas envolvendo seres humanos ${ }^{60}$. 


\section{APRESENTAÇÃO DOS RESULTADOS}

\subsection{PERFIL DOS PACIENTES ACOMETIDOS POR FLEBITE EM UMA UNIDADE DE INTERNAÇÃO CLÍNICA}

Em 2017, ocorreram 3.028 internações na Unidade de Internação Clínica com tempo de permanência dos pacientes variando entre um e 23 dias. Foram notificadas 107 flebites referentes a 96 pacientes, sendo a maioria (91,7\%), de acordo com os registros, acometida por uma flebite; $5,2 \%$, por duas; e 3,1\%, por três flebites.

Conforme indica a Tabela 1, 53,1\% dos pacientes eram do sexo masculino; $23 \%$ estavam na faixa etária de 60 a 69 anos; $15,6 \%$, na faixa de 30 a 39 anos; e $15,6 \%$, na faixa de 40 a 49 anos; $30,2 \%$ com tempo de permanência inferior a quatro dias, seguido por cinco-sete dias $(26,0 \%)$ e oito -11 dias $(26,0 \%)$.

Tabela 1 - Distribuição dos pacientes acometidos por flebite na Unidade de Internação Clínica conforme sexo, faixa etária e tempo de permanência. São PauloSP, Brasil, 2019 ( $\mathrm{N}=96)$.

(continua)

\begin{tabular}{lcc}
\hline Variáveis & N & $\%$ \\
\hline Sexo & & \\
Feminino & 45 & 46,9 \\
Masculino & 51 & 53,1 \\
Faixa etária (em anos) & & \\
10 a 19 & 1 & 1,0 \\
20 a 29 & 3 & 3,1 \\
30 a 39 & 15 & 15,6 \\
40 a 49 & 15 & 15,6 \\
50 a 59 & 13 & 13,5 \\
60 a 69 & 22 & 23,0 \\
70 a 79 & 13 & 13,5 \\
80 a 89 & 10 & 10,4 \\
90 a 99 & 4 & 4,1
\end{tabular}


Tabela 1 - Distribuição dos pacientes acometidos por flebite na Unidade de Internação Clínica conforme sexo, faixa etária e tempo de permanência. São PauloSP, Brasil, $2019(\mathrm{~N}=96)$

(conclusão)

\begin{tabular}{lcc}
\hline Variáveis & N & $\%$ \\
\hline Tempo de permanência (dias) & & \\
\hline 4 dias & 29 & 30,2 \\
$5-7$ dias & 25 & 26,0 \\
$8-11$ dias & 25 & 26,0 \\
$>12$ dias & 17 & 17,8 \\
TOTAL & 96 & $\mathbf{1 0 0 , 0}$ \\
\hline
\end{tabular}

Em relação às hipóteses diagnósticas médicas dos 96 pacientes, optou-se, pelo grande quantitativo, pelo agrupamento em categorias (Apêndice H). Alguns pacientes com registro de mais de uma hipótese diagnóstica médica foram indicados em diferentes categorias; $19,8 \%$ dos pacientes apresentavam mais do que uma doença pré-existente. No Quadro 3, verifica-se que, entre as doenças pré-existentes, destacaram-se hipertensão arterial sistêmica $(22,9 \%)$, diabetes mellitus $(15,6 \%)$ e dislipidemia (12,5\%). Sessenta e oito pacientes apresentaram hipóteses diagnósticas médicas relativas a afecções infecciosas; 16 pacientes, a afecções do sistema nervoso central e periférico; nove pacientes, a categoria afecções do aparelho digestivo.

Quadro 3 - Distribuição das doenças pré-existentes e do agrupamento, em categorias, das hipóteses diagnósticas médicas dos pacientes $(\mathrm{N}=96)$ acometidos por flebite na Unidade de Internação Clínica. São Paulo-SP, Brasil, 2019.

(continua)

\begin{tabular}{|l|c|}
\hline Doenças pré-existentes & Quantitativo de pacientes \\
\hline Hipertensão Arterial Sistêmica & 22 \\
Diabetes mellitus & 15 \\
Dislipdemia & 12 \\
Neoplasia maligna & 9 \\
Hipotireoidismo & 7 \\
\hline
\end{tabular}


Quadro 3 - Distribuição das doenças pré-existentes e do agrupamento, em categorias, das hipóteses diagnósticas médicas dos pacientes $(\mathrm{N}=96)$ acometidos por flebite na Unidade de Internação Clínica. São Paulo-SP, Brasil, 2019.

\begin{tabular}{|l|c|}
\hline \multicolumn{2}{|c|}{ (conclusão) } \\
\hline Doenças pré-existentes & Quantitativo de pacientes \\
\hline Insuficiência Coronariana & 6 \\
Transtornos Mentais e Comportamentais & 6 \\
Neuropatia & 4 \\
Insuficiência Renal Crônica & 4 \\
Doença Pulmonar Obstrutiva Crônica & 4 \\
Parkinson & 2 \\
\hline Agrupamento das hipóteses diagnósticas médicas & Quantitativo de pacientes \\
por categorias & 68 \\
\hline Afecções infecciosas & 16 \\
Afecções do sistema nervoso central e periférico & 9 \\
Afecções do aparelho digestivo & 5 \\
Sepse & 3 \\
Afecções endócrinas & 3 \\
Afecções cardíacas & 1 \\
Afecções reumáticas & 1 \\
Afecções genéticas & 1 \\
Afecções do sistema respiratório & \\
\hline
\end{tabular}

\subsection{CARACTERIZAÇÃO DAS NOTIFICAÇÕES DA OCORRÊNCIA DE FLEBITES EM UMA UNIDADE DE INTERNAÇÃO CLÍNICA}

No que diz respeito ao quantitativo de notificações da ocorrência de flebites, na Unidade de Internação Clínica, em 2017, houve variação entre três, no mês de maio, e 14 , no mês de janeiro, sendo os meses de janeiro $(13,1 \%)$, junho $(12,1 \%)$, julho $(10,3 \%)$ e outubro (10,3\%) os de maior notificação. Os turnos da tarde e da manhã apresentaram o maior número de notificações, 40,2\% e 38,3\%, e o enfermeiro, a categoria profissional que realizou a maioria das notificações $(68,2 \%)$ seguidas de 29,9\% notificações anônimas (Tabela 2). 
Tabela 2 - Distribuição das notificações de flebites, no período de janeiro a dezembro de 2017, segundo o mês, turno e categoria profissional do relator - São Paulo-SP, Brasil, 2019 (N=107)

\begin{tabular}{lcc}
\hline Variáveis & $\mathbf{N}$ & $\%$ \\
\hline Mês & 14 & 13,1 \\
Janeiro & 10 & 9,3 \\
Fevereiro & 8 & 7,5 \\
Março & 8 & 7,5 \\
Abril & 3 & 2,8 \\
Maio & 13 & 12,1 \\
Junho & 11 & 10,3 \\
Julho & 5 & 4,7 \\
Agosto & 7 & 6,5 \\
Setembro & 11 & 10,3 \\
Outubro & 10 & 9,3 \\
Novembro & 7 & 6,5 \\
Dezembro & & \\
Turno & 32 & 38,3 \\
Manhã & 41 & 40,2 \\
Tarde & 43 & 21,5 \\
Noite & 23 & 68,2 \\
Categoria profissional do relator & & 1,9 \\
Enfermeiro & 73 & \\
Técnico de enfermagem & & \\
Notificação anônima & & \\
\hline
\end{tabular}

Verifica-se, na Tabela 3, o predomínio da ocorrência de flebite em pacientes com acesso venoso estabelecido por meio do dispositivo intravenoso Jelco® (56 $52,3 \%$ ); do tempo de permanência do dispositivo de 24 h (41 - 38,3\%); da classificação em grau 2 (49 - 45,8\%); da infusão de antibióticos (50 - 46,7\%); da localização do leito distante do posto de enfermagem (56 - 52,3\%); e da presença de acompanhante (88 $-82,2 \%)$. 
Tabela 3 - Caracterização das flebites notificadas $(\mathrm{N}=107)$ quanto ao tipo de dispositivo, tempo de permanência do dispositivo, grau da flebite, categoria do fármaco infundido - São Paulo-SP, Brasil, 2019.

(continua)

\begin{tabular}{|c|c|c|}
\hline Variáveis & $\mathbf{N}$ & $\%$ \\
\hline \multicolumn{3}{|c|}{ Tipo de dispositivo } \\
\hline Jelcoß & 56 & 52,3 \\
\hline Intima® & 51 & 47,7 \\
\hline \multicolumn{3}{|c|}{ Tempo de permanência do dispositivo } \\
\hline $24 \mathrm{~h}$ & 41 & 38,3 \\
\hline $48 \mathrm{~h}$ & 28 & 26,1 \\
\hline $72 \mathrm{~h}$ & 18 & 16,8 \\
\hline $96 \mathrm{~h}$ & 6 & 5,6 \\
\hline $120 \mathrm{~h}$ & 6 & 5,6 \\
\hline $144 \mathrm{~h}$ & 5 & 4,8 \\
\hline $168 \mathrm{~h}$ & 2 & 1,9 \\
\hline Pós-retirada & 1 & 0,9 \\
\hline \multicolumn{3}{|l|}{ Grau da flebite* } \\
\hline Grau 1 & 32 & 29,9 \\
\hline Grau 2 & 49 & 45,8 \\
\hline Grau 3 & 24 & 22,4 \\
\hline Grau 4 & 2 & 1,9 \\
\hline \multicolumn{3}{|c|}{ Categoria do fármaco } \\
\hline Analgésico & 9 & 8,4 \\
\hline Anti-histamínico & 1 & 0,9 \\
\hline Anti-inflamatório & 2 & 1,9 \\
\hline Antianêmico & 1 & 0,9 \\
\hline Antiemético & 3 & 2,8 \\
\hline Antifúngico & 3 & 2,8 \\
\hline Antibiótico & 50 & 46,7 \\
\hline
\end{tabular}


Tabela 3 - Caracterização das flebites notificadas $(N=107)$ quanto ao tipo de dispositivo, tempo de permanência do dispositivo, grau da flebite, categoria do fármaco infundido - São Paulo-SP, Brasil, 2019

(conclusão)

\begin{tabular}{lcc}
\hline Variáveis & $\mathbf{N}$ & $\%$ \\
\hline Antiviral & 7 & 6,5 \\
Cristaloide & 1 & 0,9 \\
Diurético & 1 & 0,9 \\
Imunoglobulina & 10 & 9,3 \\
Solução eletrolítica & 15 & 14 \\
Ausência de registro & 4 & 3,7 \\
Localização do leito & 51 & 47,7 \\
Próximo ao posto de enfermagem & 56 & 52,3 \\
Distante do posto de enfermagem & & \\
Presença de acompanhante & 88 & 82,2 \\
Sim & 19 & 17,8 \\
\hline Não & & \\
\hline${ }^{*}$ Grau 1: presença de hiperemia no sítio de inserção do cateter com ou sem dor local; grau 2: dor no sítio de \\
inserção do cateter com hiperemia e/ou edema e endurecimento; grau 3: dor no sítio de inserção do cateter com \\
hiperemia, endurecimento e formação de cordão venoso palpável; grau 4: dor no sítio de inserção do cateter com \\
hiperemia, endurecimento e formação de cordão venoso palpável com drenagem purulenta.
\end{tabular}

Indica-se, na Tabela 4, que, em relação à distribuição do grau das 107 flebites e às variáveis sexo, faixa etária, tempo de permanência dos pacientes, não foi constatada diferença estatística significante. 
Tabela 4 - Distribuição do grau das flebites notificadas segundo as variáveis sexo, faixa etária e tempo de permanência dos pacientes - São Paulo-SP, Brasil, $2019(\mathrm{~N}=107)$

\begin{tabular}{|c|c|c|c|c|c|c|c|c|c|c|}
\hline \multirow{2}{*}{$\begin{array}{l}\text { Grau de flebite* } \\
\text { Variáveis }\end{array}$} & & \multicolumn{2}{|c|}{ Grau 1} & \multicolumn{2}{|c|}{ Grau 2} & \multicolumn{2}{|c|}{ Grau 3} & \multicolumn{2}{|c|}{ Grau 4} & \multirow{2}{*}{$\frac{\mathrm{X}^{2} \text { de } \text { Pearson }^{* *}}{\text { Sig. }}$} \\
\hline & & $\mathbf{n}$ & $\%$ & $\mathbf{n}$ & $\%$ & $\mathbf{n}$ & $\%$ & $\mathbf{n}$ & $\%$ & \\
\hline \multirow{2}{*}{ Sexo } & Masculino & 14 & $25,5 \%$ & 27 & $49,1 \%$ & 13 & $23,6 \%$ & 1 & $1,8 \%$ & \multirow[t]{2}{*}{0,779} \\
\hline & Feminino & 18 & $34,6 \%$ & 22 & $42,3 \%$ & 11 & $21,2 \%$ & 1 & $1,9 \%$ & \\
\hline \multirow{9}{*}{ Faixa etária (em anos) } & 10 a 19 & 0 & $0,0 \%$ & 1 & $100,0 \%$ & 0 & $0,0 \%$ & 0 & $0,0 \%$ & \multirow{9}{*}{0,395} \\
\hline & 20 a 29 & 1 & $33,3 \%$ & 1 & $33,3 \%$ & 1 & $33,3 \%$ & 0 & $0,0 \%$ & \\
\hline & 30 a 39 & 2 & $10,5 \%$ & 9 & $47,4 \%$ & 7 & $36,8 \%$ & 1 & $5,3 \%$ & \\
\hline & 40 a 49 & 6 & $40,0 \%$ & 8 & $53,3 \%$ & 1 & $6,7 \%$ & 0 & $0,0 \%$ & \\
\hline & 50 a 59 & 1 & $6,3 \%$ & 9 & $56,3 \%$ & 5 & $31,3 \%$ & 1 & $6,3 \%$ & \\
\hline & 60 a 69 & 8 & $30,8 \%$ & 14 & $53,8 \%$ & 4 & $15,4 \%$ & 0 & $0,0 \%$ & \\
\hline & 70 a 79 & 6 & $46,2 \%$ & 3 & $23,1 \%$ & 4 & $30,8 \%$ & 0 & $0,0 \%$ & \\
\hline & 80 a 89 & 6 & $60,0 \%$ & 3 & $30,0 \%$ & 1 & $10,0 \%$ & 0 & $0,0 \%$ & \\
\hline & 90 a 99 & 2 & $50,0 \%$ & 1 & $25,0 \%$ & 1 & $25,0 \%$ & 0 & $0,0 \%$ & \\
\hline \multirow{4}{*}{$\begin{array}{l}\text { Tempo de } \\
\text { permanência (dias) }\end{array}$} & $<4$ dias & 14 & $46,7 \%$ & 7 & $23,3 \%$ & 8 & $26,7 \%$ & 1 & $3,3 \%$ & \multirow{4}{*}{0,119} \\
\hline & 5 - 7 dias & 7 & $25,0 \%$ & 13 & $46,4 \%$ & 8 & $28,6 \%$ & 0 & $0,0 \%$ & \\
\hline & 8 - 11 dias & 7 & $24,1 \%$ & 16 & $55,2 \%$ & 6 & $20,7 \%$ & 0 & $0,0 \%$ & \\
\hline & $>12$ dias & 4 & $20,0 \%$ & 13 & $65,0 \%$ & 2 & $10,0 \%$ & 1 & $5,0 \%$ & \\
\hline
\end{tabular}

*Grau 1: presença de hiperemia no sítio de inserção do cateter com ou sem dor local; grau 2: dor no sítio de inserção do cateter com hiperemia e/ou edema e endurecimento; grau 3: dor no sítio de inserção do cateter com hiperemia, endurecimento e formação de cordão venoso palpável; grau 4: dor no sítio de inserção do cateter com hiperemia, endurecimento e formação de cordão venoso palpável com drenagem purulenta. ${ }^{* *}$ Teste qui-quadrado de Pearson. 
Evidencia-se, na Tabela 5, que houve diferença estatística significante da ocorrência de flebite grau 2 associada às doenças pré-existentes hipertensão arterial sistêmica $(p=0,020)$, transtornos mentais e comportamentais $(p=0,020)$ e neuropatia $(p=0,005)$. Os pacientes que possuíam hipertensão arterial sistêmica como doença pré-existente apresentaram, na sua maioria, flebite grau 2 (15 - 68,2\%) e grau 3 (6 - 27,3\%). Três (75\%) pacientes com as comorbidades insuficiência renal crônica e nove (75\%) com dislipidemia também apresentaram flebite grau 2. O diabetes mellitus esteve associada ao maior número de pacientes com flebite grau 2 (8 - 53,3\%) e grau 3 (4 - 26,7\%). Considerando-se os pacientes com hipótese diagnóstica de sepse, três (60\%) apresentaram flebite grau 3 .

Tabela 5 - Distribuição do grau das flebites notificadas segundo as variáveis doenças pré-existentes e agrupamento das hipóteses diagnósticas médicas - São Paulo-SP, Brasil, 2019 (N=107)

\begin{tabular}{|c|c|c|c|c|c|c|c|c|c|c|}
\hline \multirow{2}{*}{\multicolumn{2}{|c|}{$\begin{array}{c}\text { Grau de Flebite* }^{\star} \\
\text { Variáveis }\end{array}$}} & \multicolumn{2}{|c|}{ Grau 1} & \multicolumn{2}{|c|}{ Grau 2} & \multicolumn{2}{|c|}{ Grau 3} & \multicolumn{2}{|c|}{ Grau 4} & \multirow{2}{*}{$\frac{x^{2} \text { de Pearson }{ }^{* *}}{\text { Sig. }}$} \\
\hline & & $\mathbf{N}$ & $\%$ & $\mathbf{n}$ & $\%$ & $\mathbf{n}$ & $\%$ & $\mathbf{n}$ & $\%$ & \\
\hline \multicolumn{11}{|l|}{ Doenças pré-existentes } \\
\hline \multirow{2}{*}{ Neoplasia maligna } & Não & 30 & $30,90 \%$ & 43 & $44,30 \%$ & 22 & $22,70 \%$ & 2 & $2,10 \%$ & \multirow{2}{*}{0,617} \\
\hline & Sim & 2 & $22,20 \%$ & 6 & $66,70 \%$ & 1 & $11,10 \%$ & 0 & $0,00 \%$ & \\
\hline \multirow{2}{*}{$\begin{array}{l}\text { Hipertensão Arterial } \\
\text { Sistêmica }\end{array}$} & Não & 31 & $36,50 \%$ & 34 & $40,00 \%$ & 18 & $21,20 \%$ & 2 & $2,40 \%$ & \multirow{2}{*}{0,02} \\
\hline & Sim & 1 & $4,50 \%$ & 15 & $68,20 \%$ & 6 & $27,30 \%$ & 0 & $0,00 \%$ & \\
\hline \multirow{2}{*}{$\begin{array}{l}\text { Transtornos mentais e } \\
\text { comportamentais }\end{array}$} & Não & 31 & $30,70 \%$ & 45 & $44,60 \%$ & 24 & $23,80 \%$ & 1 & $1,00 \%$ & \multirow[t]{2}{*}{0,02} \\
\hline & Sim & 1 & $16,70 \%$ & 4 & $66,70 \%$ & 0 & $0,00 \%$ & 1 & $16,70 \%$ & \\
\hline \multirow{2}{*}{ Neuropatia } & Não & 31 & $30,10 \%$ & 47 & $45,60 \%$ & 24 & $23,30 \%$ & 1 & $1,00 \%$ & \multirow{2}{*}{0,005} \\
\hline & Sim & 1 & $25,00 \%$ & 2 & $50,00 \%$ & 0 & $0,00 \%$ & 1 & $25,00 \%$ & \\
\hline
\end{tabular}


Tabela 5 - Distribuição do grau das flebites notificadas segundo as variáveis doenças pré-existentes e agrupamento das hipóteses diagnósticas médicas - São Paulo-SP, Brasil, $2019(\mathrm{~N}=107)$

(continuação)

\begin{tabular}{|c|c|c|c|c|c|c|c|c|c|c|}
\hline \multirow{2}{*}{$\begin{array}{c}\text { Grau de Flebite* }^{*} \\
\text { Variáveis }\end{array}$} & & \multicolumn{2}{|c|}{ Grau 1} & \multicolumn{2}{|c|}{ Grau 2} & \multicolumn{2}{|c|}{ Grau 3} & \multicolumn{2}{|c|}{ Grau 4} & \multirow{2}{*}{$\frac{\mathrm{X}^{2} \text { de Pears }}{\text { Sig. }}$} \\
\hline & & $\mathbf{N}$ & $\%$ & $\mathbf{n}$ & $\%$ & $\mathbf{n}$ & $\%$ & $\mathbf{n}$ & $\%$ & \\
\hline \multicolumn{11}{|l|}{ Doenças pré-existentes } \\
\hline \multirow{2}{*}{ Parkinson } & Não & 31 & $29,50 \%$ & 48 & $45,70 \%$ & 24 & $22,90 \%$ & 2 & $1,90 \%$ & \multirow{2}{*}{0,855} \\
\hline & Sim & 1 & $50,00 \%$ & 1 & $50,00 \%$ & 0 & $0,00 \%$ & 0 & $0,00 \%$ & \\
\hline \multirow{2}{*}{ Insuficiência Renal Crônica } & Não & 31 & $30,10 \%$ & 46 & $44,70 \%$ & 24 & $23,30 \%$ & 2 & $1,90 \%$ & \multirow{2}{*}{0,611} \\
\hline & Sim & 1 & $25,00 \%$ & 3 & $75,00 \%$ & 0 & $0,00 \%$ & 0 & $0,00 \%$ & \\
\hline \multirow{2}{*}{ Síndrome Demencial } & Não & 30 & $28,80 \%$ & 48 & $46,20 \%$ & 24 & $23,10 \%$ & 2 & $1,90 \%$ & \multirow{2}{*}{0,522} \\
\hline & Sim & 2 & $66,70 \%$ & 1 & $33,30 \%$ & 0 & $0,00 \%$ & 0 & $0,00 \%$ & \\
\hline \multirow{2}{*}{ Dislipidemia } & Não & 31 & $32,60 \%$ & 40 & $42,10 \%$ & 22 & $23,20 \%$ & 2 & $2,10 \%$ & \multirow{2}{*}{0,166} \\
\hline & Sim & 1 & $8,30 \%$ & 9 & $75,00 \%$ & 2 & $16,70 \%$ & 0 & $0,00 \%$ & \\
\hline \multirow{2}{*}{$\begin{array}{l}\text { Doença Pulmonar } \\
\text { Obstrutiva Crônica }\end{array}$} & Não & 30 & $29,10 \%$ & 47 & $45,60 \%$ & 24 & $23,30 \%$ & 2 & $1,90 \%$ & \multirow{2}{*}{0,662} \\
\hline & Sim & 2 & $50,00 \%$ & 2 & $50,00 \%$ & 0 & $0,00 \%$ & 0 & $0,00 \%$ & \\
\hline \multirow{2}{*}{ Insuficiência Coronariana } & Não & 31 & $30,70 \%$ & 45 & $44,60 \%$ & 23 & $22,80 \%$ & 2 & $2,00 \%$ & \multirow{2}{*}{0,755} \\
\hline & Sim & 1 & $16,70 \%$ & 4 & $66,70 \%$ & 1 & $16,70 \%$ & 0 & $0,00 \%$ & \\
\hline \multirow{2}{*}{ Hipotireoidismo } & Não & 30 & $30,00 \%$ & 48 & $48,00 \%$ & 20 & $20,00 \%$ & 2 & $2,00 \%$ & \multirow{2}{*}{0,122} \\
\hline & Sim & 2 & $28,60 \%$ & 1 & $14,30 \%$ & 4 & $57,10 \%$ & 0 & $0,00 \%$ & \\
\hline \multirow{2}{*}{ Diabetes Mellitus } & Não & 29 & $31,50 \%$ & 41 & $44,60 \%$ & 20 & $21,70 \%$ & 2 & $2,20 \%$ & \multirow{2}{*}{0,74} \\
\hline & Sim & 3 & $20,00 \%$ & 8 & $53,30 \%$ & 4 & $26,70 \%$ & 0 & $0,00 \%$ & \\
\hline
\end{tabular}


Tabela 5 - Distribuição do grau das flebites notificadas segundo as variáveis doenças pré-existentes e agrupamento das hipóteses diagnósticas médicas - São Paulo-SP, Brasil, $2019(\mathrm{~N}=107)$

(continuação)

\begin{tabular}{|c|c|c|c|c|c|c|c|c|c|c|}
\hline \multirow{2}{*}{\multicolumn{2}{|c|}{$\begin{array}{c}\text { Grau de Flebite* }^{*} \text { Variáveis } \\
\end{array}$}} & \multicolumn{2}{|c|}{ Grau 1} & \multicolumn{2}{|c|}{ Grau 2} & \multicolumn{2}{|c|}{ Grau 3} & \multicolumn{2}{|c|}{ Grau 4} & \multirow{2}{*}{$\frac{x^{2} \text { de Pears }}{\text { Sig. }}$} \\
\hline & & $\mathbf{N}$ & $\%$ & $\mathbf{n}$ & $\%$ & $\mathbf{n}$ & $\%$ & $\mathbf{n}$ & $\%$ & \\
\hline \multicolumn{11}{|c|}{$\begin{array}{l}\text { Agrupamento das hipóteses } \\
\text { diagnósticas médicas }\end{array}$} \\
\hline \multirow{2}{*}{ Afecções cardíacas } & Não & 30 & $28,80 \%$ & 48 & $46,20 \%$ & 24 & $23,10 \%$ & 2 & $1,90 \%$ & \multirow{2}{*}{0,522} \\
\hline & Sim & 2 & $66,70 \%$ & 1 & $33,30 \%$ & 0 & $0,00 \%$ & 0 & $0,00 \%$ & \\
\hline \multirow{2}{*}{ Afecções reumáticas } & Não & 32 & $30,20 \%$ & 49 & $46,20 \%$ & 23 & $21,70 \%$ & 2 & $1,90 \%$ & \multirow{2}{*}{0,322} \\
\hline & Sim & 0 & $0,00 \%$ & 0 & $0,00 \%$ & 1 & $100,00 \%$ & 0 & $0,00 \%$ & \\
\hline \multirow{2}{*}{ Afecções endócrinas } & Não & 31 & $29,80 \%$ & 48 & $46,20 \%$ & 23 & $22,10 \%$ & 2 & $1,90 \%$ & \multirow{2}{*}{0,953} \\
\hline & Sim & 1 & $33,30 \%$ & 1 & $33,30 \%$ & 1 & $33,30 \%$ & 0 & $0,00 \%$ & \\
\hline \multirow{2}{*}{$\begin{array}{l}\text { Afecções do aparelho } \\
\text { digestivo }\end{array}$} & Não & 29 & $29,60 \%$ & 46 & $46,90 \%$ & 22 & $22,40 \%$ & 1 & $1,00 \%$ & \multirow{2}{*}{0,182} \\
\hline & Sim & 3 & $33,30 \%$ & 3 & $33,30 \%$ & 2 & $22,20 \%$ & 1 & $11,10 \%$ & \\
\hline \multirow{2}{*}{ Afecções genéticas } & Não & 32 & $30,20 \%$ & 48 & $45,30 \%$ & 24 & $22,60 \%$ & 2 & $1,90 \%$ & \multirow{2}{*}{0,754} \\
\hline & Sim & 0 & $0,00 \%$ & 1 & $100,00 \%$ & 0 & $0,00 \%$ & 0 & $0,00 \%$ & \\
\hline \multirow{2}{*}{ Afecções infecciosas } & Não & 10 & $25,60 \%$ & 16 & $41,00 \%$ & 12 & $30,80 \%$ & 1 & $2,60 \%$ & \multirow{2}{*}{0,434} \\
\hline & Sim & 22 & $32,40 \%$ & 33 & $48,50 \%$ & 12 & $17,60 \%$ & 1 & $1,50 \%$ & \\
\hline \multirow{2}{*}{ Sepse } & Não & 31 & $30,40 \%$ & 48 & $47,10 \%$ & 21 & $20,60 \%$ & 2 & $2,00 \%$ & \multirow{2}{*}{0,228} \\
\hline & Sim & 1 & $20,00 \%$ & 1 & $20,00 \%$ & 3 & $60,00 \%$ & 0 & $0,00 \%$ & \\
\hline \multirow{2}{*}{$\begin{array}{l}\text { Afecções do sistema } \\
\text { nervoso central e } \\
\text { periférico }\end{array}$} & Não & 29 & $31,90 \%$ & 41 & $45,10 \%$ & 19 & $20,90 \%$ & 2 & $2,20 \%$ & \multirow{2}{*}{0,602} \\
\hline & Sim & 3 & $18,80 \%$ & 8 & $50,00 \%$ & 5 & $31,30 \%$ & 0 & $0,00 \%$ & \\
\hline
\end{tabular}


Tabela 5 - Distribuição do grau das flebites notificadas segundo as variáveis doenças pré-existentes e agrupamento das hipóteses diagnósticas médicas - São Paulo-SP, Brasil, $2019(\mathrm{~N}=107)$

\begin{tabular}{|c|c|c|c|c|c|c|c|c|c|c|}
\hline \multirow{2}{*}{\multicolumn{2}{|c|}{$\frac{\text { Grau de flebite* }^{*}}{\text { Variáveis }}$}} & \multicolumn{2}{|c|}{ Grau 1} & \multicolumn{2}{|c|}{ Grau 2} & \multicolumn{2}{|c|}{ Grau 3} & \multicolumn{2}{|c|}{ Grau 4} & \multirow{2}{*}{ 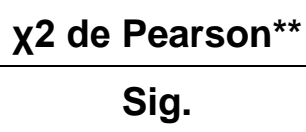 } \\
\hline & & $\mathbf{N}$ & $\%$ & $\mathbf{n}$ & $\%$ & $\mathbf{n}$ & $\%$ & $\mathbf{n}$ & $\%$ & \\
\hline \multicolumn{11}{|c|}{$\begin{array}{l}\text { Agrupamento das hipóteses } \\
\text { diagnósticas médicas }\end{array}$} \\
\hline \multirow{2}{*}{$\begin{array}{l}\text { Afecções do sistema } \\
\text { respiratório }\end{array}$} & Não & 32 & $30,20 \%$ & 48 & $45,30 \%$ & 24 & $22,60 \%$ & 2 & $1,90 \%$ & \multirow{2}{*}{0,754} \\
\hline & Sim & 0 & $0,00 \%$ & 1 & $100,00 \%$ & 0 & $0,00 \%$ & 0 & $0,00 \%$ & \\
\hline
\end{tabular}

${ }^{*}$ Grau 1: presença de hiperemia no sítio de inserção do cateter com ou sem dor local; grau 2: dor no sítio de inserção do cateter com hiperemia e/ou edema e endurecimento; grau 3: dor no sítio de inserção do cateter com hiperemia, endurecimento e formação de cordã̃o venoso palpável; grau 4: dor no sítio de inserção do cateter com hiperemia, endurecimento e formação de cordão venoso palpável com drenagem purulenta. ${ }^{*}$ Teste qui-quadrado de Pearson.

Quando analisada a variável função do relator com o grau da flebite, pode-se observar, na Tabela 6, que houve relação estatística significante $(p=0,007)$ entre a flebite grau 2 e a notificação realizada pelo enfermeiro e a notificação de forma anônima. Os técnicos de enfermagem notificaram apenas duas flebites referentes ao grau 1. 
Tabela 6 - Distribuição do grau das flebites notificadas $(\mathrm{N}=107)$ segundo as variáveis: mês da ocorrência, turno e categoria profissional do relator - São Paulo-SP, Brasil, 2017.

\begin{tabular}{|c|c|c|c|c|c|c|c|c|c|c|}
\hline \multirow{2}{*}{\multicolumn{2}{|c|}{$\frac{\text { Grau de flebite* }^{*}}{\text { Variáveis }}$}} & \multicolumn{2}{|c|}{ Grau 1} & \multicolumn{2}{|c|}{ Grau 2} & \multicolumn{2}{|c|}{ Grau 3} & \multicolumn{2}{|c|}{ Grau 4} & \multirow{2}{*}{$\frac{\mathrm{X}^{2} \text { de Pearson** }}{\text { Sig. }}$} \\
\hline & & $\mathbf{N}$ & $\%$ & $\mathbf{n}$ & $\%$ & $\mathbf{n}$ & $\%$ & $\mathbf{n}$ & $\%$ & \\
\hline \multirow{12}{*}{$\begin{array}{l}\text { Mês da } \\
\text { ocorrência }\end{array}$} & Janeiro & 4 & $28,60 \%$ & 8 & $57,10 \%$ & 2 & $14,30 \%$ & 0 & $0,00 \%$ & \multirow{12}{*}{0,255} \\
\hline & Fevereiro & 3 & $30,00 \%$ & 4 & $40,00 \%$ & 3 & $30,00 \%$ & 0 & $0,00 \%$ & \\
\hline & Março & 0 & $0,00 \%$ & 3 & $37,50 \%$ & 5 & $62,50 \%$ & 0 & $0,00 \%$ & \\
\hline & Abril & 3 & $37,50 \%$ & 3 & $37,50 \%$ & 2 & $25,00 \%$ & 0 & $0,00 \%$ & \\
\hline & Maio & 0 & $0,00 \%$ & 3 & $100,00 \%$ & 0 & $0,00 \%$ & 0 & $0,00 \%$ & \\
\hline & Junho & 1 & $7,70 \%$ & 9 & $69,20 \%$ & 2 & $15,40 \%$ & 1 & $7,70 \%$ & \\
\hline & Julho & 7 & $63,60 \%$ & 2 & $18,20 \%$ & 2 & $18,20 \%$ & 0 & $0,00 \%$ & \\
\hline & Agosto & 2 & $40,00 \%$ & 3 & $60,00 \%$ & 0 & $0,00 \%$ & 0 & $0,00 \%$ & \\
\hline & Setembro & 1 & $14,30 \%$ & 4 & $57,10 \%$ & 2 & $28,60 \%$ & 0 & $0,00 \%$ & \\
\hline & Outubro & 5 & $45,50 \%$ & 3 & $27,30 \%$ & 3 & $27,30 \%$ & 0 & $0,00 \%$ & \\
\hline & Novembro & 4 & $40,00 \%$ & 4 & $40,00 \%$ & 2 & $20,00 \%$ & 0 & $0,00 \%$ & \\
\hline & Dezembro & 2 & $28,60 \%$ & 3 & $42,90 \%$ & 1 & $14,30 \%$ & 1 & $14,30 \%$ & \\
\hline \multirow{3}{*}{ Turno } & Manhã & 11 & $26,80 \%$ & 19 & $46,30 \%$ & 9 & $22,00 \%$ & 2 & $4,90 \%$ & \multirow{3}{*}{0,467} \\
\hline & Tarde & 16 & $37,20 \%$ & 19 & $44,20 \%$ & 8 & $18,60 \%$ & 0 & $0,00 \%$ & \\
\hline & Noite & 5 & $21,70 \%$ & 11 & $47,80 \%$ & 7 & $30,40 \%$ & 0 & $0,00 \%$ & \\
\hline \multirow{3}{*}{$\begin{array}{l}\text { Categoria } \\
\text { profissional } \\
\text { do relator }\end{array}$} & Enfermeiro & 28 & $38,40 \%$ & 32 & $43,80 \%$ & 12 & $16,40 \%$ & 1 & $1,40 \%$ & \multirow{3}{*}{0,007} \\
\hline & Técnico de enfermagem & 2 & $100,00 \%$ & 0 & $0,00 \%$ & 0 & $0,00 \%$ & 0 & $0,00 \%$ & \\
\hline & Anônimo & 2 & $6,30 \%$ & 17 & $53,10 \%$ & 12 & $37,50 \%$ & 1 & $3,10 \%$ & \\
\hline
\end{tabular}

${ }^{*}$ Grau 1: presença de hiperemia no sítio de inserção do cateter com ou sem dor local; grau 2: dor no sítio de inserção do cateter com hiperemia e/ou edema e endurecimento; grau 3: dor no sítio de inserção do cateter com hiperemia, endurecimento e formação de cordão venoso palpável; grau 4: dor no sítio de inserção do cateter com hiperemia, endurecimento e formação de cordão venoso palpável com drenagem purulenta. ${ }^{* *}$ Teste qui-quadrado de Pearson. 
A Tabela 7 mostra que, dentre os 50 (100\%) pacientes que receberam antibiótico durante o período de internação, $42 \%$ apresentaram flebite grau 2 e $28 \%$ flebite grau 3. Quando analisados os dez (100\%) pacientes que utilizaram a imunoglobulina, $50 \%$ apresentaram flebite grau 3; 28 (50\%) pacientes que estavam distantes do posto de enfermagem apresentaram flebite grau 2 , seguidos do grau $3(17,9 \%)$ e do grau $4(3,6 \%)$.

Tabela 7 - Distribuição do grau das flebites notificadas segundo as variáveis tipo de dispositivo, classe do fármaco, localização do leito em relação ao posto de enfermagem e presença de acompanhante - São Paulo-SP, Brasil, 2019 (N=107)

\begin{tabular}{|c|c|c|c|c|c|c|c|c|c|c|}
\hline \multirow{2}{*}{\multicolumn{2}{|c|}{$\frac{\text { Grau de flebite }^{*}}{\text { Variáveis }}$}} & \multicolumn{2}{|c|}{ Grau 1} & \multicolumn{2}{|c|}{ Grau 2} & \multicolumn{2}{|c|}{ Grau 3} & \multicolumn{2}{|c|}{ Grau 4} & \multirow{3}{*}{$\begin{array}{c}\text { X2 de Pearson** }^{* *} \\
\text { Sig. } \\
0,929\end{array}$} \\
\hline & & \multirow{2}{*}{$\frac{\mathbf{N}}{16}$} & \multirow{2}{*}{$\frac{\%}{28,60 \%}$} & \multirow{2}{*}{$\frac{\mathbf{n}}{25}$} & \multirow{2}{*}{$\frac{\%}{44,60 \%}$} & \multirow{2}{*}{$\frac{\mathbf{N}}{14}$} & \multirow{2}{*}{$\begin{array}{c}\% \\
25,00 \%\end{array}$} & \multirow{2}{*}{$\frac{\mathbf{n}}{1}$} & \multirow{2}{*}{$\frac{\%}{1,80 \%}$} & \\
\hline Tinn dicnncitive & Jelco $\circledast$ & & & & & & & & & \\
\hline 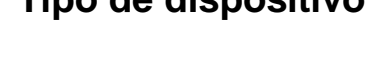 & Intima ${ }^{\circledR}$ & 16 & $31,40 \%$ & 24 & $47,10 \%$ & 10 & $19,60 \%$ & 1 & $2,00 \%$ & \\
\hline \multicolumn{11}{|l|}{ Classe do fármaco } \\
\hline \multirow{2}{*}{ Analgésico } & Não & 31 & $31,60 \%$ & 42 & $42,90 \%$ & 23 & $23,50 \%$ & 2 & $2,00 \%$ & \multirow{2}{*}{0,251} \\
\hline & Sim & 1 & $11,10 \%$ & 7 & $77,80 \%$ & 1 & $11,10 \%$ & 0 & $0,00 \%$ & \\
\hline \multirow{2}{*}{ Anti-histamínico } & Não & 31 & $29,20 \%$ & 49 & $46,20 \%$ & 24 & $22,60 \%$ & 2 & $1,90 \%$ & \multirow{2}{*}{0,5} \\
\hline & Sim & 1 & $100,00 \%$ & 0 & $0,00 \%$ & 0 & $0,00 \%$ & 0 & $0,00 \%$ & \\
\hline \multirow{2}{*}{ Anti-inflamatório } & Não & 30 & $28,60 \%$ & 49 & $46,70 \%$ & 24 & $22,90 \%$ & 2 & $1,90 \%$ & \multirow{2}{*}{0,189} \\
\hline & Sim & 2 & $100,00 \%$ & 0 & $0,00 \%$ & 0 & $0,00 \%$ & 0 & $0,00 \%$ & \\
\hline
\end{tabular}


Tabela 7 - Distribuição do grau das flebites notificadas segundo as variáveis tipo de dispositivo, classe do fármaco, localização do leito em relação ao posto de enfermagem e presença de acompanhante - São Paulo-SP, Brasil, 2019 (N=107)

\begin{tabular}{|c|c|c|c|c|c|c|c|c|c|c|}
\hline \multirow{2}{*}{\multicolumn{2}{|c|}{$\frac{\text { Grau de flebite* }^{*}}{\text { Variáveis }}$}} & \multicolumn{2}{|c|}{ Grau 1} & \multicolumn{2}{|c|}{ Grau 2} & \multicolumn{2}{|c|}{ Grau 3} & \multicolumn{2}{|c|}{ Grau 4} & \multirow{4}{*}{$\begin{array}{c}\text { X2 de Pearson** }^{*} \\
\text { Sig. } \\
0,754\end{array}$} \\
\hline & & \multirow{2}{*}{$\frac{\mathbf{N}}{32}$} & \multirow{2}{*}{$\begin{array}{c}\% \\
30,20 \%\end{array}$} & \multirow{2}{*}{$\frac{n}{48}$} & \multirow{2}{*}{$\begin{array}{c}\% \\
45,30 \%\end{array}$} & \multirow{2}{*}{$\frac{\mathbf{N}}{24}$} & \multirow{2}{*}{$\frac{\%}{22,60 \%}$} & \multirow{2}{*}{$\begin{array}{l}\mathbf{n} \\
2\end{array}$} & \multirow{2}{*}{$\begin{array}{c}\% \\
1,90 \%\end{array}$} & \\
\hline Antianômico & Não & & & & & & & & & \\
\hline 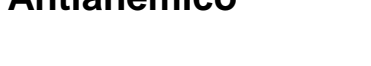 & Sim & 0 & $0,00 \%$ & 1 & $100,00 \%$ & 0 & $0,00 \%$ & 0 & $0,00 \%$ & \\
\hline \multirow{2}{*}{ Antiemético } & Não & 31 & $29,80 \%$ & 48 & $46,20 \%$ & 24 & $23,10 \%$ & 1 & $1,00 \%$ & \multirow{2}{*}{0,001} \\
\hline & Sim & 1 & $33,30 \%$ & 1 & $33,30 \%$ & 0 & $0,00 \%$ & 1 & $33,30 \%$ & \\
\hline \multirow{2}{*}{ Antifúngico } & Não & 31 & $29,80 \%$ & 47 & $45,20 \%$ & 24 & $23,10 \%$ & 2 & $1,90 \%$ & \multirow{2}{*}{0,788} \\
\hline & Sim & 1 & $33,30 \%$ & 2 & $66,70 \%$ & 0 & $0,00 \%$ & 0 & $0,00 \%$ & \\
\hline \multirow{2}{*}{ Antibiótico } & Não & 17 & $29,80 \%$ & 28 & $49,10 \%$ & 10 & $17,50 \%$ & 2 & $3,50 \%$ & \multirow{2}{*}{0,341} \\
\hline & Sim & 15 & $30,00 \%$ & 21 & $42,00 \%$ & 14 & $28,00 \%$ & 0 & $0,00 \%$ & \\
\hline \multirow{2}{*}{ Antiviral } & Não & 30 & $30,00 \%$ & 45 & $45,00 \%$ & 24 & $24,00 \%$ & 1 & $1,00 \%$ & \multirow{2}{*}{0,045} \\
\hline & $\operatorname{Sim}$ & 2 & $28,60 \%$ & 4 & $57,10 \%$ & 0 & $0,00 \%$ & 1 & $14,30 \%$ & \\
\hline \multirow{2}{*}{ Cristaloide } & Não & 32 & $30,20 \%$ & 48 & $45,30 \%$ & 24 & $22,60 \%$ & 2 & $1,90 \%$ & \multirow{2}{*}{0,754} \\
\hline & Sim & 0 & $0,00 \%$ & 1 & $100,00 \%$ & 0 & $0,00 \%$ & 0 & $0,00 \%$ & \\
\hline \multirow{2}{*}{ Diurético } & Não & 31 & $29,20 \%$ & 49 & $46,20 \%$ & 24 & $22,60 \%$ & 2 & $1,90 \%$ & \multirow{2}{*}{0,5} \\
\hline & Sim & 1 & $100,00 \%$ & 0 & $0,00 \%$ & 0 & $0,00 \%$ & 0 & $0,00 \%$ & \\
\hline \multirow{2}{*}{ Imunoglobulina } & Não & 31 & $32,00 \%$ & 45 & $46,40 \%$ & 19 & $19,60 \%$ & 2 & $2,10 \%$ & \multirow{2}{*}{0,139} \\
\hline & Sim & 1 & $10,00 \%$ & 4 & $40,00 \%$ & 5 & $50,00 \%$ & 0 & $0,00 \%$ & \\
\hline \multirow{2}{*}{ Solução eletrolítica } & Não & 26 & $28,30 \%$ & 43 & $46,70 \%$ & 21 & $22,80 \%$ & 2 & $2,20 \%$ & \multirow{2}{*}{0,778} \\
\hline & Sim & 6 & $40,00 \%$ & 6 & $40,00 \%$ & 3 & $20,00 \%$ & 0 & $0,00 \%$ & \\
\hline
\end{tabular}


Tabela 7 - Distribuição do grau das flebites notificadas segundo as variáveis tipo de dispositivo, classe do fármaco, localização do leito em relação ao posto de enfermagem e presença de acompanhante - São Paulo-SP, Brasil, 2019 (N=107)

\begin{tabular}{|c|c|c|c|c|c|c|c|c|c|c|}
\hline \multirow{2}{*}{\multicolumn{2}{|c|}{$\frac{\text { Grau de Flebite* }^{*}}{\text { Variáveis }}$}} & \multicolumn{2}{|c|}{ Grau 1} & \multicolumn{2}{|c|}{ Grau 2} & \multicolumn{2}{|c|}{ Grau 3} & \multicolumn{2}{|c|}{ Grau 4} & \multirow{4}{*}{$\begin{array}{c}\mathbf{X}^{2} \text { de Pearson** } \\
\text { Sig. } \\
0,987\end{array}$} \\
\hline & & \multirow{3}{*}{$\begin{array}{c}\mathbf{N} \\
31 \\
1\end{array}$} & \multirow{3}{*}{$\begin{array}{c}\% \\
30,10 \% \\
25,00 \%\end{array}$} & \multirow{3}{*}{$\begin{array}{c}\mathbf{n} \\
47 \\
2\end{array}$} & \multirow{3}{*}{$\begin{array}{c}\% \\
45,60 \% \\
50,00 \%\end{array}$} & \multirow{3}{*}{$\begin{array}{c}\mathbf{N} \\
23 \\
1\end{array}$} & \multirow{3}{*}{$\begin{array}{c}\% \\
22,30 \% \\
25,00 \%\end{array}$} & \multirow{3}{*}{$\begin{array}{l}\mathbf{n} \\
2 \\
0\end{array}$} & \multirow{3}{*}{$\begin{array}{c}\% \\
1,90 \% \\
0,00 \%\end{array}$} & \\
\hline Aunângio do moriatma & Não & & & & & & & & & \\
\hline 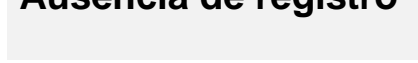 & Sim & & & & & & & & & \\
\hline \multirow{2}{*}{ Localização do leito } & Próximo & 16 & $31,40 \%$ & 21 & $41,20 \%$ & 14 & $27,50 \%$ & 0 & $0,00 \%$ & \multirow{2}{*}{0,329} \\
\hline & Distante & 16 & $28,60 \%$ & 28 & $50,00 \%$ & 10 & $17,90 \%$ & 2 & $3,60 \%$ & \\
\hline \multirow{2}{*}{$\begin{array}{l}\text { Presença de } \\
\text { acompanhante }\end{array}$} & Não & 5 & $26,30 \%$ & 11 & $57,90 \%$ & 3 & $15,80 \%$ & 0 & $0,00 \%$ & \multirow{2}{*}{0,632} \\
\hline & Sim & 27 & $30,70 \%$ & 38 & $43,20 \%$ & 21 & $23,90 \%$ & 2 & $2,30 \%$ & \\
\hline
\end{tabular}

*Grau 1: presença de hiperemia no sítio de inserção do cateter com ou sem dor local; grau 2: dor no sítio de inserção do cateter com hiperemia e/ou edema e endurecimento; grau 3: dor no sítio de inserção do cateter com hiperemia, endurecimento e formação de cordão venoso palpável; grau 4: dor no sítio de inserção do cateter com hiperemia, endurecimento e formação de cordão venoso palpável com drenagem purulenta. ${ }^{* *}$ Teste qui-quadrado de Pearson.

No período estudado, a classificação de risco para o desenvolvimento do EA flebite (sem risco, baixo, moderado ou alto risco) foi documentada diariamente pelos enfermeiros da Unidade de Internação Clínica, por meio da Sistematização da Assistência de Enfermagem (SAE) considerando-se fatores como fragilidade capilar, obesidade, histórico prévio de flebite, uso de fármacos irritantes ou vesicantes, entre outros. Assim, 57 pacientes (47,7\%) foram classificados como de baixo risco; $23,4 \%$, de risco moderado; $22,4 \%$, de alto risco; e 6,5\%, sem risco para desenvolvimento de flebite.

Em relação à avaliação de risco para desenvolvimento de flebite, não foi verificada diferença estatística significante entre o risco para desenvolvimento de flebite e as variáveis sexo, faixa etária, tempo de permanência dos pacientes (Tabela 8), doenças 
pré-existentes e agrupamento das hipóteses diagnósticas médicas (Tabela 9), mês da ocorrência, turno (manhã, tarde ou noite) e categoria profissional do relator (Tabela 10).

Tabela 8 - Distribuição da avaliação de risco para desenvolvimento de flebite segundo as variáveis sexo, faixa etária e tempo de permanência dos pacientes - São Paulo-SP, Brasil, 2017.

\begin{tabular}{|c|c|c|c|c|c|c|c|c|c|c|}
\hline \multicolumn{2}{|c|}{ Avaliação de Risco } & \multicolumn{2}{|c|}{ Sem risco } & \multicolumn{2}{|c|}{ Baixo } & \multicolumn{2}{|c|}{ Moderado } & \multicolumn{2}{|c|}{ Alto } & \multirow{2}{*}{$\frac{x^{2} \text { de Pearson }}{\text { Sig. }}$} \\
\hline & & $\mathbf{n}$ & $\%$ & $\mathbf{n}$ & $\%$ & $\mathbf{N}$ & $\%$ & $\mathbf{n}$ & $\%$ & \\
\hline \multirow{2}{*}{ Sexo } & Masculino & 4 & $7,3 \%$ & 23 & $41,8 \%$ & 13 & $23,6 \%$ & 15 & $27,3 \%$ & \multirow{2}{*}{0,354} \\
\hline & Feminino & 3 & $5,8 \%$ & 28 & $53,8 \%$ & 12 & $23,1 \%$ & 9 & $17,3 \%$ & \\
\hline \multirow{9}{*}{ Faixa etária } & 10 a 19 & 0 & $0,0 \%$ & 0 & $0,0 \%$ & 0 & $0,0 \%$ & 1 & $100,0 \%$ & \multirow{9}{*}{0,985} \\
\hline & 20 a 29 & 1 & $33,3 \%$ & 0 & $0,0 \%$ & 0 & $0,0 \%$ & 2 & $66,7 \%$ & \\
\hline & 30 a 39 & 1 & $5,3 \%$ & 11 & $57,9 \%$ & 6 & $31,6 \%$ & 1 & $5,3 \%$ & \\
\hline & 40 a 49 & 1 & $6,7 \%$ & 5 & $33,3 \%$ & 4 & $26,7 \%$ & 5 & $33,3 \%$ & \\
\hline & 50 a 59 & 0 & $0,0 \%$ & 9 & $56,3 \%$ & 2 & $12,5 \%$ & 5 & $31,3 \%$ & \\
\hline & 60 a 69 & 2 & $7,7 \%$ & 9 & $34,6 \%$ & 8 & $30,8 \%$ & 7 & $26,9 \%$ & \\
\hline & 70 a 79 & 1 & $7,7 \%$ & 9 & $69,2 \%$ & 3 & $23,1 \%$ & 0 & $0,0 \%$ & \\
\hline & 80 a 89 & 0 & $0,0 \%$ & 6 & $60,0 \%$ & 1 & $10,0 \%$ & 3 & $30,0 \%$ & \\
\hline & 90 a 99 & 1 & $25,0 \%$ & 2 & $50,0 \%$ & 1 & $25,0 \%$ & 0 & $0,0 \%$ & \\
\hline \multirow{4}{*}{$\begin{array}{l}\text { Tempo de } \\
\text { permanência }\end{array}$} & $<4$ dias & 4 & $13,3 \%$ & 17 & $56,7 \%$ & 3 & $10,0 \%$ & 6 & $20,0 \%$ & \multirow{4}{*}{0,786} \\
\hline & $5-7$ dias & 0 & $0,0 \%$ & 13 & $46,4 \%$ & 8 & $28,6 \%$ & 7 & $25,0 \%$ & \\
\hline & 8 - 11 dias & 2 & $6,9 \%$ & 13 & $44,8 \%$ & 7 & $24,1 \%$ & 7 & $24,1 \%$ & \\
\hline & $>12$ dias & 1 & $5,0 \%$ & 8 & $40,0 \%$ & 7 & $35,0 \%$ & 4 & $20,0 \%$ & \\
\hline
\end{tabular}

* Teste qui-quadrado de Pearson. 
Tabela 9 - Distribuição da avaliação de risco para desenvolvimento de flebite segundo as variáveis doenças pré-existentes e agrupamento das hipóteses diagnósticas médicas - São Paulo-SP, Brasil, 2017

(continua)

\begin{tabular}{|c|c|c|c|c|c|c|c|c|c|c|}
\hline \multicolumn{2}{|c|}{ Avaliação de risco } & \multicolumn{2}{|c|}{ Sem risco } & \multicolumn{2}{|c|}{ Baixo } & \multicolumn{2}{|c|}{ Moderado } & \multicolumn{2}{|c|}{ Alto } & \multirow{2}{*}{$\frac{x^{2} \text { de Pear }}{\text { Sig. }}$} \\
\hline & & $\mathbf{n}$ & $\%$ & $\mathbf{n}$ & $\%$ & $\mathbf{n}$ & $\%$ & $\mathbf{n}$ & $\%$ & \\
\hline \multicolumn{11}{|c|}{ Doenças pré-existentes } \\
\hline \multirow{2}{*}{ Neoplasia maligna } & Não & 7 & $7,2 \%$ & 49 & $50,5 \%$ & 21 & $21,6 \%$ & 20 & $20,6 \%$ & \multirow{2}{*}{0,706} \\
\hline & $\operatorname{Sim}$ & 0 & $0,0 \%$ & 1 & $11,1 \%$ & 4 & $44,4 \%$ & 4 & $44,4 \%$ & \\
\hline \multirow{2}{*}{$\begin{array}{l}\text { Hipertensão } \\
\text { Arterial Sistêmica }\end{array}$} & Não & 6 & $7,1 \%$ & 41 & $48,2 \%$ & 18 & $21,2 \%$ & 20 & $23,5 \%$ & \multirow{2}{*}{0,429} \\
\hline & Sim & 1 & $4,5 \%$ & 10 & $45,5 \%$ & 7 & $31,8 \%$ & 4 & $18,2 \%$ & \\
\hline \multirow{2}{*}{$\begin{array}{l}\text { Transtornos } \\
\text { mentais e } \\
\text { comportamentais }\end{array}$} & Não & 5 & $5,0 \%$ & 51 & $50,5 \%$ & 23 & $22,8 \%$ & 22 & $21,8 \%$ & \multirow{2}{*}{0,801} \\
\hline & Sim & 2 & $33,3 \%$ & 0 & $0,0 \%$ & 2 & $33,3 \%$ & 2 & $33,3 \%$ & \\
\hline \multirow{2}{*}{ Neuropatia } & Não & 7 & $6,8 \%$ & 49 & $47,6 \%$ & 24 & $23,3 \%$ & 23 & $22,3 \%$ & \multirow{2}{*}{0,142} \\
\hline & Sim & 0 & $0,0 \%$ & 2 & $50,0 \%$ & 1 & $25,0 \%$ & 1 & $25,0 \%$ & \\
\hline \multirow{2}{*}{ Parkinson } & Não & 6 & $5,7 \%$ & 50 & $47,6 \%$ & 25 & $23,8 \%$ & 24 & $22,9 \%$ & \multirow{2}{*}{0,931} \\
\hline & Sim & 1 & $50,0 \%$ & 1 & $50,0 \%$ & 0 & $0,0 \%$ & 0 & $0,0 \%$ & \\
\hline \multirow{2}{*}{$\begin{array}{l}\text { Insuficiência } \\
\text { Renal Crônica }\end{array}$} & Não & 7 & $6,8 \%$ & 49 & $47,6 \%$ & 24 & $23,3 \%$ & 23 & $22,3 \%$ & \multirow{2}{*}{0,865} \\
\hline & Sim & 0 & $0,0 \%$ & 2 & $50,0 \%$ & 1 & $25,0 \%$ & 1 & $25,0 \%$ & \\
\hline \multirow{2}{*}{$\begin{array}{l}\text { Síndrome } \\
\text { Demencial }\end{array}$} & Não & 6 & $5,8 \%$ & 49 & $47,1 \%$ & 25 & $24,0 \%$ & 24 & $23,1 \%$ & \multirow{2}{*}{0,898} \\
\hline & Sim & 1 & $33,3 \%$ & 2 & $66,7 \%$ & 0 & $0,0 \%$ & 0 & $0,0 \%$ & \\
\hline \multirow{2}{*}{ Dislipidemia } & Não & 7 & $7,4 \%$ & 46 & $48,4 \%$ & 20 & $21,1 \%$ & 22 & $23,2 \%$ & \multirow{2}{*}{0,161} \\
\hline & Sim & 0 & $0,0 \%$ & 5 & $41,7 \%$ & 5 & $41,7 \%$ & 2 & $16,7 \%$ & \\
\hline
\end{tabular}


Tabela 9 - Distribuição da avaliação de risco para desenvolvimento de flebite segundo as variáveis doenças pré-existentes e agrupamento das hipóteses diagnósticas médicas - São Paulo-SP, Brasil, 2017

\begin{tabular}{|c|c|c|c|c|c|c|c|c|c|c|}
\hline \multicolumn{2}{|c|}{ Avaliação de risco } & \multicolumn{2}{|c|}{ Sem risco } & \multicolumn{2}{|c|}{ Baixo } & \multicolumn{2}{|c|}{ Moderado } & \multicolumn{2}{|c|}{ Alto } & \multirow{2}{*}{$\frac{x^{2} \text { de Pearson }}{\text { Sig. }}$} \\
\hline & & $\mathbf{n}$ & $\%$ & $\mathbf{n}$ & $\%$ & $\mathbf{n}$ & $\%$ & $\mathbf{n}$ & $\%$ & \\
\hline \multirow{2}{*}{$\begin{array}{l}\text { Doença Pulmonar } \\
\text { Obstrutiva } \\
\text { Crônica }\end{array}$} & Não & 7 & $6,8 \%$ & 50 & $48,5 \%$ & 23 & $22,3 \%$ & 23 & $22,3 \%$ & \multirow{2}{*}{0,865} \\
\hline & Sim & 0 & $0,0 \%$ & 1 & $25,0 \%$ & 2 & $50,0 \%$ & 1 & $25,0 \%$ & \\
\hline \multirow{2}{*}{$\begin{array}{l}\text { Insuficiência } \\
\text { Coronariana }\end{array}$} & Não & 7 & $6,9 \%$ & 46 & $45,5 \%$ & 25 & $24,8 \%$ & 23 & $22,8 \%$ & \multirow{2}{*}{0,342} \\
\hline & Sim & 0 & $0,0 \%$ & 5 & $83,3 \%$ & 0 & $0,0 \%$ & 1 & $16,7 \%$ & \\
\hline \multirow{2}{*}{ Hipotireoidismo } & Não & 7 & $7,0 \%$ & 44 & $44,0 \%$ & 25 & $25,0 \%$ & 24 & $24,0 \%$ & \multirow{2}{*}{0,434} \\
\hline & Sim & 0 & $0,0 \%$ & 7 & $100,0 \%$ & 0 & $0,0 \%$ & 0 & $0,0 \%$ & \\
\hline \multirow{2}{*}{ Diabetes Mellitus } & Não & 5 & $5,4 \%$ & 46 & $50,0 \%$ & 21 & $22,8 \%$ & 20 & $21,7 \%$ & \multirow{2}{*}{0,789} \\
\hline & Sim & 2 & $13,3 \%$ & 5 & $33,3 \%$ & 4 & $26,7 \%$ & 4 & $26,7 \%$ & \\
\hline \multicolumn{11}{|c|}{$\begin{array}{l}\text { Agrupamento das hipóteses } \\
\text { diagnósticas médicas }\end{array}$} \\
\hline \multirow{2}{*}{$\begin{array}{l}\text { Afecções } \\
\text { cardíacas }\end{array}$} & Não & 7 & $6,7 \%$ & 48 & $46,2 \%$ & 25 & $24,0 \%$ & 24 & $23,1 \%$ & \multirow{2}{*}{0,898} \\
\hline & Sim & 0 & $0,0 \%$ & 3 & $100,0 \%$ & 0 & $0,0 \%$ & 0 & $0,0 \%$ & \\
\hline \multirow{2}{*}{$\begin{array}{l}\text { Afecções } \\
\text { reumáticas }\end{array}$} & Não & 7 & $6,6 \%$ & 51 & $48,1 \%$ & 24 & $22,6 \%$ & 24 & $22,6 \%$ & \multirow{2}{*}{0,965} \\
\hline & Sim & 0 & $0,0 \%$ & 0 & $0,0 \%$ & 1 & $100,0 \%$ & 0 & $0,0 \%$ & \\
\hline \multirow{2}{*}{$\begin{array}{l}\text { Afecções } \\
\text { endócrinas }\end{array}$} & Não & 7 & $6,7 \%$ & 50 & $48,1 \%$ & 25 & $24,0 \%$ & 22 & $21,2 \%$ & \multirow{2}{*}{0,898} \\
\hline & Sim & 0 & $0,0 \%$ & 1 & $33,3 \%$ & 0 & $0,0 \%$ & 2 & $66,7 \%$ & \\
\hline \multirow{2}{*}{$\begin{array}{l}\text { Afecções do } \\
\text { aparelho digestivo }\end{array}$} & Não & 7 & $7,1 \%$ & 47 & $48,0 \%$ & 24 & $24,5 \%$ & 20 & $20,4 \%$ & \multirow{2}{*}{0,709} \\
\hline & Sim & 0 & $0,0 \%$ & 4 & $44,4 \%$ & 1 & $11,1 \%$ & 4 & $44,4 \%$ & \\
\hline
\end{tabular}


Tabela 9 - Distribuição da avaliação de risco para desenvolvimento de flebite segundo as variáveis doenças pré-existentes e agrupamento das hipóteses diagnósticas médicas - São Paulo-SP, Brasil, 2017

\begin{tabular}{|c|c|c|c|c|c|c|c|c|c|c|}
\hline \multicolumn{2}{|c|}{ Avaliação de risco } & \multicolumn{2}{|c|}{ Sem risco } & \multicolumn{2}{|c|}{ Baixo } & \multicolumn{2}{|c|}{ Moderado } & \multicolumn{2}{|c|}{ Alto } & \multirow{2}{*}{$\frac{x^{2} \text { de Pearson }}{\text { Sig. }}$} \\
\hline & & $\mathbf{n}$ & $\%$ & $\mathbf{n}$ & $\%$ & $\mathbf{n}$ & $\%$ & $\mathbf{n}$ & $\%$ & \\
\hline \multirow{2}{*}{$\begin{array}{l}\text { Afecções } \\
\text { genéticas }\end{array}$} & Não & 7 & $6,6 \%$ & 50 & $47,2 \%$ & 25 & $23,6 \%$ & 24 & $22,6 \%$ & \multirow{2}{*}{0,000} \\
\hline & Sim & 0 & $0,0 \%$ & 1 & $100,0 \%$ & 0 & $0,0 \%$ & 0 & $0,0 \%$ & \\
\hline \multirow{2}{*}{$\begin{array}{l}\text { Afecções } \\
\text { infecciosas }\end{array}$} & Não & 1 & $2,6 \%$ & 22 & $56,4 \%$ & 8 & $20,5 \%$ & 8 & $20,5 \%$ & \multirow{2}{*}{0,552} \\
\hline & Sim & 6 & $8,8 \%$ & 29 & $42,6 \%$ & 17 & $25,0 \%$ & 16 & $23,5 \%$ & \\
\hline \multirow{2}{*}{ Sepse } & Não & 7 & $6,9 \%$ & 50 & $49,0 \%$ & 21 & $20,6 \%$ & 24 & $23,5 \%$ & \multirow{2}{*}{0,242} \\
\hline & Sim & 0 & $0,0 \%$ & 1 & $20,0 \%$ & 4 & $80,0 \%$ & 0 & $0,0 \%$ & \\
\hline \multirow{2}{*}{$\begin{array}{l}\text { Afecções do } \\
\text { sistema nervoso } \\
\text { central e } \\
\text { periférico }\end{array}$} & Não & 6 & $6,6 \%$ & 39 & $42,9 \%$ & 24 & $26,4 \%$ & 22 & $24,2 \%$ & \multirow[b]{2}{*}{0,518} \\
\hline & Sim & 1 & $6,3 \%$ & 12 & $75,0 \%$ & 1 & $6,3 \%$ & 2 & $12,5 \%$ & \\
\hline \multirow{2}{*}{$\begin{array}{l}\text { Afecções do } \\
\text { sistema } \\
\text { respiratório }\end{array}$} & Não & 7 & $6,6 \%$ & 51 & $48,1 \%$ & 24 & $22,6 \%$ & 24 & $22,6 \%$ & \multirow[b]{2}{*}{0,965} \\
\hline & Sim & 0 & $0,0 \%$ & 0 & $0,0 \%$ & 1 & $100,0 \%$ & 0 & $0,0 \%$ & \\
\hline
\end{tabular}

* Teste qui-quadrado de Pearson. 
Tabela 10 - Distribuição da avaliação de risco para desenvolvimento de flebite segundo as variáveis segundo as variáveis: mês da ocorrência, turno e categoria profissional do relator - São Paulo-SP, Brasil, 2017

\begin{tabular}{|c|c|c|c|c|c|c|c|c|c|c|}
\hline \multicolumn{2}{|c|}{ Avaliação de risco } & \multicolumn{2}{|c|}{ Sem risco } & \multicolumn{2}{|c|}{ Baixo } & \multicolumn{2}{|c|}{ Moderado } & \multicolumn{2}{|c|}{ Alto } & \multirow{2}{*}{$\frac{x^{2} \text { de Pearson }}{\text { Sig. }}$} \\
\hline & & $\mathbf{n}$ & $\%$ & $\mathbf{n}$ & $\%$ & $\mathbf{N}$ & $\%$ & $\mathbf{n}$ & $\%$ & \\
\hline \multirow{12}{*}{ Mês da ocorrência } & Janeiro & 2 & $14,3 \%$ & 5 & $35,7 \%$ & 5 & $35,7 \%$ & 2 & $14,3 \%$ & \multirow{12}{*}{0,510} \\
\hline & Fevereiro & 1 & $10,0 \%$ & 5 & $50,0 \%$ & 3 & $30,0 \%$ & 1 & $10,0 \%$ & \\
\hline & Março & 0 & $0,0 \%$ & 6 & $75,0 \%$ & 2 & $25,0 \%$ & 0 & $0,0 \%$ & \\
\hline & Abril & 0 & $0,0 \%$ & 5 & $62,5 \%$ & 2 & $25,0 \%$ & 1 & $12,5 \%$ & \\
\hline & Maio & 0 & $0,0 \%$ & 2 & $66,7 \%$ & 1 & $33,3 \%$ & 0 & $0,0 \%$ & \\
\hline & Junho & 0 & $0,0 \%$ & 6 & $46,2 \%$ & 3 & $23,1 \%$ & 4 & $30,8 \%$ & \\
\hline & Julho & 1 & $9,1 \%$ & 7 & $63,6 \%$ & 0 & $0,0 \%$ & 3 & $27,3 \%$ & \\
\hline & Agosto & 0 & $0,0 \%$ & 3 & $60,0 \%$ & 1 & $20,0 \%$ & 1 & $20,0 \%$ & \\
\hline & Setembro & 1 & $14,3 \%$ & 2 & $28,6 \%$ & 1 & $14,3 \%$ & 3 & $42,9 \%$ & \\
\hline & Outubro & 1 & $9,1 \%$ & 5 & $45,5 \%$ & 1 & $9,1 \%$ & 4 & $36,4 \%$ & \\
\hline & Novembro & 1 & $10,0 \%$ & 2 & $20,0 \%$ & 5 & $50,0 \%$ & 2 & $20,0 \%$ & \\
\hline & Dezembro & 0 & $0,0 \%$ & 3 & $42,9 \%$ & 1 & $14,3 \%$ & 3 & $42,9 \%$ & \\
\hline \multirow{3}{*}{ Turno } & Manhã & 4 & $9,8 \%$ & 18 & $43,9 \%$ & 6 & $14,6 \%$ & 13 & $31,7 \%$ & \multirow{3}{*}{0,782} \\
\hline & Tarde & 2 & $4,7 \%$ & 19 & $44,2 \%$ & 12 & $27,9 \%$ & 10 & $23,3 \%$ & \\
\hline & Noite & 1 & $4,3 \%$ & 14 & $60,9 \%$ & 7 & $30,4 \%$ & 1 & $4,3 \%$ & \\
\hline \multirow{3}{*}{$\begin{array}{l}\text { Categoria } \\
\text { profissional do } \\
\text { relator }\end{array}$} & Enfermeiro & 3 & $4,1 \%$ & 34 & $46,6 \%$ & 20 & $27,4 \%$ & 16 & $21,9 \%$ & \multirow{3}{*}{0,596} \\
\hline & $\begin{array}{l}\text { Técnico de } \\
\text { Enfermagem }\end{array}$ & 1 & $50,0 \%$ & 1 & $50,0 \%$ & 0 & $0,0 \%$ & 0 & $0,0 \%$ & \\
\hline & $\begin{array}{l}\text { Notificação } \\
\text { anônima }\end{array}$ & 3 & $9,4 \%$ & 16 & $50,0 \%$ & 5 & $15,6 \%$ & 8 & $25,0 \%$ & \\
\hline
\end{tabular}

\footnotetext{
* Teste qui-quadrado de Pearson.
} 
Segundo a Tabela 11, não foi constatada diferença estatística significante entre o risco para desenvolvimento de flebite e as variáveis tipo de dispositivo intravenoso, localização do leito em relação ao posto de enfermagem (próximo ou distante) e presença de acompanhante. Houve diferença estatística significante apenas para o baixo risco de desenvolvimento de flebite associado ao uso de solução eletrolítica $(p=0,003)$ e antiviral $(p=0,018)$.

Tabela 11 - Distribuição da avaliação de risco para desenvolvimento de flebite segundo as variáveis tipo de dispositivo, classe do fármaco, localização do leito em relação ao posto de enfermagem e presença de acompanhante - São Paulo-SP, Brasil, 2017.

\begin{tabular}{|c|c|c|c|c|c|c|c|c|c|c|}
\hline \multicolumn{2}{|c|}{ Avaliação de Risco } & \multicolumn{2}{|c|}{ Sem risco } & \multicolumn{2}{|c|}{ Baixo } & \multicolumn{2}{|c|}{ Moderado } & \multicolumn{2}{|c|}{ Alto } & \multirow{2}{*}{$\frac{x^{2} \text { de Pearson }}{\text { Sig. }}$} \\
\hline & & $\mathbf{n}$ & $\%$ & $\mathbf{n}$ & $\%$ & $\mathbf{n}$ & $\%$ & $\mathbf{n}$ & $\%$ & \\
\hline \multirow{2}{*}{$\begin{array}{l}\text { Tipo de } \\
\text { dispositivo }\end{array}$} & Jelco® & 2 & $3,6 \%$ & 29 & $51,8 \%$ & 13 & $23,2 \%$ & 12 & $21,4 \%$ & \multirow{2}{*}{0,939} \\
\hline & Intima® & 5 & $9,8 \%$ & 22 & $43,1 \%$ & 12 & $23,5 \%$ & 12 & $23,5 \%$ & \\
\hline \multicolumn{11}{|l|}{$\begin{array}{l}\text { Classe do } \\
\text { fármaco }\end{array}$} \\
\hline \multirow{2}{*}{ Analgésico } & Não & 7 & $7,1 \%$ & 46 & $46,9 \%$ & 21 & $21,4 \%$ & 24 & $24,5 \%$ & \multirow{2}{*}{0,709} \\
\hline & $\operatorname{Sim}$ & 0 & $0,0 \%$ & 5 & $55,6 \%$ & 4 & $44,4 \%$ & 0 & $0,0 \%$ & \\
\hline \multirow{2}{*}{ Anti-histamínico } & Não & 7 & $6,6 \%$ & 50 & $47,2 \%$ & 25 & $23,6 \%$ & 24 & $22,6 \%$ & \multirow{2}{*}{0,965} \\
\hline & Sim & 0 & $0,0 \%$ & 1 & $100,0 \%$ & 0 & $0,0 \%$ & 0 & $0,0 \%$ & \\
\hline \multirow{2}{*}{ Anti-inflamatório } & Não & 7 & $6,7 \%$ & 51 & $48,6 \%$ & 24 & $22,9 \%$ & 23 & $21,9 \%$ & \multirow{2}{*}{0,931} \\
\hline & Sim & 0 & $0,0 \%$ & 0 & $0,0 \%$ & 1 & $50,0 \%$ & 1 & $50,0 \%$ & \\
\hline \multirow{2}{*}{ Antianêmico } & Não & 7 & $6,6 \%$ & 50 & $47,2 \%$ & 25 & $23,6 \%$ & 24 & $22,6 \%$ & \multirow{2}{*}{0,965} \\
\hline & Sim & 0 & $0,0 \%$ & 1 & $100,0 \%$ & 0 & $0,0 \%$ & 0 & $0,0 \%$ & \\
\hline
\end{tabular}


Tabela 11 - Distribuição da avaliação de risco para desenvolvimento de flebite segundo as variáveis tipo de dispositivo, classe do fármaco, localização do leito em relação ao posto de enfermagem e presença de acompanhante - São Paulo-SP, Brasil, 2017.

\begin{tabular}{|c|c|c|c|c|c|c|c|c|c|c|}
\hline \multicolumn{2}{|c|}{ Avaliação de risco } & \multicolumn{2}{|c|}{ Sem risco } & \multicolumn{2}{|c|}{ Baixo } & \multicolumn{2}{|c|}{ Moderado } & \multicolumn{2}{|c|}{ Alto } & \multirow{2}{*}{$\frac{x^{2} \text { de Pearson }}{\text { Sig. }}$} \\
\hline & & $\mathbf{n}$ & $\%$ & $\mathbf{n}$ & $\%$ & $\mathbf{n}$ & $\%$ & $\mathbf{n}$ & $\%$ & \\
\hline \multirow{2}{*}{ Antiemético } & Não & 7 & $6,7 \%$ & 50 & $48,1 \%$ & 25 & $24,0 \%$ & 22 & $21,2 \%$ & \multirow{2}{*}{0,898} \\
\hline & Sim & 0 & $0,0 \%$ & 1 & $33,3 \%$ & 0 & $0,0 \%$ & 2 & $66,7 \%$ & \\
\hline \multirow{2}{*}{ Antifungico } & Não & 7 & $6,7 \%$ & 51 & $49,0 \%$ & 24 & $23,1 \%$ & 22 & $21,2 \%$ & \multirow{2}{*}{0,898} \\
\hline & $\operatorname{Sim}$ & 0 & $0,0 \%$ & 0 & $0,0 \%$ & 1 & $33,3 \%$ & 2 & $66,7 \%$ & \\
\hline \multirow{2}{*}{ Antibiótico } & Não & 2 & $3,5 \%$ & 29 & $50,9 \%$ & 14 & $24,6 \%$ & 12 & $21,1 \%$ & \multirow{2}{*}{0,183} \\
\hline & $\operatorname{Sim}$ & 5 & $10,0 \%$ & 22 & $44,0 \%$ & 11 & $22,0 \%$ & 12 & $24,0 \%$ & \\
\hline \multirow{2}{*}{ Antiviral } & Não & 7 & $7,0 \%$ & 49 & $49,0 \%$ & 22 & $22,0 \%$ & 22 & $22,0 \%$ & \multirow{2}{*}{0,018} \\
\hline & Sim & 0 & $0,0 \%$ & 2 & $28,6 \%$ & 3 & $42,9 \%$ & 2 & $28,6 \%$ & \\
\hline \multirow{2}{*}{ Cristaloide } & Não & 7 & $6,6 \%$ & 50 & $47,2 \%$ & 25 & $23,6 \%$ & 24 & $22,6 \%$ & \multirow{2}{*}{0,965} \\
\hline & Sim & 0 & $0,0 \%$ & 1 & $100,0 \%$ & 0 & $0,0 \%$ & 0 & $0,0 \%$ & \\
\hline \multirow{2}{*}{ Diurético } & Não & 7 & $6,6 \%$ & 50 & $47,2 \%$ & 25 & $23,6 \%$ & 24 & $22,6 \%$ & \multirow{2}{*}{0,965} \\
\hline & Sim & 0 & $0,0 \%$ & 1 & $100,0 \%$ & 0 & $0,0 \%$ & 0 & $0,0 \%$ & \\
\hline \multirow{2}{*}{ Imunoglobulina } & Não & 7 & $7,2 \%$ & 45 & $46,4 \%$ & 22 & $22,7 \%$ & 23 & $23,7 \%$ & \multirow{2}{*}{0,680} \\
\hline & Sim & 0 & $0,0 \%$ & 6 & $60,0 \%$ & 3 & $30,0 \%$ & 1 & $10,0 \%$ & \\
\hline \multirow{2}{*}{$\begin{array}{l}\text { Solução } \\
\text { eletrolítica }\end{array}$} & Não & 6 & $6,5 \%$ & 42 & $45,7 \%$ & 23 & $25,0 \%$ & 21 & $22,8 \%$ & \multirow{2}{*}{0,003} \\
\hline & Sim & 1 & $6,7 \%$ & 9 & $60,0 \%$ & 2 & $13,3 \%$ & 3 & $20,0 \%$ & \\
\hline \multirow{2}{*}{$\begin{array}{l}\text { Ausência de } \\
\text { registro }\end{array}$} & Não & 6 & $5,8 \%$ & 49 & $47,6 \%$ & 25 & $24,3 \%$ & 23 & $22,3 \%$ & \multirow{2}{*}{0,865} \\
\hline & Sim & 1 & $25,0 \%$ & 2 & $50,0 \%$ & 0 & $0,0 \%$ & 1 & $25,0 \%$ & \\
\hline
\end{tabular}


Tabela 11 - Distribuição da avaliação de risco para desenvolvimento de flebite segundo as variáveis tipo de dispositivo, classe do fármaco, localização do leito em relação ao posto de enfermagem e presença de acompanhante - São Paulo-SP, Brasil, 2017.

\begin{tabular}{lllllllllll} 
Localização do & Próximo & 3 & $15,8 \%$ & 4 & $21,1 \%$ & 5 & $26,3 \%$ & 7 & $36,8 \%$ & 0 \\
leito & Distante & 4 & $4,5 \%$ & 47 & $53,4 \%$ & 20 & $22,7 \%$ & 17 & $19,3 \%$ & 0,477 \\
Presença de & Não & 3 & $5,9 \%$ & 19 & $37,3 \%$ & 14 & $27,5 \%$ & 15 & $29,4 \%$ & 0,092 \\
acompanhante & Sim & 4 & $7,1 \%$ & 32 & $57,1 \%$ & 11 & $19,6 \%$ & 9 & $16,1 \%$ & 90 \\
\hline
\end{tabular}

* Teste qui-quadrado de Pearson.

A partir da notificação do EA flebite, os profissionais classificaram o dano causado ao paciente (sem dano, dano leve, dano moderado, dano grave, óbito), sendo encontrados registros de que 93,5\% dos pacientes sofreram dano leve; 4,7\%, dano moderado; e 1,9\% não sofreram danos. Não houve registro de pacientes classificados como dano grave ou óbito devido.

Quanto ao dano causado pela flebite, não foi encontrada diferença estatística significante ao se analisar as variáveis sexo, faixa etária, tempo de permanência dos pacientes (Tabela 12), mês da ocorrência, turno (manhã, tarde ou noite) e categoria profissional do relator (Tabela 14), tipo de dispositivo intravenoso, tempo de permanência do dispositivo, classe do fármaco, localização do leito em relação ao posto de enfermagem (próximo ou distante) e presença de acompanhante (Tabela 15). Considerando-se a associação entre classificação de danos e os fármacos infundidos, apenas a Oxacilina ( $p=0,007)$, pertencente à classe dos antibióticos, apresentou diferença estatística significante com o dano leve. 
Tabela 12 - Distribuição da classificação do dano ocasionado pelo EA flebite segundo as variáveis sexo, faixa etária e tempo de permanência dos pacientes - São Paulo-SP, Brasil, 2017.

\begin{tabular}{|c|c|c|c|c|c|c|c|c|c|c|}
\hline \multirow{2}{*}{\multicolumn{2}{|c|}{$\begin{array}{c}\text { Classificação do dano* } \\
\text { Variáveis }\end{array}$}} & \multicolumn{2}{|c|}{ Sem dano } & \multicolumn{2}{|c|}{ Leve } & \multicolumn{2}{|c|}{ Moderado } & \multicolumn{2}{|c|}{ Grave } & \multirow{2}{*}{ 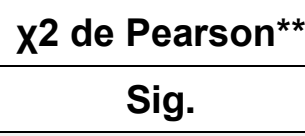 } \\
\hline & & $\mathbf{n}$ & $\%$ & $\mathbf{n}$ & $\%$ & $\mathbf{n}$ & $\%$ & $\mathbf{n}$ & $\%$ & \\
\hline \multirow{2}{*}{ Sexo } & Masculino & 1 & $1,8 \%$ & 53 & $96,4 \%$ & 1 & $1,8 \%$ & 0 & $0,0 \%$ & \multirow{2}{*}{0,554} \\
\hline & Feminino & 1 & $1,9 \%$ & 47 & $90,4 \%$ & 4 & $7,7 \%$ & 0 & $0,0 \%$ & \\
\hline \multirow{9}{*}{ Faixa etária } & 10 a 19 & 0 & $0,0 \%$ & 1 & $100,0 \%$ & 0 & $0,0 \%$ & 0 & $0,0 \%$ & \multirow{9}{*}{0,178} \\
\hline & 20 a 29 & 0 & $0,0 \%$ & 3 & $100,0 \%$ & 0 & $0,0 \%$ & 0 & $0,0 \%$ & \\
\hline & 30 a 39 & 1 & $5,3 \%$ & 17 & $89,5 \%$ & 1 & $5,3 \%$ & 0 & $0,0 \%$ & \\
\hline & 40 a 49 & 0 & $0,0 \%$ & 14 & $93,3 \%$ & 1 & $6,7 \%$ & 0 & $0,0 \%$ & \\
\hline & 50 a 59 & 1 & $6,3 \%$ & 14 & $87,5 \%$ & 1 & $6,3 \%$ & 0 & $0,0 \%$ & \\
\hline & 60 a 69 & 0 & $0,0 \%$ & 25 & $96,2 \%$ & 1 & $3,8 \%$ & 0 & $0,0 \%$ & \\
\hline & 70 a 79 & 0 & $0,0 \%$ & 13 & $100,0 \%$ & 0 & $0,0 \%$ & 0 & $0,0 \%$ & \\
\hline & 80 a 89 & 0 & $0,0 \%$ & 9 & $90,0 \%$ & 1 & $10,0 \%$ & 0 & $0,0 \%$ & \\
\hline & 90 a 99 & 0 & $0,0 \%$ & 4 & $100,0 \%$ & 0 & $0,0 \%$ & 0 & $0,0 \%$ & \\
\hline \multirow{4}{*}{$\begin{array}{l}\text { Tempo de } \\
\text { permanência }\end{array}$} & $<4$ dias & 1 & $3,3 \%$ & 28 & $93,3 \%$ & 1 & $3,3 \%$ & 0 & $0,0 \%$ & \multirow{4}{*}{0,449} \\
\hline & 5 - 7 dias & 0 & $0,0 \%$ & 27 & $96,4 \%$ & 1 & $3,6 \%$ & 0 & $0,0 \%$ & \\
\hline & 8 - 11 dias & 1 & $3,4 \%$ & 27 & $93,1 \%$ & 1 & $3,4 \%$ & 0 & $0,0 \%$ & \\
\hline & $>12$ dias & 0 & $0,0 \%$ & 18 & $90,0 \%$ & 2 & $10,0 \%$ & 0 & $0,0 \%$ & \\
\hline
\end{tabular}

*Sem dano: nenhum sintoma detectado e não foi necessário tratamento; Dano leve: apresentou sintomas leves, danos mínimos ou intermediários com duração rápida, pequeno tratamento ou somente observação; Dano moderado: paciente sintomático que necessitou de intervenção (terapêutica adicional), aumento do tempo de internação, dano ou perda de função, danos permanentes ou em longo prazo. Dano grave: foi necessário intervenção de grande porte para salvar a vida do paciente ou causou grandes danos ou perda de função permanentes ou em longo prazo; Óbito: causado pelo evento. 
$\mathrm{Na}$ Tabela 13, verifica-se que houve diferença estatística significante do dano causado pela flebite associado às doenças pré-existentes transtorno mental e de comportamento $(p=0,014)$ e hipotireoidismo $(p=0,042)$ e a hipótese diagnóstica médica de sepse $(p=0,023)$.

Tabela 13 - Distribuição da classificação do dano ocasionado pelo EA flebite segundo as variáveis doenças pré-existentes e agrupamento das hipóteses diagnósticas médicas - São Paulo-SP, Brasil, 2017

(continua)

\begin{tabular}{|c|c|c|c|c|c|c|c|c|c|c|}
\hline \multirow{2}{*}{\multicolumn{2}{|c|}{$\begin{array}{c}\text { Classificação do dano* } \\
\text { Variáveis }\end{array}$}} & \multicolumn{2}{|c|}{ Sem dano } & \multicolumn{2}{|c|}{ Leve } & \multicolumn{2}{|c|}{ Moderado } & \multicolumn{2}{|c|}{ Grave } & \multirow{2}{*}{$\frac{x^{2} \text { de Pears }}{n}$} \\
\hline & & $\mathbf{n}$ & $\%$ & $\mathbf{n}$ & $\%$ & $\mathbf{n}$ & Variáveis & $\mathbf{n}$ & $\%$ & \\
\hline \multicolumn{11}{|c|}{ Doenças pré-existentes } \\
\hline \multirow{2}{*}{ Neoplasia maligna } & Não & 2 & $2,1 \%$ & 90 & $92,8 \%$ & 5 & $5,2 \%$ & 0 & $0,0 \%$ & \multirow{2}{*}{0,065} \\
\hline & Sim & 0 & $0,0 \%$ & 9 & $100,0 \%$ & 0 & $0,0 \%$ & 0 & $0,0 \%$ & \\
\hline \multirow{2}{*}{$\begin{array}{l}\text { Hipertensão } \\
\text { Arterial Sistêmica }\end{array}$} & Não & 2 & $2,4 \%$ & 80 & $94,1 \%$ & 3 & $3,5 \%$ & 0 & $0,0 \%$ & \multirow{2}{*}{0,737} \\
\hline & $\operatorname{Sim}$ & 0 & $0,0 \%$ & 20 & $90,9 \%$ & 2 & $9,1 \%$ & 0 & $0,0 \%$ & \\
\hline \multirow{2}{*}{$\begin{array}{l}\text { Transtornos } \\
\text { mentais e } \\
\text { comportamentais }\end{array}$} & Não & 2 & $2,0 \%$ & 94 & $93,1 \%$ & 5 & $5,0 \%$ & 0 & $0,0 \%$ & \multirow{2}{*}{0,014} \\
\hline & Sim & 0 & $0,0 \%$ & 6 & $100,0 \%$ & 0 & $0,0 \%$ & 0 & $0,0 \%$ & \\
\hline \multirow{2}{*}{ Neuropatia } & Não & 2 & $1,9 \%$ & 97 & $94,2 \%$ & 4 & $3,9 \%$ & 0 & $0,0 \%$ & \multirow{2}{*}{0,961} \\
\hline & Sim & 0 & $0,0 \%$ & 3 & $75,0 \%$ & 1 & $25,0 \%$ & 0 & $0,0 \%$ & \\
\hline \multirow{2}{*}{ Parkinson } & Não & 2 & $1,9 \%$ & 98 & $93,3 \%$ & 5 & $4,8 \%$ & 0 & $0,0 \%$ & \multirow{2}{*}{0,078} \\
\hline & Sim & 0 & $0,0 \%$ & 2 & $100,0 \%$ & 0 & $0,0 \%$ & 0 & $0,0 \%$ & \\
\hline \multirow{2}{*}{$\begin{array}{l}\text { Insuficiência Renal } \\
\text { Crônica }\end{array}$} & Não & 2 & $1,9 \%$ & 96 & $93,2 \%$ & 5 & $4,9 \%$ & 0 & $0,0 \%$ & \multirow{2}{*}{0,961} \\
\hline & Sim & 0 & $0,0 \%$ & 4 & $100,0 \%$ & 0 & $0,0 \%$ & 0 & $0,0 \%$ & \\
\hline
\end{tabular}


Tabela 13 - Distribuição da classificação do dano ocasionado pelo EA flebite segundo as variáveis doenças pré-existentes e agrupamento das hipóteses diagnósticas médicas - São Paulo-SP, Brasil, 2017

(continuação)

\begin{tabular}{|c|c|c|c|c|c|c|c|c|c|c|}
\hline \multirow{2}{*}{\multicolumn{2}{|c|}{$\frac{\text { Classificação do dano* }}{\text { Variáveis }}$}} & \multicolumn{2}{|c|}{ Sem dano } & \multicolumn{2}{|c|}{ Leve } & \multicolumn{2}{|c|}{ Moderado } & \multicolumn{2}{|c|}{ Grave } & \multirow{2}{*}{$\frac{\text { X2 de Pearson** }^{*}}{n}$} \\
\hline & & $\mathbf{n}$ & $\%$ & $\mathbf{n}$ & $\%$ & $\mathbf{n}$ & Variáveis & $\mathbf{n}$ & $\%$ & \\
\hline \multirow{2}{*}{$\begin{array}{l}\text { Síndrome } \\
\text { Demencial }\end{array}$} & Não & 2 & $1,9 \%$ & 97 & $93,3 \%$ & 5 & $4,8 \%$ & 0 & $0,0 \%$ & \multirow{2}{*}{0,169} \\
\hline & Sim & 0 & $0,0 \%$ & 3 & $100,0 \%$ & 0 & $0,0 \%$ & 0 & $0,0 \%$ & \\
\hline \multirow{2}{*}{ Dislipidemia } & Não & 1 & $1,1 \%$ & 89 & $93,7 \%$ & 5 & $5,3 \%$ & 0 & $0,0 \%$ & \multirow{2}{*}{0,373} \\
\hline & Sim & 1 & $8,3 \%$ & 11 & $91,7 \%$ & 0 & $0,0 \%$ & 0 & $0,0 \%$ & \\
\hline \multirow{2}{*}{$\begin{array}{l}\text { Doença Pulmonar } \\
\text { Obstrutiva Crônica }\end{array}$} & Não & 2 & $1,9 \%$ & 96 & $93,2 \%$ & 5 & $4,9 \%$ & 0 & $0,0 \%$ & \multirow{2}{*}{0,574} \\
\hline & Sim & 0 & $0,0 \%$ & 4 & $100,0 \%$ & 0 & $0,0 \%$ & 0 & $0,0 \%$ & \\
\hline \multirow{2}{*}{$\begin{array}{l}\text { Insuficiência } \\
\text { Coronariana }\end{array}$} & Não & 2 & $2,0 \%$ & 95 & $94,1 \%$ & 4 & $4,0 \%$ & 0 & $0,0 \%$ & \multirow{2}{*}{0,297} \\
\hline & Sim & 0 & $0,0 \%$ & 5 & $83,3 \%$ & 1 & $16,7 \%$ & 0 & $0,0 \%$ & \\
\hline \multirow{2}{*}{ Hipotireoidismo } & Não & 2 & $2,0 \%$ & 94 & $94,0 \%$ & 4 & $4,0 \%$ & 0 & $0,0 \%$ & \multirow{2}{*}{0,042} \\
\hline & Sim & 0 & $0,0 \%$ & 6 & $85,7 \%$ & 1 & $14,3 \%$ & 0 & $0,0 \%$ & \\
\hline \multirow{2}{*}{ Diabetes mellitus } & Não & 2 & $2,2 \%$ & 86 & $93,5 \%$ & 4 & $4,3 \%$ & 0 & $0,0 \%$ & \multirow{2}{*}{0,531} \\
\hline & Sim & 0 & $0,0 \%$ & 14 & $93,3 \%$ & 1 & $6,7 \%$ & 0 & $0,0 \%$ & \\
\hline \multicolumn{11}{|c|}{ Hipóteses diagnósticas médicas } \\
\hline \multirow{2}{*}{$\begin{array}{l}\text { Afecções } \\
\text { Cardíacas }\end{array}$} & Não & 2 & $1,9 \%$ & 97 & $93,3 \%$ & 5 & $4,8 \%$ & 0 & $0,0 \%$ & \multirow{2}{*}{0,335} \\
\hline & Sim & 0 & $0,0 \%$ & 3 & $100,0 \%$ & 0 & $0,0 \%$ & 0 & $0,0 \%$ & \\
\hline \multirow{2}{*}{$\begin{array}{l}\text { Afecções } \\
\text { Reumáticas }\end{array}$} & Não & 2 & $1,9 \%$ & 99 & $93,4 \%$ & 5 & $4,7 \%$ & 0 & $0,0 \%$ & \multirow{2}{*}{0,346} \\
\hline & Sim & 0 & $0,0 \%$ & 1 & $100,0 \%$ & 0 & $0,0 \%$ & 0 & $0,0 \%$ & \\
\hline \multirow{2}{*}{$\begin{array}{l}\text { Afecções } \\
\text { Endócrinas }\end{array}$} & Não & 2 & $1,9 \%$ & 97 & $93,3 \%$ & 5 & $4,8 \%$ & 0 & $0,0 \%$ & \multirow{2}{*}{0,290} \\
\hline & Sim & 0 & $0,0 \%$ & 3 & $100,0 \%$ & 0 & $0,0 \%$ & 0 & $0,0 \%$ & \\
\hline
\end{tabular}


Tabela 13 - Distribuição da classificação do dano ocasionado pelo EA flebite segundo as variáveis doenças pré-existentes e agrupamento das hipóteses diagnósticas médicas - São Paulo-SP, Brasil, 2017

(conclusão)

\begin{tabular}{|c|c|c|c|c|c|c|c|c|c|c|}
\hline \multirow{2}{*}{\multicolumn{2}{|c|}{$\begin{array}{c}\text { Classificação do dano* } \\
\text { Variáveis }\end{array}$}} & \multicolumn{2}{|c|}{ Sem dano } & \multicolumn{2}{|c|}{ Leve } & \multicolumn{2}{|c|}{ Moderado } & \multicolumn{2}{|c|}{ Grave } & \multirow{4}{*}{$\begin{array}{c}\mathbf{x}^{2} \text { de Pearson } \\
\mathbf{n} \\
0,331\end{array}$} \\
\hline & & \multirow{2}{*}{$\frac{n}{2}$} & \multirow{2}{*}{$\frac{\%}{2,0 \%}$} & \multirow{2}{*}{$\frac{\mathbf{n}}{91}$} & \multirow{2}{*}{$\begin{array}{c}\% \\
92,9 \%\end{array}$} & \multirow{2}{*}{$\begin{array}{l}\mathbf{n} \\
5\end{array}$} & \multirow{2}{*}{$\frac{\text { Variáveis }}{5,1 \%}$} & \multirow{2}{*}{$\begin{array}{l}\mathbf{n} \\
0\end{array}$} & \multirow{2}{*}{$\frac{\%}{0,0 \%}$} & \\
\hline Afeccões do & Não & & & & & & & & & \\
\hline aparelho digestivo & Sim & 0 & $0,0 \%$ & 9 & $100,0 \%$ & 0 & $0,0 \%$ & 0 & $0,0 \%$ & \\
\hline \multirow{2}{*}{$\begin{array}{l}\text { Afecções } \\
\text { Genéticas }\end{array}$} & Não & 2 & $1,9 \%$ & 100 & $94,3 \%$ & 4 & $3,8 \%$ & 0 & $0,0 \%$ & \multirow{2}{*}{0,775} \\
\hline & Sim & 0 & $0,0 \%$ & 0 & $0,0 \%$ & 1 & $100,0 \%$ & 0 & $0,0 \%$ & \\
\hline \multirow{2}{*}{$\begin{array}{l}\text { Afecções } \\
\text { Infecciosas }\end{array}$} & Não & 0 & $0,0 \%$ & 37 & $94,9 \%$ & 2 & $5,1 \%$ & 0 & $0,0 \%$ & \multirow{2}{*}{0,426} \\
\hline & Sim & 2 & $2,9 \%$ & 63 & $92,6 \%$ & 3 & $4,4 \%$ & 0 & $0,0 \%$ & \\
\hline \multirow{2}{*}{ Sepse } & Não & 2 & $2,0 \%$ & 96 & $94,1 \%$ & 4 & $3,9 \%$ & 0 & $0,0 \%$ & \multirow{2}{*}{0,023} \\
\hline & Sim & 0 & $0,0 \%$ & 4 & $80,0 \%$ & 1 & $20,0 \%$ & 0 & $0,0 \%$ & \\
\hline \multirow{2}{*}{$\begin{array}{l}\text { Afecções do } \\
\text { sistema nervoso } \\
\text { central e periférico }\end{array}$} & Não & 2 & $2,2 \%$ & 84 & $92,3 \%$ & 5 & $5,5 \%$ & 0 & $0,0 \%$ & \multirow{2}{*}{0,105} \\
\hline & Sim & 0 & $0,0 \%$ & 16 & $100,0 \%$ & 0 & $0,0 \%$ & 0 & $0,0 \%$ & \\
\hline \multirow{2}{*}{$\begin{array}{l}\text { Afecções do } \\
\text { sistema } \\
\text { respiratório }\end{array}$} & Não & 2 & $1,9 \%$ & 99 & $93,4 \%$ & 5 & $4,7 \%$ & 0 & $0,0 \%$ & \multirow{2}{*}{0,346} \\
\hline & Sim & 0 & $0,0 \%$ & 1 & $100,0 \%$ & 0 & $0,0 \%$ & 0 & $0,0 \%$ & \\
\hline
\end{tabular}

*Sem dano: nenhum sintoma detectado e não foi necessário tratamento; Dano leve: apresentou sintomas leves, danos mínimos ou intermediários com duração rápida, pequeno tratamento ou somente observação; Dano moderado: paciente sintomático que necessitou de intervenção (terapêutica adicional), aumento do tempo de internação, dano ou perda de função, danos permanentes ou em longo prazo. Dano grave: foi necessário intervenção de grande porte para salvar a vida do paciente ou causou grandes danos ou perda de função permanentes ou em longo prazo; Óbito: causado pelo evento. 
Tabela 14 - Distribuição da classificação do dano ocasionado pelo EA flebite segundo as variáveis segundo as variáveis: mês da ocorrência, turno e categoria profissional do relator - São Paulo-SP, Brasil, 2017

\begin{tabular}{|c|c|c|c|c|c|c|c|c|c|c|}
\hline \multirow{2}{*}{\multicolumn{2}{|c|}{$\begin{array}{c}\text { Classificação do dano* } \\
\text { Variáveis } \\
\end{array}$}} & \multicolumn{2}{|c|}{ Sem dano } & \multicolumn{2}{|c|}{ Leve } & \multicolumn{2}{|c|}{ Moderado } & \multicolumn{2}{|c|}{ Grave } & \multirow{2}{*}{$\frac{x^{2} \text { de Pearson** }}{n}$} \\
\hline & & $\mathbf{n}$ & $\%$ & $\mathbf{n}$ & $\%$ & $\mathbf{n}$ & Variáveis & $\mathbf{n}$ & $\%$ & \\
\hline \multirow{12}{*}{ Mês da ocorrência } & Janeiro & 1 & $7,1 \%$ & 13 & $92,9 \%$ & 0 & $0,0 \%$ & 0 & $0,0 \%$ & \\
\hline & Fevereiro & 0 & $0,0 \%$ & 10 & $100,0 \%$ & 0 & $0,0 \%$ & 0 & $0,0 \%$ & \\
\hline & Março & 0 & $0,0 \%$ & 8 & $100,0 \%$ & 0 & $0,0 \%$ & 0 & $0,0 \%$ & \\
\hline & Abril & 0 & $0,0 \%$ & 8 & $100,0 \%$ & 0 & $0,0 \%$ & 0 & $0,0 \%$ & \\
\hline & Maio & 0 & $0,0 \%$ & 3 & $100,0 \%$ & 0 & $0,0 \%$ & 0 & $0,0 \%$ & \\
\hline & Junho & 0 & $0,0 \%$ & 11 & $84,6 \%$ & 2 & $15,4 \%$ & 0 & $0,0 \%$ & \\
\hline & Julho & 0 & $0,0 \%$ & 10 & $90,9 \%$ & 1 & $9,1 \%$ & 0 & $0,0 \%$ & \\
\hline & Agosto & 0 & $0,0 \%$ & 4 & $80,0 \%$ & 1 & $20,0 \%$ & 0 & $0,0 \%$ & \\
\hline & Setembro & 1 & $14,3 \%$ & 5 & $71,4 \%$ & 1 & $14,3 \%$ & 0 & $0,0 \%$ & \\
\hline & Outubro & 0 & $0,0 \%$ & 11 & $100,0 \%$ & 0 & $0,0 \%$ & 0 & $0,0 \%$ & \\
\hline & Novembro & 0 & $0,0 \%$ & 10 & $100,0 \%$ & 0 & $0,0 \%$ & 0 & $0,0 \%$ & \\
\hline & Dezembro & 0 & $0,0 \%$ & 7 & $100,0 \%$ & 0 & $0,0 \%$ & 0 & $0,0 \%$ & \\
\hline \multirow{3}{*}{ Turno } & Manhã & 1 & $2,4 \%$ & 37 & $90,2 \%$ & 3 & $7,3 \%$ & 0 & $0,0 \%$ & \\
\hline & Tarde & 1 & $2,3 \%$ & 41 & $95,3 \%$ & 1 & $2,3 \%$ & 0 & $0,0 \%$ & 0,159 \\
\hline & Noite & 0 & $0,0 \%$ & 22 & $95,7 \%$ & 1 & $4,3 \%$ & 0 & $0,0 \%$ & \\
\hline \multirow{3}{*}{$\begin{array}{l}\text { Categoria } \\
\text { profissional do } \\
\text { relator }\end{array}$} & Enfermeiro & 1 & $1,4 \%$ & 70 & $95,9 \%$ & 2 & $2,7 \%$ & 0 & $0,0 \%$ & \multirow{3}{*}{0,161} \\
\hline & $\begin{array}{l}\text { Técnico de } \\
\text { Enfermagem }\end{array}$ & 0 & $0,0 \%$ & 2 & $100,0 \%$ & 0 & $0,0 \%$ & 0 & $0,0 \%$ & \\
\hline & $\begin{array}{l}\text { Notificação } \\
\text { anônima }\end{array}$ & 1 & $3,1 \%$ & 28 & $87,5 \%$ & 3 & $9,4 \%$ & 0 & $0,0 \%$ & \\
\hline
\end{tabular}

*Sem dano: nenhum sintoma detectado e não foi necessário tratamento; Dano leve: apresentou sintomas leves, danos mínimos ou intermediários com duração rápida, pequeno tratamento ou somente observação; Dano moderado: paciente sintomático que necessitou de intervenção (terapêutica adicional), aumento do tempo de internação, dano ou perda de função, danos permanentes ou em longo prazo. Dano grave: foi necessário intervenção de grande porte para salvar a vida do paciente ou causou grandes danos ou perda de função permanentes ou em longo prazo; Obito: causado pelo evento. 
Tabela 15 - Distribuição da classificação do dano ocasionado pelo EA flebite segundo as variáveis tipo de dispositivo, tempo de permanência do dispositivo, classe do fármaco, localização do leito em relação ao posto de enfermagem e presença de acompanhante - São Paulo-SP, Brasil, 2017.

\begin{tabular}{|c|c|c|c|c|c|c|c|c|c|c|}
\hline \multirow{2}{*}{\multicolumn{2}{|c|}{$\begin{array}{c}\text { Classificação do dano* } \\
\text { Variáveis }\end{array}$}} & \multicolumn{2}{|c|}{ Sem dano } & \multicolumn{2}{|c|}{ Leve } & \multicolumn{2}{|c|}{ Moderado } & \multicolumn{2}{|c|}{ Grave } & \multirow{4}{*}{$\begin{array}{c}\mathbf{x} \text { de Pearson }{ }^{\star *} \\
\mathbf{n} \\
0,561\end{array}$} \\
\hline & & $\mathbf{n}$ & $\%$ & $\mathbf{n}$ & $\%$ & $\mathbf{n}$ & Variáveis & $\mathbf{n}$ & $\%$ & \\
\hline \multirow{2}{*}{$\begin{array}{l}\text { Tipo de } \\
\text { dispositivo }\end{array}$} & Jelco® & 1 & $1,8 \%$ & 52 & $92,9 \%$ & 3 & $5,4 \%$ & 0 & $0,0 \%$ & \\
\hline & Intimaß & 1 & $2,0 \%$ & 48 & $94,1 \%$ & 2 & $3,9 \%$ & 0 & $0,0 \%$ & \\
\hline \multicolumn{11}{|c|}{ Classificação do fármaco } \\
\hline \multirow{2}{*}{ Analgésico } & Não & 2 & $2,0 \%$ & 91 & $92,9 \%$ & 5 & $5,1 \%$ & 0 & $0,0 \%$ & \multirow{2}{*}{0,184} \\
\hline & Sim & 0 & $0,0 \%$ & 9 & $100,0 \%$ & 0 & $0,0 \%$ & 0 & $0,0 \%$ & \\
\hline \multirow{2}{*}{ Anti-histamínico } & Não & 2 & $1,9 \%$ & 99 & $93,4 \%$ & 5 & $4,7 \%$ & 0 & $0,0 \%$ & \multirow{2}{*}{0,775} \\
\hline & Sim & 0 & $0,0 \%$ & 1 & $100,0 \%$ & 0 & $0,0 \%$ & 0 & $0,0 \%$ & \\
\hline \multirow{2}{*}{ Anti-inflamatório } & Não & 2 & $1,9 \%$ & 98 & $93,3 \%$ & 5 & $4,8 \%$ & 0 & $0,0 \%$ & \multirow{2}{*}{0,491} \\
\hline & $\operatorname{Sim}$ & 0 & $0,0 \%$ & 2 & $100,0 \%$ & 0 & $0,0 \%$ & 0 & $0,0 \%$ & \\
\hline \multirow{2}{*}{ Antianêmico } & Não & 2 & $1,9 \%$ & 99 & $93,4 \%$ & 5 & $4,7 \%$ & 0 & $0,0 \%$ & \multirow{2}{*}{0,775} \\
\hline & $\operatorname{Sim}$ & 0 & $0,0 \%$ & 1 & $100,0 \%$ & 0 & $0,0 \%$ & 0 & $0,0 \%$ & \\
\hline \multirow{2}{*}{ Antiemético } & Não & 2 & $1,9 \%$ & 97 & $93,3 \%$ & 5 & $4,8 \%$ & 0 & $0,0 \%$ & \multirow{2}{*}{0,290} \\
\hline & $\operatorname{Sim}$ & 0 & $0,0 \%$ & 3 & $100,0 \%$ & 0 & $0,0 \%$ & 0 & $0,0 \%$ & \\
\hline \multirow{2}{*}{ Antifúngico } & Não & 2 & $1,9 \%$ & 97 & $93,3 \%$ & 5 & $4,8 \%$ & 0 & $0,0 \%$ & \multirow{2}{*}{0,213} \\
\hline & Sim & 0 & $0,0 \%$ & 3 & $100,0 \%$ & 0 & $0,0 \%$ & 0 & $0,0 \%$ & \\
\hline \multirow{2}{*}{ Antibiótico } & Não & 2 & $3,5 \%$ & 51 & $89,5 \%$ & 4 & $7,0 \%$ & 0 & $0,0 \%$ & \multirow{2}{*}{0,540} \\
\hline & Sim & 0 & $0,0 \%$ & 49 & $98,0 \%$ & 1 & $2,0 \%$ & 0 & $0,0 \%$ & \\
\hline
\end{tabular}


Tabela 15 - Distribuição da classificação do dano ocasionado pelo EA flebite segundo as variáveis tipo de dispositivo, tempo de permanência do dispositivo, classe do fármaco, localização do leito em relação ao posto de enfermagem e presença de acompanhante - São Paulo-SP, Brasil, 2017.

(conclusão)

\begin{tabular}{|c|c|c|c|c|c|c|c|c|c|c|}
\hline \multirow{2}{*}{\multicolumn{2}{|c|}{$\begin{array}{c}\text { Classificação do dano* } \\
\text { Variáveis }\end{array}$}} & \multicolumn{2}{|c|}{ Sem dano } & \multicolumn{2}{|c|}{ Leve } & \multicolumn{2}{|c|}{ Moderado } & \multicolumn{2}{|c|}{ Grave } & \multirow{3}{*}{$\begin{array}{c}\text { X2 de Pearson** }^{* *} \\
\mathbf{n}\end{array}$} \\
\hline & & $\mathbf{n}$ & $\%$ & $\mathbf{n}$ & $\%$ & $\mathbf{n}$ & Variáveis & $\mathbf{n}$ & $\%$ & \\
\hline \multirow{2}{*}{ Antiviral } & Não & 1 & $1,0 \%$ & 95 & $95,0 \%$ & 4 & $4,0 \%$ & 0 & $0,0 \%$ & \\
\hline & Sim & 1 & $14,3 \%$ & 5 & $71,4 \%$ & 1 & $14,3 \%$ & 0 & $0,0 \%$ & \\
\hline \multirow{2}{*}{ Cristaloide } & Não & 2 & $1,9 \%$ & 99 & $93,4 \%$ & 5 & $4,7 \%$ & 0 & $0,0 \%$ & \multirow{2}{*}{0,775} \\
\hline & Sim & 0 & $0,0 \%$ & 1 & $100,0 \%$ & 0 & $0,0 \%$ & 0 & $0,0 \%$ & \\
\hline \multirow{2}{*}{ Diurético } & Não & 2 & $1,9 \%$ & 99 & $93,4 \%$ & 5 & $4,7 \%$ & 0 & $0,0 \%$ & \multirow{2}{*}{0,775} \\
\hline & $\operatorname{Sim}$ & 0 & $0,0 \%$ & 1 & $100,0 \%$ & 0 & $0,0 \%$ & 0 & $0,0 \%$ & \\
\hline \multirow{2}{*}{ Imunoglobulina } & Não & 2 & $2,1 \%$ & 90 & $92,8 \%$ & 5 & $5,2 \%$ & 0 & $0,0 \%$ & \multirow{2}{*}{0,564} \\
\hline & Sim & 0 & $0,0 \%$ & 10 & $100,0 \%$ & 0 & $0,0 \%$ & 0 & $0,0 \%$ & \\
\hline \multirow{2}{*}{ Solução eletrolítica } & Não & 1 & $1,1 \%$ & 89 & $96,7 \%$ & 2 & $2,2 \%$ & 0 & $0,0 \%$ & \multirow{2}{*}{0,716} \\
\hline & Sim & 1 & $6,7 \%$ & 11 & $73,3 \%$ & 3 & $20,0 \%$ & 0 & $0,0 \%$ & \\
\hline \multirow{2}{*}{$\begin{array}{l}\text { Ausência de } \\
\text { registro }\end{array}$} & Não & 2 & $1,9 \%$ & 96 & $93,2 \%$ & 5 & $4,9 \%$ & 0 & $0,0 \%$ & \multirow{2}{*}{0,369} \\
\hline & Sim & 0 & $0,0 \%$ & 4 & $100,0 \%$ & 0 & $0,0 \%$ & 0 & $0,0 \%$ & \\
\hline \multirow{2}{*}{$\begin{array}{l}\text { Localização do } \\
\text { leito }\end{array}$} & Próximo & 1 & $2,0 \%$ & 50 & $98,0 \%$ & 0 & $0,0 \%$ & 0 & $0,0 \%$ & \multirow{2}{*}{0,165} \\
\hline & Distante & 1 & $1,8 \%$ & 50 & $89,3 \%$ & 5 & $8,9 \%$ & 0 & $0,0 \%$ & \\
\hline \multirow{2}{*}{$\begin{array}{l}\text { Presença de } \\
\text { acompanhante }\end{array}$} & Não & 1 & $5,3 \%$ & 17 & $89,5 \%$ & 1 & $5,3 \%$ & 0 & $0,0 \%$ & \multirow{2}{*}{0,034} \\
\hline & Sim & 1 & $1,1 \%$ & 83 & $94,3 \%$ & 4 & $4,5 \%$ & 0 & $0,0 \%$ & \\
\hline
\end{tabular}

*Sem dano: nenhum sintoma detectado e não foi necessário tratamento; Dano leve: apresentou sintomas leves, danos mínimos ou intermediários com duração rápida, pequeno tratamento ou somente observação; Dano moderado: paciente sintomático que necessitou de intervenção (terapêutica adicional), aumento do tempo de internação, dano ou perda de função, danos permanentes ou em longo prazo. Dano grave: foi necessário intervenção de grande porte para salvar a vida do paciente ou causou grandes danos ou perda de função permanentes ou em longo prazo; Obito: causado pelo evento. 
Demonstra-se na Tabela 16 que não houve diferença estatística significante entre o tempo de permanência do cateter e as variáveis grau da flebite, classificação do dano e avaliação de risco. Na ocorrência de flebite grau 1, o tempo de permanência do dispositivo foi de 2,5 dias com variação de dois a quatro dias; na flebite grau 2, de três dias com variação entre dois e cinco dias; na flebite grau 3 foi de três dias com variação de dois a 3,5 dias e na flebite grau 4 de seis dias com variação de três a nove dias. 0 tempo de permanência do dispositivo nos pacientes que apresentaram dano moderado foi de três dias com variação entre três e quatro dias. 
Tabela 16 - Distribuição do tempo de permanência do cateter segundo as variáveis grau de flebite, classificação do dano e avaliação de risco - São Paulo-SP, Brasil, 2019

\begin{tabular}{|c|c|c|c|c|c|}
\hline \multirow{2}{*}{ Variáveis } & & \multicolumn{4}{|c|}{ Tempo de permanência (em dias) do cateter } \\
\hline & & Mediana & $25 \%$ & $75 \%$ & Sig. ${ }^{* *}$ \\
\hline \multirow{4}{*}{ Grau de flebite } & Grau 1 & 2,5 & 2,0 & 4,0 & \multirow{4}{*}{0,173} \\
\hline & Grau 2 & 3,0 & 2,0 & 5,0 & \\
\hline & Grau 3 & 3,0 & 2,0 & 3,5 & \\
\hline & Grau 4 & 6,0 & 3,0 & 9,0 & \\
\hline \multirow{4}{*}{ Classificação do dano } & Nenhum & 2,0 & 1,0 & 3,0 & \multirow{4}{*}{0,81} \\
\hline & Leve & 3,0 & 2,0 & 4,0 & \\
\hline & Moderado & 3,0 & 3,0 & 4,0 & \\
\hline & Grave & - & - & - & \\
\hline \multirow{4}{*}{ Avaliação risco } & Sem risco & 2,0 & 1,0 & 3,0 & \multirow{4}{*}{0,324} \\
\hline & Baixo & 3,0 & 2,0 & 4,0 & \\
\hline & Moderado & 3,0 & 3,0 & 4,0 & \\
\hline & Alto & 3,0 & 2,0 & 4,0 & \\
\hline
\end{tabular}

\subsection{IDENTIFICAÇÃO DO CDM DOS PROCEDIMENTOS REALIZADOS PARA O TRATAMENTO DO EA FLEBITE}

No período de abril a setembro de 2018 foram realizadas, conforme orientação estatística, 15 observações não participantes de cada um dos três procedimentos decorrentes da ocorrência do EA flebite em pacientes da Unidade de Internação Clínica: "aplicação de pomada de extrato de flor de camomila"; "aplicação de compressas" e "instalação de AVP". Considerando-se que esses três procedimentos estão devidamente padronizados no HCE e que foram realizados para o tratamento dos diferentes graus de flebite notificados em 2017, procederam-se a cinco observações de cada um deles para o manejo de flebite grau 1 , cinco de flebite grau 2 e cinco de flebite grau 3. Durante o período supracitado de coleta de dados, não houve a ocorrência de flebite grau 4 e todos os procedimentos observados foram realizados exclusivamente por técnicos de enfermagem. 
No que diz respeito ao procedimento "aplicação de pomada de extrato de flor de camomila", o tempo de duração variou de 3,00 a 4,00 min., com média de 3,33 $(\mathrm{DP}=0,49) \mathrm{min}$. Na Tabela 17, verifica-se que o custo da MOB de técnico de enfermagem, US\$ 0.40 (DP=0.06), representou 72,7\% do CDM total (US\$ 0.55 $\mathrm{DP}=0.06)$ desse procedimento.

Tabela 17 - Distribuição das observações do procedimento "aplicação de pomada de extrato de flor de camomila", segundo o custo com MOB de técnico de enfermagem, custo com material e custo direto médio total - São Paulo SP, 2019

\begin{tabular}{lccccc}
\hline \multicolumn{1}{c}{ Observações } & $\mathbf{n}^{*}$ & Média US\$ & DP US\$ & $\begin{array}{c}\text { Mediana } \\
\text { US\$ }\end{array}$ & $\begin{array}{c}\text { Valores } \\
\text { mínimo e } \\
\text { máximo } \\
\text { US\$ }\end{array}$ \\
\hline $\begin{array}{l}\text { Custo MOB* técnico } \\
\text { de enfermagem }\end{array}$ & 15 & 0.40 & 0.06 & 0.36 & $0.36-0.48$ \\
$\begin{array}{l}\text { Custo material } \\
\text { CDM Total }\end{array}$ & 15 & 0.15 & 0.00 & 0.15 & $0.15-0.15$ \\
\hline
\end{tabular}

${ }^{*}$ cinco observações de cada grau (1, 2 e 3$)$ de flebite; ${ }^{* \star} \mathrm{MOB}$ - mão de obra direta

Os tempos mínimo e máximo de duração do procedimento "aplicação de compressas" foram de 3,00 min., com média de 3,00 (DP=0,00) min. Constata-se, na Tabela 18, que o custo da MOB de técnico de enfermagem, US $\$ 0.36(\mathrm{DP}=0.00)$, prevaleceu na composição do CDM total, US\$ $0.51(\mathrm{DP}=0.00)$, correspondendo a $70,6 \%$ deste. 
Tabela 18 - Distribuição das observações do procedimento "aplicação de compressas", segundo o custo com MOB de técnico de enfermagem, custo com material e custo direto médio - São Paulo - SP, 2019

\begin{tabular}{lccccc}
\hline \multicolumn{1}{c}{ Observações } & $\mathbf{N}$ & $\begin{array}{c}\text { Média } \\
\text { US\$ }\end{array}$ & $\begin{array}{c}\text { DP } \\
\text { US\$ }\end{array}$ & $\begin{array}{c}\text { Mediana } \\
\text { US\$ }\end{array}$ & $\begin{array}{c}\text { Valores mínimo e } \\
\text { máximo US\$ }\end{array}$ \\
\hline $\begin{array}{l}\text { Custo MOB } \text { MO }^{* *} \text { técnico } \\
\text { de enfermagem }\end{array}$ & 15 & 0.36 & 0.00 & 0.36 & $0.36-0.36$ \\
$\begin{array}{l}\text { Custo material } \\
\text { CDM Total }\end{array}$ & 15 & 0.15 & 0.00 & 0.15 & $0.15-0.15$ \\
\hline
\end{tabular}

${ }^{*}$ cinco observações de cada grau $(1,2$ e 3$)$ de flebite; ** MOB - mão de obra direta

As observações referentes ao procedimento "instalação de AVP" serão apresentadas de acordo com o cateter periférico utilizado (7 observações nas quais o AVP ocorreu por meio do cateter jelco® - Tabelas 19 e 08 - por meio do cateter íntima® - Tabela 20). Esclarece-se que no HCE está padronizada a indicação do cateter jelco® para a infusão de medicamentos não vesicantes e não irritantes e para uso de contraste nos exames de diagnóstico, quando necessário, e do cateter íntima® para a infusão de medicamentos vesicantes e irritantes não quimioterápicos, quimioterápicos, dois medicamentos compatíveis de forma simultânea e para pacientes com fragilidade venosa.

O tempo de duração do procedimento "instalação de AVP com cateter jelco®" variou de 7,00 a 9,00 min., com média de 7,86 (DP=0,69) min. Observa-se, na Tabela 19, a predominância do custo com material, US $\$ 2.91$ ( $D P=0.00)$, equivalente a $75,6 \%$ do CDM total (US\$ 3.85 - DP=0.08). 
Tabela 19 - Distribuição das observações do procedimento "instalação de acesso venoso periférico com cateter jelco®", segundo o custo com MOB de técnico de enfermagem, custo com material e custo direto médio - São Paulo - SP, 2019

\begin{tabular}{lccccc}
\hline \multicolumn{1}{c}{ Observações } & $\mathbf{N}$ & $\begin{array}{c}\text { Média } \\
\text { US\$ }\end{array}$ & $\begin{array}{c}\text { DP } \\
\text { US\$ }\end{array}$ & $\begin{array}{c}\text { Mediana } \\
\text { US\$ }\end{array}$ & $\begin{array}{c}\text { Valores mínimo e } \\
\text { máximo US\$ }\end{array}$ \\
\hline $\begin{array}{l}\text { Custo MOB } \\
\text { de enfermagem }\end{array}$ & 07 & 0.94 & 0.08 & 0.96 & $0.84-1.08$ \\
$\begin{array}{l}\text { Custo material } \\
\text { CDM Total }\end{array}$ & 07 & 2.91 & 0.00 & 2.91 & $2.91-2.91$ \\
\hline
\end{tabular}

*duas observações de flebite grau1, três observações de flebite grau 2 e duas observações de flebite grau $3 ;{ }^{*} \mathrm{MOB}$ - mão de obra direta

No procedimento "instalação de AVP com cateter jelco®" observou-se a utilização dos materiais conforme padronizado com destaque ao custo unitário dos itens: película transparente com fenda $(7 \mathrm{~cm} \times 7 \mathrm{~cm})$ - US\$1.01, conector de sistema fechado (US\$0.53) e cateter jelco® (US\$0.32).

Houve variação na duração do procedimento "instalação de AVP com cateter íntima®" entre 7,00 e 9,00 min., com média de 8,00 (DP=0,53) min. Na Tabela 20, indica-se o impacto do custo com material, US\$ $7.94(\mathrm{DP}=0.00)$, para a composição do CDM total, US\$ $8.90(\mathrm{DP}=0.06)$, representando $89,2 \%$ deste.

Tabela 20 - Distribuição das observações do procedimento "instalação de acesso venoso periférico com cateter íntima®", segundo o custo com MOB de técnico de enfermagem, custo com material e custo direto médio - São Paulo - SP, 2019

\begin{tabular}{lccccc}
\hline \multicolumn{1}{c}{ Observações } & $\mathbf{n}^{*}$ & $\begin{array}{c}\text { Média } \\
\text { US\$ }\end{array}$ & $\begin{array}{c}\text { DP } \\
\text { US\$ }\end{array}$ & $\begin{array}{c}\text { Mediana } \\
\text { US\$ }\end{array}$ & $\begin{array}{c}\text { Valores mínimo e } \\
\text { máximo US\$ }\end{array}$ \\
\hline $\begin{array}{l}\text { Custo MOB }{ }^{\star *} \text { técnico } \\
\text { de enfermagem }\end{array}$ & 08 & 0.96 & 0.06 & 0.96 & $0.84-1.08$ \\
$\begin{array}{l}\text { Custo material } \\
\text { CDM Total }\end{array}$ & 08 & 7.94 & 0.00 & 7.94 & $7.94-7.94$ \\
\hline
\end{tabular}

**três observações de flebite grau1, duas observações de flebite grau 2 e três observações de flebite grau $3 ;{ }^{*} \mathrm{MOB}$ - mão de obra direta 
No procedimento "instalação de AVP com cateter íntima®" os materiais de maior custo unitário foram o cateter íntima® (US\$4.82), a película transparente com fenda $(7 \mathrm{~cm} \times 7 \mathrm{~cm})$ - US\$1.01 e o conector de sistema fechado (US\$0.53). Esclarecese que nesse procedimento o consumo de materiais também ocorreu conforme o padronizado, tendo sido utilizados dois conectores de sistema fechado visto que o cateter íntima® possui duas vias de acesso para a infusão de medicamentos.

\subsection{ESTIMATIVA DO CDM DOS PROCEDIMENTOS REALIZADOS PARA O TRATAMENTO DO EA FLEBITE NA UNIDADE DE INTERNAÇÃO CLÍNICA EM 2017}

Conforme anteriormente citado, foi notificada, em 2017, a ocorrência de 107 flebites associadas a 96 pacientes hospitalizados na Unidade de Internação Clínica. A partir da análise dos 96 (100\%) prontuários, evidenciou-se que 62 (64,6\%) não continham o registro da "aplicação de compressas"; 17 (17,7\%) estavam sem o registro da "aplicação de pomada de extrato de flor de camomila"; e 17 (17,7\%) sem qualquer registro de procedimento para o tratamento da flebite, indicando não conformidade entre a realização dos procedimentos, preconizados para o manejo do EA flebite e a respectiva documentação. Dentre os $17,7 \%$ dos prontuários sem nenhum registro, 11,2\% eram de pacientes portadores de flebite grau 1 e $5.6 \%$, de pacientes com flebite grau 2.

Verificou-se, conforme demonstrado na Tabela 21, o registro da realização de 656 (100\%) procedimentos, sendo a maioria (326 - 49,7\%) para o tratamento de flebite grau 2 e para a flebite grau $3(172-26,2 \%)$. Os procedimentos mais realizados no tratamento do EA flebite foram a "aplicação da pomada de extrato de flor de camomila" (473 - 72,1\%) e a "aplicação de compressas" (93 - 14,2\%). 
Tabela 21 - Distribuição dos procedimentos realizados para o tratamento de flebite em pacientes da Unidade de Internação Clínica, no ano de 2017, segundo o grau da flebite, tipo de procedimento e quantitativo - São Paulo - SP, 2019

\begin{tabular}{|c|c|c|c|c|c|}
\hline $\begin{array}{l}\text { Grau } \\
\text { da } \\
\text { flebite }\end{array}$ & $\begin{array}{c}\text { Aplicação de pomada } \\
\text { de extrato de flor de } \\
\text { camomila }\end{array}$ & $\begin{array}{l}\text { Aplicação de } \\
\text { compressas }\end{array}$ & $\begin{array}{l}\text { Instalação de acesso } \\
\text { venoso periférico com } \\
\text { cateter jelco } \AA\end{array}$ & $\begin{array}{l}\text { Instalação de acesso venoso } \\
\text { periférico com cateter íntima }{ }^{\circledR}\end{array}$ & $\begin{array}{c}\text { Total } \\
\%\end{array}$ \\
\hline 2 & 243 & 43 & 23 & 17 & $326-49,7 \%$ \\
\hline 3 & 124 & 32 & 8 & 8 & $172-26,2 \%$ \\
\hline Total & 473 & 93 & 48 & 42 & $656-100,00 \%$ \\
\hline
\end{tabular}

$\mathrm{Na}$ Tabela 22, verifica-se que a estimativa do CDM total dos 656 procedimentos correspondeu a US\$866.18 ao ano, com destaque para o impacto do CDM dos procedimentos "instalação de AVP com cateter íntima®” (42 procedimentos - 6,4\%), com CDM estimado em US\$373.80, e "aplicação de pomada de extrato de flor de camomila" (473 procedimentos - 72,1\%), CDM estimado em US\$ 260.15.

A "instalação de AVP", somando-se os dois tipos de cateteres utilizados (48 instalações com cateter jelco® - US\$184.80 e 42 com cateter íntima® - US\$373.80), foi o procedimento com a estimativa de CDM mais elevado (US\$558.60 - 90 procedimentos), correspondendo a $64.5 \%$ do CDM total. O manejo da flebite grau 2 apresentou o maior quantitativo de procedimentos registrados (326/ano) e o CDM total mais elevado (US\$ 395.43 - 45,7\%), seguido da flebite grau 1 com 141 procedimentos registrados ao ano e CDM total de US\$260.01 (30,0\%). Tais resultados vão ao encontro do quantitativo das ocorrências de flebite em 2017, anteriormente apresentado na Tabela 3 (49 flebites grau 2 - 45,8\% e 32 flebites grau 1 - 29,9\%). 
Tabela 22 - Distribuição dos procedimentos realizados para o tratamento de flebite em pacientes da Unidade de Internação Clínica, no ano de 2017, segundo o grau da flebite, tipo de procedimento e quantitativo e estimativa do custo direto médio - São Paulo - SP, 2019

\begin{tabular}{|c|c|c|c|c|c|c|c|c|c|}
\hline $\begin{array}{l}\text { Grau } \\
\text { da } \\
\text { flebite }\end{array}$ & $\begin{array}{l}\text { Aplicação de } \\
\text { pomada de } \\
\text { extrato de flor de } \\
\text { camomila }\end{array}$ & $\begin{array}{l}\text { CDM } \\
\text { US\$ }\end{array}$ & $\begin{array}{l}\text { Aplicação de } \\
\text { compressas }\end{array}$ & $\begin{array}{l}\text { CDM } \\
\text { US\$ }\end{array}$ & $\begin{array}{l}\text { Instalação } \\
\text { de acesso } \\
\text { venoso } \\
\text { periférico } \\
\text { com cateter } \\
\text { jelco® }\end{array}$ & $\begin{array}{l}\text { CDM } \\
\text { US\$ }\end{array}$ & $\begin{array}{l}\text { Instalação de } \\
\text { acesso } \\
\text { venoso } \\
\text { periférico } \\
\text { com cateter } \\
\text { íntima }{ }^{\circledR}\end{array}$ & $\begin{array}{l}\text { CDM } \\
\text { US\$ }\end{array}$ & $\begin{array}{c}\text { CDM total - \% } \\
\text { US\$ }\end{array}$ \\
\hline 1 & 94 & 51.70 & 16 & 8.16 & 15 & 57.75 & 16 & 142.40 & $260.01-30,0 \%$ \\
\hline 2 & 243 & 133.65 & 43 & 21.93 & 23 & 88.55 & 17 & 151.30 & $395.43-45,7 \%$ \\
\hline 3 & 124 & 68.20 & 32 & 16.32 & 8 & 30.80 & 8 & 71.20 & $186.52-21,5 \%$ \\
\hline 4 & 12 & 6.60 & 2 & 1.02 & 2 & 7.70 & 1 & 8.90 & $24.22-2,8 \%$ \\
\hline Total & 473 & 260.15 & 93 & 47.43 & 48 & 184.80 & 42 & 373.80 & $866.18-100,00 \%$ \\
\hline
\end{tabular}


5 DISCUSSÃO 


\section{DISCUSSÃO}

Em 2017, 96 pacientes da Unidade de Internação Clínica foram acometidos pelo EA flebite, a maioria $(29-30,2 \%)$ com tempo de permanência inferior a quatro dias, seguido por cinco-sete dias (25-26,0\%) e oito-11 dias (25-26,0\%). Os pacientes internados nesta unidade geralmente apresentam um tempo de permanência prolongado, sendo crescente, na atualidade, o número de pacientes idosos, com alta dependência para os cuidados da equipe de enfermagem e com múltiplas comorbidades que demandam várias ações de suporte da equipe multidisciplinar no processo de recuperação e desospitalização. É frequente a hospitalização de pacientes para tratamento por afecções neurológicas, que recebem medicações e necessitam de acompanhamento por vários dias, e, há aproximadamente dois anos, a Unidade de Internação Clínica tornou-se referência para pacientes da psiquiatria, que também permanecem hospitalizados por vários dias para controle da sua patologia.

Pesquisa retrospectiva, realizada em um hospital do noroeste paulista, pertencente à Rede de Hospitais Sentinela da ANVISA, verificou a incidência de flebites por meio da coleta de dados em 176 fichas eletrônicas de notificação deste EA, referentes ao ano de 2017. A média de permanência dos pacientes internados foi de 22,30 dias, sendo que $53,4 \%$ dos pacientes permaneceram internados por um período inferior a 15 dias $^{61}$. No Distrito Federal, estudo realizado em uma unidade de internação clínica, no qual se identificou a presença de flebite em $60 \%$ dos pacientes e em $55,6 \%$ dos AVP, a média do tempo de permanência dos pacientes foi de 17,86 dias $( \pm 14,37)$, variando de dois a 93 dias, sendo que a maioria $(76 \%)$ dos pacientes permaneceu internada por até 20 dias $^{4}$.

Em uma unidade de neurocirurgia de um hospital universitário, na cidade de São Paulo, estudo verificou que o tempo de internação dos pacientes acometidos pela flebite variou de um a 53 dias. A amostra foi composta por 60 pacientes e evidenciou que nove apresentaram um episódio de flebite; um paciente, três episódios de flebite; e um, quatro episódios de flebite ${ }^{62}$. Estudo realizado no centro-oeste do Brasil sobre a ocorrência de EA em idosos internados mostrou que, nos pacientes que 
permaneceram internados por um período igual ou superior a nove dias, a probabilidade era 34 vezes maior de sofrer dano, comparados aos demais ${ }^{63}$.

Neste estudo, a maioria $(53,1 \%)$ dos pacientes com flebites eram do sexo masculino, resultado semelhante aos encontrados na literatura ${ }^{61,64-67}$. Pesquisa de coorte com 171 adultos internados em uma unidade de internação clínica de um hospital universitário em Porto Alegre investigou a incidência de flebite e os fatores de risco associados, mostrando que $51,5 \%$ destes pacientes eram homens ${ }^{64}$.

Estudo prospectivo, quantitativo, do tipo descritivo-exploratório, realizado num hospital geral do Vale do Paraíba, identificou a presença de flebite e as principais causas para o desenvolvimento de complicações. No total, 76 pacientes foram entrevistados, $31,6 \%$ evoluíram com flebite, sendo $54,2 \%$ do sexo masculino ${ }^{65}$. No noroeste paulista, do total de 176 notificações de flebite, 70,4\% dos pacientes acometidos também eram do sexo masculino ${ }^{61}$.

Investigação realizada num hospital de ensino público do interior do Paraná em três unidades de internação adulto, destinadas para o atendimento em clínica médica e cirúrgica geral, identificou a prevalência de flebites em uma amostra de 174 pacientes, tendo sido avaliados 221 AVP e, dentre os 42 que apresentaram sinais clínicos de flebite, $57,4 \%$ dos pacientes correspondiam ao sexo masculino ${ }^{66}$.

A experiência clínica da pesquisadora tem indicado que o quantitativo de homens que são internados com doenças crônicas não transmissíveis e complicações é maior, geralmente os pacientes do sexo masculino relatam que os sintomas apresentados, como sinais de infecção, não foram por eles valorizados. Assim, quando procuram atendimento médico, necessitam de internação e suporte da equipe para o tratamento hospitalar. Ademais, percebe-se que são mais resistentes as orientações da equipe de saúde em relação ao autocuidado.

No Zimbábue, pesquisa realizada na unidade de clínica médico-cirúrgica propôs estudar os fatores relacionados ao paciente e ao dispositivo vascular para o desenvolvimento de flebite e $52,2 \%$ dos indivíduos eram homens. A idade variou de 23 a 80 anos, 28,2\% dos pacientes tinham entre 30 e 39 anos, 26,0\%, entre 40 e 49 anos e $23,9 \%$, mais de 60 anos $^{67}$. 
Constatou-se, no presente estudo, que maioria dos pacientes (23\%) estava na faixa etária de 60-69 anos, seguida de 15,6\% na faixa de 30-39 anos e 15,6\% na faixa de 40-49 anos. Estudo realizado em Brasília (Distrito Federal), que verificou a incidência de flebite em uma unidade de clínica médica em 100 pacientes internados, demonstrou a variação de idade de $20-94$ anos, sendo $53 \%$ dos pacientes com idade superior a 60 anos $^{4}$, resultado próximo encontrado em outro estudo, no qual 43,7\% das notificações de flebite estiveram associadas a pacientes com 60 anos ou mais ${ }^{61}$.

Hospital público do Distrito Federal analisou, de forma retrospectiva e descritiva, os incidentes notificados no período de janeiro de 2011 a setembro de 2014, considerando o perfil dos pacientes que tiveram o EA flebite, e, destes, $23,4 \%$ pertenciam à faixa etária acima dos 60 anos $^{68}$.

No ano de 2018 os idosos com 65 anos ou mais representaram 9,22\% da população brasileira, segundo dados do IBGE, e a previsão para o ano de 2028 é de que faça parte de $12,74 \%$ dos habitantes ${ }^{69}$. As organizações de saúde precisam investir em mudanças para incrementar o atendimento aos idosos, em todos os níveis de assistência, sendo necessária, além de adequações em processos e estruturas, a capacitação continuada dos profissionais de saúde para viabilizar a prestação de serviços com segurança e qualidade.

É perceptível o aumento do quantitativo de pessoas acima de 60 anos hospitalizadas na Unidade de Internação Clínica. Por isso, o HCE vem adotando medidas para atender a esse grupo que permanece internado por um período prolongado para tratamento, sendo imprescindível a atuação da equipe multiprofissional visto que a assistência aos idosos, focada em suas necessidades específicas, é um desafio para os serviços de saúde, especialmente para os profissionais de enfermagem que atuam junto a eles nas $24 \mathrm{~h}$, ininterruptamente.

O investimento na força de trabalho e na formação dos profissionais de saúde que prestarão os cuidados para essa população é prioridade, com a finalidade de assistir as especificidades no processo de envelhecimento, no cuidado e na atenção integral à saúde da população idosa ${ }^{70}$. É crucial melhorar o atendimento ofertado para essa população com o objetivo de prestar assistência livre de danos ${ }^{63}$.

Os idosos possuem um número maior de doenças pré-existentes, consequentemente, podem apresentar maior fragilidade na rede vascular periférica, 
quando comparados aos demais pacientes, e têm maior risco para desenvolver o EA flebite ${ }^{71}$.

A presente pesquisa mostrou que os pacientes com flebite portam as doenças pré-existentes hipertensão arterial sistêmica, diabetes melitus e dislipdemia, corroborando os achados em outros estudos ${ }^{72-73}$. O mesmo ocorreu com a hipótese diagnóstica, sendo a afecção infecciosa a causa principal de internação desses pacientes $^{72}$. Pesquisa realizada na Amazônia ocidental brasileira mostrou que a presença de doença crônica e a hipótese diagnóstica de infecção tiveram relação estatística significativa para que o paciente desenvolvesse flebite no período da internação durante o uso do AVP74.

Características semelhantes foram encontradas em outra pesquisa no Zimbábue, 63,0\% dos pacientes internados que apresentaram flebite tinham como causa da internação afecções infecciosas. Múltiplas doenças pré-existentes estavam presentes em $89,3 \%$ dos indivíduos da amostra, sendo que 13,0\% apresentavam diabetes melitus ${ }^{67}$.

Indo de encontro a esses resultados, num hospital no noroeste paulista, as hipóteses diagnósticas prevalentes em pacientes com flebite foram as afecções cardiovasculares $(32,9 \%)$, seguidas de afecções traumáticas $(11,9 \%)$, septicemias $(3,4 \%)$ e $51,8 \%$ relacionadas a neoplasias, cirroses, vírus da imunodeficiência humana, entre outras ${ }^{61}$.

Além da mudança na estrutura etária da população brasileira, como já citado anteriormente, a falta de cuidados com a saúde, relacionada à prática de atividade física, consumo de alimentos saudáveis, uso do tabaco, entre outros, está aumentando o número de pessoas com doenças crônicas não transmissíveis. No Brasil, tornou-se um problema de saúde pública, há mais indivíduos internados decorrentes das complicações ${ }^{75}$. Presença de doenças vasculares, diabetes melitus, neuropatia periférica e tabagismo correspondem a fatores que aumentam o risco para o desenvolvimento de flebite ${ }^{76}$.

Ressalta-se que, neste estudo, houve diferença estatística significante da ocorrência de flebite grau 2 associada às doenças pré-existentes hipertensão arterial sistêmica e neuropatia. Aqueles que tinham hipertensão arterial sistêmica apresentaram, na sua maioria, flebite graus 2 e 3 (6-27,3\%). Os pacientes com 
diabetes mellitus estiveram associados ao maior número de ocorrências de flebite grau 2 e grau 3.

Outro fator importante foi a diferença estatística significante da ocorrência da flebite grau 2 associada aos pacientes com transtornos mentais e comportamentais. A Unidade de Internação Clínica tem recebido um número crescente de pacientes acometidos por afecções psiquiátricas e o HCE tem investido em programas de capacitação dos colaboradores, visando à prestação de cuidados qualificados. Contudo, ainda há melhorias para se realizar, pois há dificuldades a serem enfrentadas pelos profissionais de saúde para compreender e atender às necessidades específicas de cuidados destinados a esses pacientes.

Foram notificadas 107 flebites, com variação mensal do quantitativo durante o ano de 2017, sendo janeiro, junho, julho e outubro os meses de maior notificação, resultado parecido com o de estudo que apontou maior índice de ocorrência de flebite nos meses de maio, junho e julho ${ }^{61}$. Ressalta-se que, durante a estação do inverno, aumenta o número de pessoas internadas com afecções respiratórias, bronquite, pneumonia, entre outras, e, como parte do tratamento, há a necessidade da instalação e manutenção de AVP para infusão de antibióticos, contribuindo para o risco de desenvolvimento de flebite.

Hospital universitário no sul de Minas Gerais realizou o levantamento das 189 fichas de notificação de EA no ano de 2012 e analisou os eventos por mês. Maio, agosto e setembro foram os meses com maior número de notificações e os EA relatados estavam relacionados a erro de medicação, farmacovigilância, hemovigilância, queda e outros eventos (flebite, perda de cateter, queimadura e lesão por pressão) ${ }^{77}$.

Hospital universitário do interior do Estado de São Paulo, com 877 leitos, analisou as notificações de incidentes, utilizando a base de dados do gerenciamento de risco no período de agosto de 2015 a julho de 2016. Foram notificados 4.691 incidentes relacionados à segurança do paciente, destes, 344 eram EA, e a flebite foi a quarta causa de notificação com 13,8\%. O estudo mostrou que os enfermeiros foram responsáveis por $70,6 \%$ das notificações ${ }^{78}$. No presente estudo, os enfermeiros foram responsáveis por $68,2 \%$ das notificações do EA flebite, sendo $29,9 \%$ das notificações anônimas. 
Hospital de ensino de alta complexidade na cidade de Ribeirão Preto comparou as notificações realizadas de forma manuscrita e informatizada, e o enfermeiro foi responsável por $71,5 \%$ e $76,6 \%$ dos registros, respectivamente ${ }^{79}$. No Distrito Federal $26,3 \%$ das notificações foram realizadas por enfermeiros e em 60,8\% delas não havia registro sobre a categoria profissional ${ }^{68}$. Estudo realizado em Minas Gerais obteve resultados diferentes, os técnicos de enfermagem foram responsáveis por $68,5 \%$ das notificações e os enfermeiros, por $10,9 \%$.

É primordial sensibilizar a equipe e estimular a notificação desse EA, o que, além de mostrar o comprometimento com a qualidade do cuidado prestado, possibilita caracterizar a flebite, auxiliando a conhecer as causas e direcionar os processos de melhoria para mitigar a sua ocorrência. Os profissionais, por vezes, não notificam o EA por medo de punição, tornando difícil o conhecimento da sua real magnitude com a prática da subnotificação ${ }^{79}$. A notificação do EA é fundamental para se evidenciar as falhas e direcionar a adoção de medidas corretivas para se aumentar a segurança do paciente e dos profissionais.

Quanto ao período de notificação da ocorrência de flebite, neste estudo verificou-se a concentração de notificações nos períodos vespertino (40,2\%) e matutino (38,3\%). Hospital universitário no sul de Minas Gerais, por meio das fichas de notificações de EA, evidenciou que o maior número de notificações ocorreu no período noturno (40,2\%), seguido do período matutino $(22,2 \%)$ e o período da tarde $(6,4 \%)^{77}$. Estudo verificou que as notificações ocorreram com maior frequência no período da manhã (43,7\%), por haver maior movimentação da equipe multiprofissional e a realização do maior número de procedimentos, seguido pelo período da tarde $(40,7 \%)^{78}$.

Segundo relatório da ANVISA, no período de janeiro de 2014 a dezembro de 2018, 59,6\% das notificações de EA foram realizadas no período das 07 às 19 h; no Estado de São Paulo esse valor correspondeu a 62,7\% das notificações. No período supracitado, foram notificadas 14.428 flebites no Brasil 80 .

A maioria (57 - 47,7\%) dos pacientes com flebite foi classificada como de baixo risco para desenvolver flebite, sendo $23,4 \%$ de risco moderado, $22,4 \%$ de alto risco e $6,5 \%$ sem risco. O HCE utiliza uma escala própria construída para avaliar o risco do paciente para a flebite, e, de acordo com a pontuação dos critérios estabelecidos, o 
paciente é classificado e automaticamente são geradas as medidas de intervenção. Estudos sobre essa temática precisam ser realizados para validar o uso dessas escalas que classificam o risco de o paciente desenvolver flebite a fim de apoiar o enfermeiro na prescrição dos cuidados de acordo com as necessidades de cada paciente.

A classificação de risco para desenvolvimento da flebite, considerando-se fatores intrínsecos e extrínsecos, é realizada diariamente pelo enfermeiro na Unidade de Internação Clínica e tem validade de 24 h. A partir dessa classificação, os cuidados são direcionados, de acordo com as necessidades do paciente, a fim de se evitar que o EA ocorra. Caso o paciente seja classificado como de risco moderado ou alto e tenha previsão de TIV superior a sete dias, o enfermeiro poderá discutir com a equipe médica a possibilidade da indicação de outra via de acesso venoso, como exemplo, CCIP (Cateter Central de Inserção Periférica), evitando complicações vasculares.

A maioria dos pacientes que tiveram flebite estavam com o cateter havia menos de 24 h, seguido de 48 e 72 h, resultado que vai ao encontro com estudo no qual o tempo de permanência do dispositivo de pacientes que apresentaram flebite foi menor que $72 \mathrm{~h}^{61}$.

Estudo de coorte descritivo na unidade de clínica médica de um hospital em Portugal determinou a taxa de incidência e os fatores de risco para flebite e infiltração em 110 pacientes. O tempo de permanência do cateter venoso periférico até a retirada por causa da flebite foi de $30 \%$ nos pacientes com tempo de permanência de $24 \mathrm{~h}$; 28,0\% de 25-48 h; e 11,8\% 49-72 h73, ao contrário do que foi encontrado na população em uma unidade de internação clínica, em que 13\% dos pacientes que apresentaram flebite estavam com o cateter entre dois e quatro dias e $86,9 \%$ havia mais de quatro $\operatorname{dias}^{67}$.

$\mathrm{Na}$ Turquia, pesquisa transversal determinou o efeito do tempo da troca do cateter venoso periférico no desenvolvimento de flebite, pacientes com dispositivo inseridos por menos de $48 \mathrm{~h}$ tiveram 5,8 vezes mais chance de desenvolver flebite, entre 49 a 96 h o risco era 2,8 vezes maior, ambos comparados àqueles que estavam com o cateter de 97-120 h. As análises mostraram que a incidência de flebite era maior nos dispositivos com 48 h ou menos, seguido daqueles com 49-96 h e 97 a 120 h $^{81}$. 
No Vale do Paraíba, a média de permanência dos cateteres venosos nos pacientes que desenvolveram flebite foi de $49 \mathrm{~h}$. Uma recomendação realizada foi a importância de se observar o aspecto do curativo quanto à presença de sangue, pois $66,7 \%$ dos pacientes que sofreram com esse EA estavam com o curativo sujo ${ }^{65}$.

É preciso avaliar sistematicamente a cobertura dos AVP pelo risco de flebite bacteriana. Estes devem ser avaliados periodicamente e trocados sempre que expostos ao risco de infecção ${ }^{82}$. Estudo prospectivo analisou a microbiologia das superfícies externas e lúmens dos cateteres venosos periféricos de pacientes hospitalizados. O resultado foi preocupante, pois $40 \%$ dos lumens apresentaram crescimento bacteriano, com destaque às bactérias Staphylococcus aureus e Pseudomonas aeruginosa. Os cuidados com a manutenção do dispositivo e as boas práticas na manipulação são fundamentais para se evitar a ocorrência de infecções localizadas (flebite) e de corrente sanguínea ${ }^{83}$.

A ANVISA, visando à prevenção de infecção de corrente sanguínea, recomenda a retirada do cateter o mais breve possível e indica que o AVP não deve ser trocado de forma rotineira num tempo inferior a $96 \mathrm{~h}$, exceto quando instalado em situação de emergência com comprometimento da técnica asséptica. O prazo para troca do dispositivo em prazos maiores, ou quando clinicamente indicado, dependerá da adoção boas práticas da instituição como avaliação rotineira do sítio de inserção, integridade do vaso, integridade do AVP e do curativo ${ }^{51}$.

$\mathrm{Na}$ Austrália, realizou-se um estudo multicêntrico, randomizado, controlado, não cego, nas unidades de clínica médica e cirúrgica em três hospitais universitários em Queensland, com o objetivo de avaliar o efeito do procedimento de substituição do cateter venoso periférico, quando clinicamente indicado. Participaram da amostra 3.283 pacientes, tendo sido avaliados 5.907 AVP que foram divididos em dois grupos: substituição do AVP, quando clinicamente indicado, e substituição do AVP de rotina. O tempo de permanência do dispositivo nos pacientes do grupo substituição do AVP, quando clinicamente indicado, variou entre 48-561 h e no grupo substituição do AVP de rotina foram entre 48-96 h. Em ambos os grupos 7\% dos pacientes tiveram flebite, somente um paciente, pertencente ao grupo substituição do AVP de rotina, teve infecção de corrente sanguínea, relacionada ao AVP. Os autores relataram que os riscos de infecção estavam primeiramente relacionados com o procedimento na inserção do cateter e, posteriormente, com a manipulação do dispositivo. Concluíram 
que os AVP poderiam ser substituídos, quando clinicamente indicado, dessa forma se evitaria a punção de até 6 milhões de dispositivos, diminuir-se-iam os custos relacionados à mão de obra e uso de materiais para o procedimento ${ }^{84}$.

No HCE as orientações da Comissão de Controle de Infecção Hospitalar consistem em retirar o AVP o mais precocemente; manter o dispositivo intravascular somente quando o paciente estiver utilizando medicação endovenosa; tentar a substituição para via oral assim que possível; manter vigilância e realizar a troca do cateter a cada sete dias ou quando houver qualquer sinal de flebite.

A flebite grau 2 representou 45,8\% das notificações na Unidade de Internação Clínica do HCE. Em um hospital universitário no interior do Paraná a flebite grau 2 correspondeu a $57,2 \%$ dos eventos, seguido de grau $3(33,3 \%)^{66}$. Um hospital da Rede Sentinela, no município do Recife, mostrou que $63,2 \%$ das flebites notificadas na Gerência de Risco foram classificadas como grau 1, seguido de 27,0\% do grau 2 e de $5,3 \%$ do grau $3^{82}$. Resultado semelhante foi encontrado no hospital no Vale da Paraíba com 41,6\% dos casos classificados como flebite grau $1 ; 37,5 \%$ grau $2 ; 16,7 \%$ grau 3; e apenas 4,2\% grau 465. Estudo realizado em Portugal indicou que as flebites graus $1(37,0 \%)$ e $2(53.6 \%)$ também foram as mais presentes ${ }^{85}$.

No setor de Internação Clínica do Hospital das Clínicas de Uberlândia analisaram-se a prevalência de flebite e os fatores predisponentes, e, dos 144 dispositivos venosos periféricos avaliados, 23,6\% apresentaram flebite. O grau de flebite 2 foi mais prevalente, representando $64,7 \%$, enquanto que o grau 4 foi o menor com $5,9 \% 86$.

Os medicamentos são fatores que podem contribuir para o desenvolvimento de flebite em razão das propriedades químicas, $\mathrm{pH}$ e osmolaridade ${ }^{82}$. No presente estudo, 50 (100\%) pacientes que estavam em uso de antibióticos apresentaram flebite, a maioria (42\%) apresentou flebite grau 2, seguida de flebite grau $3(28 \%)$, dessa forma fica evidente que os cuidados para pacientes em antibioticoterapia devem ser redobrados.

Estudo realizado em três instituições de saúde na Sérvia e na Croácia utilizou um questionário para avaliar a percepção dos enfermeiros sobre os fatores de risco para flebite, com foco no conhecimento sobre os medicamentos e soluções que 
contribuem para o desenvolvimento desse EA. Após análise dos questionários, identificou-se que, segundo esses enfermeiros, os medicamentos com maior concentração ou soluções com pH elevado correspondiam aos fatores para o desenvolvimento de flebite e que os antibióticos Vancomicina e a benzilpenicilina tinham potencial significativo para a ocorrência daquela ${ }^{52}$.

Outra pesquisa, por intermédio de uma revisão de literatura, identificou quais os fatores de risco para o desenvolvimento da flebite e constatou que $57,1 \%$ dos artigos relataram que o uso de antibióticos está relacionado aos fatores de risco para o desenvolvimento desse $E A^{87}$. Estudo verificou que o uso de antibióticos estava presente em $13 \%$ dos pacientes que tiveram esse EA, sendo que $50 \%$ dos pacientes que estavam com antimicrobiano apresentaram grau da flebite mais avançado, outras medicações como cristaloides também estavam em uso ${ }^{67}$.

As classes de antibióticos e analgésicos compreendem fármacos causadores de flebite, uma das justificativas é a diluição incorreta desses medicamentos e as interações que podem ocorrer quando a salinização ao término da infusão não é realizada ${ }^{82}$.

Há estudos que também encontram outros fármacos como causas da flebite, destacando-se o uso de soros de manutenção com eletrólitos, antieméticos, anticonvulsivantes e broncodilatadores ${ }^{65}$. Na Turquia, o uso de antibióticos estava presente em $78,4 \%$ dos casos de flebite, tendo sido indicado o risco para se desenvolver flebite de 2,4 vezes maior nos pacientes que fizeram uso desse fármaco. Da mesma maneira, a infusão de nutrição parenteral aumentou o risco para flebite em três vezes mais em comparação aos pacientes que não receberam essa terapia ${ }^{81}$.

Estudo observacional prospectivo identificou a incidência de flebite e os fatores de risco para o seu desenvolvimento. Naquele, a análise estatística evidenciou a relação entre os fatores de risco para flebite: "administração de cloreto de potássio, "antibióticos endovenosos" e as medicações "levofloxacina" e "azitromicina". A probabilidade é 1,95 vezes maior, quando utilizado cloreto de potássio, e 1,92 maior em uso de antibioticoterapia endovenosa ${ }^{85}$.

Os profissionais da equipe de enfermagem passam a maior parte do tempo assistindo os pacientes, e a atividade mais frequente, durante o período de 
hospitalização, é a administração de medicamentos. O conhecimento sobre incompatibilidade medicamentosa, diluição, tempo de infusão é relevante e imprescindível para o cuidado, portanto ter uma equipe bem orientada, além de pacientes que participam do seu cuidado, é uma maneira efetiva para evitar a ocorrência de EA.

Analisando-se o número de notificações, 52,3\% dos pacientes utilizaram o dispositivo Jelcoß e evoluíram, na sua maioria, com flebite graus 2 e 3 . Neste estudo não foi constatada diferença estatística significante entre o risco para desenvolvimento de flebite e o tipo de dispositivo utilizado pelo paciente. Contudo, The Infusion Nursing Standards of Practice recomenda o uso de cateter com sistema de estabilização integrada, reiterando que este tipo de dispositivo deve ser utilizado sempre que possível $^{3}$.

Ensaio clínico randomizado, realizado numa instituição de ensino de grande porte, na Unidade de Internação Clínica e Cirúrgica, analisou as complicações decorrentes do uso de cateter venoso periférico em adultos. Dois grupos participaram da amostra: cateter de segurança completo (grupo experimental) e cateter curto flexível (grupo controle). As causas para retirada do cateter foram alta hospitalar e, na sequência, a ocorrência de flebite em 18,34\% dos pacientes. No grupo experimental, o uso de soluções, analgésicos e sedativos foi relevante; no grupo controle sobressaíram a infusão de soluções e a não administração de analgésicos e sedativos. $O$ estudo mostrou que cateter de segurança completo de poliuretano teve taxas menores de complicações após o quarto dia de uso ${ }^{72}$.

No HCE há recomendações quanto às indicações de uso de cada dispositivo para o estabelecimento de AVP; o Jelco® é indicado para a infusão de medicamentos não vesicantes e irritantes, infusão de contraste em bomba na tomografia/ressonância magnética e provas funcionais no laboratório. $O$ cateter íntima $®$ é indicado para infusão de medicamentos vesicantes e irritantes não quimioterápicos, infusão de quimioterápicos, infusão de dois medicamentos simultâneos, quando compatíveis, para se evitar o uso de polifix ou torneirinha, para pacientes com fragilidade venosa. Este dispositivo possui asas que facilitam a sua punção e estabilização durante o tempo de permanência no vaso.

Durante a administração de medicamentos por via endovenosa é visível que o dispositivo com estabilização integrada oferece maior conforto para o paciente. 
Quando utilizado Jelco®, ao se conectar a seringa ou equipo de soro, mesmo se segurando para se evitar a movimentação do cateter, o paciente refere desconforto. Há também situações, nas quais não há interação medicamentosa e se utiliza o polifix, o que contribui para a movimentação do dispositivo no interior do vaso.

Nas notificações de flebite analisadas, encontrou-se o registro de que $93,5 \%$ dos pacientes sofreram dano leve e 4,7\%, dano moderado, à semelhança de estudo que analisou os incidentes notificados em um hospital público e concluiu que o dano leve foi o mais frequente, seguido por dano moderado68.

Estudos que relatam a classificação do dano causado pela flebite são escassos na literatura, por isso, neste estudo, comparou-se a frequência do dano com outros $E A^{(78-79)}$. Conhecer o dano causado pela flebite é imprescindível, visto que a ocorrência deste EA pode levar a comprometimento temporário ou permanente do membro acometido.

Estudo realizado em um hospital no Estado de São Paulo, em duas unidades denominadas $A$ e $B$, obteve como resultado 4.691 notificações de incidentes, sendo que 344 foram classificados como EA (lesões de pele, flebite, queda, eventos relacionados à cirurgia, medicamentos, perda de dispositivos, entre outros). O dano leve, decorrente do EA, nas unidades A e B, foi de $67,9 \%$ e $54,7 \%$, respectivamente; o dano moderado correspondeu a $28,0 \%$ na unidade $A$ e a $34,2 \%$ na unidade $B$, causando incapacidade temporária e prolongando o tempo de internação do paciente $^{78}$.

Estudo com pacientes internados na unidade de internação cirúrgica de um hospital que está integrado à rede sentinela na região Centro-Oeste, verificou que, dos 218 EA (retirada não programada de cateteres/sondas/drenos, infiltração venosa, infecção hospitalar, lesão por pressão, queimadura química por produto, entre outros), $77,0 \%$ dos pacientes tiveram dano leve; $16,4 \%$, moderado; e 2,2\%, dano grave. Os autores relataram que as mudanças de atitudes, desde a alta gestão até os profissionais da ponta do cuidado, podem minimizar a ocorrência desses incidentes. Consideraram também que mesmo os incidentes sem danos constituem riscos para agravamento do EA e que os profissionais devem ser estimulados para notificar a fim de estabelecer medidas preventivas para mitigá-los ${ }^{79}$.

O paciente que tem um dano decorrente de um EA pode ter algum tipo de comprometimento, temporário ou definitivo, que pode acarretar prejuízos físicos, psíquicos e/ou socioeconômicos. Conhecer a magnitude de um EA e sua repercussão 
para o paciente, família e sociedade propicia, aos profissionais de saúde, a reflexão sobre a importância de se executar práticas seguras, evitando/minimizando-se os riscos.

A gestão de risco identifica, avalia e controla os riscos e incidentes relacionados aos serviços de saúde ${ }^{28}$. Nessa perspectiva, o HCE possui a gerência de segurança assistencial e risco, que utiliza a matriz de risco assistencial que identifica, de forma pró-ativa, condições de risco na assistência à saúde e auxilia no processo de melhoria para prevenir e diminuir a ocorrência de falhas que ocasionem EA. Na matriz de risco assistencial da Unidade de Internação Clínica o EA flebite tem destaque, os membros da equipe multidisciplinar são orientados para observar, sistematicamente, a presença de hiperemia no AVP e, caso seja presenciada tal ocorrência, comunicá-la, imediatamente, a algum profissional da equipe de enfermagem para avaliação e retirada do dispositivo. Realiza-se o controle de quantos AVP apresentaram hiperemia a cada turno (manhã, tarde e noite) e ao final do mês é possível conhecer com que frequência esse evento ocorreu na unidade. Espera-se, com essas ações, identificar precocemente a flebite, integrando toda a equipe multidisciplinar nos cuidados preventivos, e evitar que esse EA ocorra de forma mais grave.

Dentre os pacientes que apresentaram flebite, 52,3\% estavam localizados distantes do posto de enfermagem da Unidade de Internação Clínica e 82,2\% tinham acompanhante no momento em que o EA ocorreu. Geralmente aqueles que necessitam de vigilância constante, como pacientes de maior complexidade clínica e psiquiátricos, são acomodados próximos do posto de enfermagem para que, quando necessário, o deslocamento dos profissionais da equipe de saúde seja mais rápido para se agilizar o atendimento imediato.

Os quartos que ficam nas extremidades da Unidade de Internação Clínica demandam maior tempo de deslocamento da equipe, o que pode resultar na demora do atendimento ao paciente, quando acionada a campainha para relatar o término da infusão do fármaco ou dor no local de inserção do AVP durante a TIV. Esse período entre o atendimento da campainha e a chegada do profissional ao quarto pode intensificar, ainda mais, a irritação do vaso pela demora em pausar a infusão e avaliar o paciente. Então, entende-se ser necessária a realização de outros estudos para avaliar essa variável.

A presença de familiares/acompanhantes é importante e pode contribuir para reduzir a ocorrência de EA. Para tanto, os familiares/acompanhantes e pacientes 
devem conhecer os seus direitos e deveres, entendendo os riscos aos quais estão expostos e requerendo, dos profissionais, cuidado seguro, mediado por clareza na comunicação. A ANVISA dispõe de material com orientações para pacientes, familiares/acompanhantes que tenham interesse nas ações de segurança, explicitando de que forma podem contribuir com gestores e profissionais da saúde na prevenção de $E A^{88}$.

Pesquisa realizada na Unidade de Internação Pediátrica de um hospital escola em Porto Alegre analisou como as acompanhantes/cuidadoras e profissionais da saúde reconhecem os EA no cuidado ao paciente. Houve relatos nos quais as acompanhantes/cuidadoras identificaram falhas tais como que a criança tinha recebido duas vezes a mesma medicação; que houve identificação incorreta do paciente; que o exame físico não tinha sido realizado de forma detalhada; que houve falhas de comunicação. Quando analisado o papel da acompanhante/cuidadora na segurança da criança hospitalizada, houve relato, por parte dos profissionais, de que a fiscalização do acompanhante/cuidador é essencial para colaborar na prevenção da ocorrência de $E A^{89}$.

Estudo realizado em duas unidades neonatais em Belo Horizonte com 14 enfermeiros compreendeu a atuação da família na segurança do paciente. Os enfermeiros afirmaram que o cuidado centrado nos familiares combateu o estresse e diminuiu a ocorrência de incidentes e de EA. No entanto, referiram não se sentirem à vontade com os familiares, por não estarem preparados para lidar com a presença deles no cuidado e encontrarem dificuldades sobre quais estratégias adotarem para auxiliar na segurança do paciente ${ }^{90}$.

No dia a dia é perceptível a necessidade de se melhorar os registros dos cuidados com o AVP de forma adequada, contendo data da punção, tipo de dispositivo, local da punção, número de tentativas realizadas, avaliação da inserção do cateter, fármacos em uso e data programada para troca ${ }^{80}$. A falta de registros completos sobre os AVP foi uma dificuldade encontrada no presente estudo, como também já indicado em estudos da literatura ${ }^{65,82}$.

Estudo prospectivo, quantitativo, descritivo-exploratório analisou a presença ou não de flebite em 76 pacientes internados em um hospital geral e identificou que $23,7 \%$ das anotações de enfermagem estavam incompletas e não tinham informações quanto à data, hora, local de punção e calibre do dispositivo ${ }^{65}$. Hospital Sentinela no 
município de Recife identificou a necessidade de se melhorar os registros no prontuário do paciente quanto à data da troca da punção, local do dispositivo, além da falta de registro dos medicamentos em uso no AVP e avaliação da inserção ${ }^{82}$.

Quanto à conduta relatada na notificação de flebites ocorridas na Unidade de Internação Clínica, em 2017, 48,86\% referiram-se à retirada dos dispositivos; 16,65\%, à realização de nova punção; e 17,04\%, à adoção de outros procedimentos padronizados no HCE para o tratamento da flebite ("aplicação de pomada de extrato de flor de camomila"; "aplicação de compressas”). Porém, em 20,45\% das notificações não havia registros sobre os procedimentos adotados. Conforme anteriormente mencionado, a notificação correta é de extrema importância para a quantificação da ocorrência do EA flebite e realização da análise das causas e fatores contribuintes visando à avaliação de riscos e à adoção de medidas para se melhorar a segurança do paciente ${ }^{61}$.

O desconhecimento sobre o erro pode conduzir o profissional aos sentimentos de culpa e medo, cooperando para a omissão do fato. Portanto, são imprescindíveis a discussão sobre o tema segurança do paciente e a propagação da cultura não punitiva, associada à ocorrência de EA, com as finalidades de identificar lacunas que ofereçam risco para o paciente, auxiliar na prevenção dos erros e promover a cultura de segurança. Destaca-se que, apesar de a equipe de saúde estar preocupada com a segurança do paciente, ainda há subnotificação dos EA pelo medo da cultura punitiva 32 .

Conforme anteriormente mencionado, o tratamento das 107 flebites, notificadas em 2017, foi efetivado por meio da realização dos três procedimentos padronizados no HCE: "aplicação de pomada de extrato de flor de camomila"; "aplicação de compressas" e "instalação de AVP”. Então, para se subsidiar a apuração do CDM, procederam-se a 15 observações de cada um desses procedimentos (05 para flebite grau 1, 05 para flebite grau 2 e 05 para flebite grau 3). Importante destacar que, no período da coleta de dados para o custeio dos procedimentos supracitados, não houve ocorrência da flebite grau 4, indicativo da melhoria contínua da qualidade do cuidado prestado ao paciente que evitou a evolução da flebite em grau inicial para o grau mais avançado. 
A identificação precoce da flebite evita o desenvolvimento de complicações e o agravamento com formação de cordão venoso palpável e presença de exsudato purulento que pode levar à infecção de corrente sanguínea ${ }^{3,82}$. Nessa direção, reiterase ser preciso avaliar sistematicamente o sítio de inserção do cateter a cada plantão; orientar a equipe multidisciplinar para o reconhecimento dos sinais de flebite; reforçar, no momento em que o paciente referir dor durante a infusão e/ou apresentar hiperemia no local de inserção do dispositivo, a necessidade da retirada do AVP e a programação de nova punção.

Com a finalidade de promover o cuidado com a participação da equipe multidisciplinar, no período da manhã e da tarde é realizada uma reunião entre as equipes assistencial e de apoio (hospedagem e copa) da Unidade de Internação Clínica, denominada "pit stop", com duração máxima de 20 min. Nesse momento, são sinalizados aspectos importantes do atendimento individualizado ao paciente, identificadas as suas necessidades de cuidado e realizado o alinhamento de ações entre os membros da equipe. As metas de cuidado são estabelecidas baseadas na avaliação da equipe multidisciplinar, nas últimas $24 \mathrm{~h}$, almejando o envolvimento do paciente no seu cuidado, direcionando as ações prioritárias para a sua recuperação, e a prevenção de danos. A ações estabelecidas no plano de cuidados são compartilhadas com os pacientes e familiares, em linguagem clara e objetiva, para que compreendam e participem do cuidado.

Em cada quarto, há um quadro intitulado "plano multidisciplinar" que contém informações sobre os cuidados prestados pela equipe de saúde, e no campo "meta do cuidado" são preconizadas orientações envolvendo o paciente e sua família. Quando identificado o risco de flebite, a orientação diária é para que o paciente comunique dor, vermelhidão e inchaço no local do AVP, durante e/ou após a infusão dos medicamentos; este é esclarecido sobre qual medicamento está recebendo e se há associação com maior risco para desenvolvimento de flebite.

Pacientes e familiares bem orientados sobre os possíveis riscos à segurança do cuidado tendem a ser mais ativos, além de constituírem importantes fontes de informação e prevenção de EA. O paciente deve ser o foco da atuação dos profissionais e da alta gestão dos serviços de saúde no processo de cuidar, deixando de ser expectador e atuando ativamente no processo de recuperação, garantindo um 
cuidado seguro. Assim, acredita-se que a sinergia entre paciente, família e equipe multidisciplinar contribuirá para o sucesso do tratamento ${ }^{88}$.

Em relação aos custos, nos procedimentos "aplicação de pomada de extrato de flor de camomila" e "aplicação de compressas", obtiveram-se CDM de US\$ 0.55 $(\mathrm{DP}=0.06)$ e US\$ 0.51 ( $\mathrm{DP}=0.00)$, respectivamente. A composição do CDM desses dois procedimentos foi influenciada, significativamente, pelo custo da MOD de técnico de enfermagem. Nos procedimentos "instalação de AVP com cateter jelco®" e “instalação de AVP com cateter íntima®” o CDM (US\$ 3.85 -DP=0.08 e US\$ 8.90 $\mathrm{DP}=0.06$ ) foi impactado pelo custo com material, com destaque para os itens película transparente com fenda $7 \mathrm{~cm} \times 7 \mathrm{~cm}$ (US\$1.01), conector de sistema fechado (US\$0.53), cateter jelco® (US\$ 0.32) e cateter íntima® (US\$ 4.82).

Os procedimentos supracitados foram realizados apenas por técnicos de enfermagem da Unidade de Internação Clínica. Tal fato já era esperado, visto que, na prática assistencial, os profissionais de nível médio estão direcionados aos cuidados diretos aos pacientes e os enfermeiros, aos cuidados indiretos, executando cuidados diretos aos pacientes de maior complexidade assistencial. Considera-se adequada a execução desses procedimentos por técnicos de enfermagem, devidamente capacitados e experientes, especialmente por esta categoria apresentar um valor mais baixo da MOD/minuto em relação à MOD/minuto do enfermeiro.

Considerando-se que, de acordo com o protocolo do HCE, os procedimentos "aplicação de pomada de extrato de flor de camomila" e "aplicação de compressas" deveriam ser realizados a cada $6 \mathrm{~h}$ nas primeiras $24 \mathrm{~h}$ e que 0 paciente poderia necessitar de, pelo menos, uma punção com AVP para dar seguimento na TIV, a somatória dos tempos médios para cada procedimento, segundo o número de vezes em que é realizado, o técnico de enfermagem permaneceria, em média, 33,25 min. nas primeiras $24 \mathrm{~h}$, executando os procedimentos para o manejo do EA flebite. Vale ressaltar que a ocorrência do EA resulta no consumo de recursos humanos e materiais que poderiam ser alocados para outras finalidades, como exemplo, adoção de ações preventivas a fim de se evitar os ricos de novos EA. Esse tempo médio despendido pelo técnico de enfermagem para o tratamento da flebite, caso este EA fosse evitado, poderia ser investido na prestação de outros cuidados aos demais pacientes e/ou na execução de ações para se prevenir a ocorrência de EA. 
Verificou-se, nesta pesquisa, que o CDM total pode ser mais impactado pelo valor da MOD dos profissionais executantes, em decorrência do tempo despendido, ou pelo consumo de recursos materiais, variando conforme o procedimento objeto de custeio, à semelhança do observado em estudos sobre o custo direto de diferentes procedimentos de enfermagem ${ }^{(16,91-93)}$.

Na Unidade de Terapia Intensiva de Queimaduras do Hospital das Clínicas da Faculdade de Medicina da Universidade de São Paulo (HC-FMUSP), realizou-se um estudo quantitativo, exploratório-descritivo, do tipo estudo de caso único para se identificar o CDM dos procedimentos controle de sinais vitais, administração de medicamentos via intravenosa, mensuração de diurese, curativo e verificação da glicemia capilar, todos realizados por profissionais da equipe de enfermagem. Dentre os procedimentos avaliados, "controle de sinais vitais" obteve custo com materiais de US\$ 0.44 (DP=0.15) com maior representatividade $(67,02 \%)$ para o CDM total desse procedimento, assim como o procedimento "curativo" cujo CDM com material foi de US\$ 57.69 (DP=122.12) com expressão importante no CDM total, diferente do procedimento "verificação da glicemia capilar" no qual o custo da MOD da equipe de enfermagem (US\$ 0.48 - DP=0.34) teve o maior impacto no CDM total. Em relação aos procedimentos "administração de medicamentos via intravenosa" e "mensuração de diurese", o CDM dos medicamentos/soluções foram os mais elevados na composição do CDM total (US\$ 6.62 - DP=24.30 e US\$ 5.14 - DP=2.75 respectivamente). Os autores concluíram que a assistência hospitalar a pacientes portadores de queimaduras é onerosa, pois consome recursos humanos, materiais e estruturais. Estudos para conhecer os custos desses procedimentos podem contribuir na tomada de decisão gerencial e assistencial para evitar desperdícios e auxiliar no controle dos custos sem interferir na qualidade da assistência ofertada para esses pacientes ${ }^{91}$.

Estudo realizado na Fundação Hospitalar de Minas Gerais avaliou o custo do tratamento de lesões por pressão em pacientes com internação superior a $24 \mathrm{~h}$. Para a análise de custo, foi utilizado o Sistema de Custeio Baseado em Atividades - ABC, tendo sido mapeados os macroprocessos e processos relacionados à lesão por pressão, identificados os recursos consumidos com mão de obra e materiais em cada atividade. Os custos dos procedimentos realizados no curativo da lesão por pressão com coberturas, materiais e recursos humanos variaram de $R \$ 16,41$ a $R \$ 260,18$, 
essa variação ocorreu pelas diversas categorias e extensão da lesão e também pela variedade de coberturas utilizadas no procedimento. A cobertura primária teve o maior impacto no custo, excluindo os curativos realizados com hidrogel e alginato de cálcio. Tendo-se em conta a mesma categoria de lesão por pressão e tipo de cobertura utilizada, houve uma variação nos custos entre 3,5\% a 614,6\%. A pesquisa mostrou que os custos envolvidos no tratamento da lesão por pressão são expressivos e conhecer essa realidade auxilia na tomada de decisão para a alocação racional dos recursos ${ }^{92}$.

Outro estudo envolvendo custos com curativos de lesão por pressão com pacientes hospitalizados nas Unidades de Internação Clínica, Cirúrgica e Unidade de Terapia Intensiva Adulto (UTIA) de um hospital universitário no Estado de São Paulo identificou o CDM relativo à mão de obra dos profissionais da equipe de enfermagem e do consumo de materiais e soluções utilizados no procedimento curativo de lesão por pressão, no total foram realizadas 228 observações referentes a 55 lesões por pressão. Os custos com materiais e soluções referentes às lesões por pressão categoria I, II e IV foram de US\$16.26 (DP=12.97), US\$ 4.65 (DP=7.37) e US\$ 3.31 $(\mathrm{DP}=5.22)$, respectivamente, e tiveram maior impacto no CDM total. No entanto, os curativos das lesões categoria III inclassificáveis e suspeita de lesão tissular profunda tiveram a MOD com maior impacto no CDM total, e os custos da MOD relacionados às respectivas categorias foram US\$ $8.20(\mathrm{DP}=7.11)$, US\$ $4.80(\mathrm{DP}=4.32)$ e US $\$ 2.26$ $(\mathrm{DP}=1.58)$. Compreender os custos relacionados aos procedimentos que são executados é vital, pois com essa informação é possível propor ações que contribuam para a racionalização dos custos e, consequentemente, para a sustentabilidade financeira dos serviços de saúde ${ }^{16}$.

Estudo realizado no Instituto Central (IC) do HC-FMUSP identificou o custo direto total médio e de cada etapa dos procedimentos instalação, manutenção e desligamento da bomba de analgesia controlada pelo paciente. Na instalação e manutenção da bomba de analgesia controlada pelo paciente o custo com material foi de $R \$ 75,05(D P=0,14)$ e $R \$ 74,98(D P=0,06)$, respectivamente, e ocasionou maior impacto no custo total médio. Todavia, para se realizar o desligamento da bomba de analgesia controlada pelo paciente, o custo da $\operatorname{MOD}(R \$ 4,13-\mathrm{DP}=0,74)$ foi mais expressiva no custo direto total médio. O custo total médio da instalação, manutenção 
e o desligamento da bomba de analgesia controlada pelo paciente, com infusão de morfina ou fentanil, correspondeu a $R \$ 107,91, R \$ 110,55$ e $R \$ 4,94$, respectivamente ${ }^{93}$.

Esta pesquisa mostrou a forte influência dos custos dos materiais nos procedimentos "instalação de acesso venoso periférico com cateter íntima®" e “instalação de acesso venoso periférico com cateter jelco®”, porque os itens utilizados nesses procedimentos são mais onerosos. Contudo, entende-se que esse custo se trata de um investimento institucional necessário visto que os materiais utilizados na confecção desses dispositivos intravenosos reduzem o risco de flebite nos pacientes e dispõem de tecnologias que minimizam a exposição ao sangue durante a punção, protegendo o profissional executante do risco associado ao contato com material biológico.

Reitera-se que, no HCE, a Comissão de Controle e Infecção Hospitalar recomenda a retirada do cateter o mais breve possível; nessa direção é imprescindível que os profissionais avaliem, diariamente, a pertinência de sua permanência para viabilização da TIV prescrita e as condições clínicas associadas.

Estudo realizado numa UTI que dispõe de 29 leitos utilizou a prática baseada em evidências para realizar um teste piloto comparando a troca rotineira (72-96 h) do AVP versus a substituição, quando clinicamente indicada, para avaliar se a mudança dessa prática aumentaria o risco de flebite e infecção. Optou-se pela escolha da UTI em razão do maior uso de AVP nos últimos três meses antes da mudança dessa prática. Na primeira etapa do estudo, buscaram-se na literatura as melhores evidências sobre essa prática, para se obter subsídios científicos visando-se à autorização para a realização do projeto. Na sequência, as enfermeiras foram orientadas sobre a nova rotina, e nesse hospital a prática vigente era a troca do AVP a cada 96 h. Para o cálculo do custo, utilizou-se a estimativa de custo baseado na literatura, no qual o custo para cada punção era de US\$10.00 e o tempo dispendido para a realização do procedimento era de 20 min. Após a mudança da prática, os resultados mostraram que a quantidade de cateteres utilizados diminuiu em $14,2 \%$, com isso o impacto estimado nos custos foi de US\$2100.00 relacionado ao AVP no período de três meses. Nesse mesmo período, a economia estimada quanto ao dispêndio de tempo de profissionais de enfermagem foi de $70 \mathrm{~h}$. A taxa média de flebite foi de $2,4 \%$ (DP=0,9\%) e mês a mês foi de 2,0\% (março), 1,9\% (abril) e 3,5\% 
(maio); esses resultados foram considerados positivos visto que, de acordo com a INS, essa taxa deve ser de, no máximo, 5\%. Os resultados da pesquisa foram favoráveis para a mudança da prática na UTI visto que o índice de desenvolvimento de flebite foi baixo com a substituição do cateter, quando clinicamente indicado. $A$ partir de então, a prática foi expandida para as demais unidades da instituição a fim de otimizar os custos prejuízos à qualidade da assistência96.

$\mathrm{Na}$ Inglaterra, as diretrizes nacionais baseadas na Prevenção de Infecções Associadas a Cuidados de Saúde recomendam a substituição do AVP, quando clinicamente indicado, pois é uma medida segura para o paciente e que reduz os custos. Contudo, a informação sobre o impacto na redução dos custos associados a essa prática ainda era desconhecida pelo sistema de saúde público da Inglaterra National Health Service. Portanto, realizou-se um estudo para se analisar o custoefetividade da substituição de rotina do cateter (72-96 horas) versus quando clinicamente indicado na perspectiva do National Health Service. As informações sobre preço dos materiais e da mão de obra, referentes ao ano de 2013, foram fornecidas pelo próprio National Health Service. A substituição do AVP, quando clinicamente indicada, foi associada a uma redução de $21,0 \%$ do consumo de recursos materiais e do tempo (4 min.) dispendido pela enfermagem por paciente. No grupo que substituiu o AVP a cada 72-96 h o custo médio com os materiais foi de $£$ $12,26(\mathrm{DP}=7,75)$, e com a mão de obra foi de $£ 7,00(\mathrm{DP}=4,87)$; no grupo que realizou a troca do cateter, quando clinicamente indicado, o custo médio com o material foi de $£ 10,86(\mathrm{DP}=6,98)$ e de $£ 6,15(\mathrm{DP}=4,39)$ com mão de obra. Não houve significância estatística na taxa de flebite e nas infecções de corrente sanguínea nos dois grupos. A estimativa da economia com a troca do AVP, quando clinicamente indicada, em cinco anos seria de aproximadamente $£ 40$ milhões para o National Health Service ${ }^{95}$.

Estudo realizado na enfermaria da pediatria do Hospital Universitário Antônio Pedro levantou os custos do dispositivo intravascular periférico do tipo Jelco® durante o período de internação e identificou as causas da troca dos AVP. A principal causa de perda de AVP foi decorrente de flebite (63,1\% dos pacientes) e verificou-se que as falhas infusionais (flebite, extravasamento e infiltração) aumentaram o consumo de dispositivos, pela troca frequente, interferindo nos recursos disponíveis para esse procedimento. Foram analisados os custos referentes ao consumo de 460 cateteres do tipo Jelco®, em internações superiores a sete dias, nas quais foram gastos entre 
$R \$ 25,00$ e $R \$ 100,00$ com AVP em $52 \%$ dos casos; em $21 \%$ foi gasto um valor superior a $R \$ 200,00$; em $16 \%$ o valor gasto foi inferior a $R \$ 25,00$; e em $11 \%$ foram gastos entre $R \$ 100,00$ a 200,00. Demonstrou-se que os custos com o consumo dos dispositivos para o estabelecimento de AVP representaram $31 \%$ do valor repassado pelo SUS relativo a essas internações ${ }^{96}$.

Estudo exploratório, descritivo, com abordagem quantitativa, realizado na Universidade Federal de São Paulo, com 186 graduandos de enfermagem, identificou o ponto de vista destes graduandos sobre o desperdício de materiais durante a assistência. A maioria $(53,2 \%)$ relatou que o desperdício de materiais ocorria nos lugares onde realizavam estágio e relacionou o desperdício das oportunidades de aprendizagem para executar os procedimentos. O desperdício de materiais é frequente e eleva os custos para os serviços de saúde, sendo preciso conscientizar os graduandos sobre o tema para que o uso dos materiais seja realizado de forma racional. A equipe de enfermagem é responsável pelo uso de recursos materiais consumidos nos cuidados aos pacientes, e o enfermeiro, desde a sua formação inicial na graduação, deve ser sensibilizado e orientado sobre o impacto do desperdício de materiais, pois, futuramente, atuará em instituições de saúde e será um importante elemento multiplicador de tais conhecimentos ${ }^{97}$.

Pesquisa realizada com enfermeiros de um hospital privado da cidade de São Paulo observou a atividade dos enfermeiros nos níveis de planejamento, focando seus conhecimentos sobre gerenciamento de custos. Quando questionados sobre a abordagem do conteúdo gerenciamento de custos na graduação, 74,3\% responderam que o tema foi abordado na grade curricular e 25,7\% negaram. Todavia, a maioria $(57,7 \%)$ afirmou que a abordagem não foi satisfatória, pois o conteúdo não foi aprofundado de forma a auxiliar o processo decisório no cotidiano da profissão; 45\% do grupo não souberam explicar a importância do conhecimento sobre gerenciamento de custos e sua aplicação na prática ${ }^{98}$. É preocupante identificar que os enfermeiros têm pouco conhecimento sobre gestão de custos e gerenciamento de recursos materiais.

Com os avanços tecnológicos e o aumento da complexidade assistencial, exigem-se cada vez mais dos profissionais da saúde conhecimentos sobre a alocação racional de recursos de materiais para assegurar a disponibilidade, em quantidade e 
qualidade, para atender às demandas dos serviços de saúde sem comprometer a integridade do paciente no cuidado. O enfermeiro, por ser responsável pelo gerenciamento das unidades e coordenar a assistência prestada, tem papel fundamental na determinação dos materiais que serão utilizados, analisando a sua qualidade e especificações técnicas. É preciso também conhecer o perfil da unidade que gerencia e quais são os materiais e medicamentos mais consumidos a fim de se realizar a provisão adequada, o uso racional dos insumos disponíveis e a otimização dos recursos ${ }^{99}$.

Estudo realizado no "Everywhere Hospital", com 250 leitos, avaliou as complicações e falhas das terapias infusionais e demonstrou o custo da má qualidade referente às potenciais falhas associadas ao uso do AVP (flebite, infecção, infiltração, extravasamento, oclusão) em 6.490 pacientes. Aplicou-se uma fórmula para se mensurar a magnitude do problema e identificar de que forma esses processos poderiam ser melhorados no uso de dispositivos periféricos. As estimativas de custo foram decorrentes de consultas aos enfermeiros e gerentes de compras da instituição. Nesse hospital, cujo protocolo estabelece que o paciente pode ser puncionado até quatro vezes, houve 3.510 tentativas sem sucesso e, tendo-se em vista o custo estimado com materiais e recursos humanos para o procedimento punção de AVP (US\$ 35.00), o custo relativo às tentativas de punção totalizou US\$122.850. Os custos aplicados na pesquisa referiram-se a quantias estimadas, considerando-se que ocorreram 566 flebites no período de um mês e que foram necessárias 396 novas punções, o custo estimado para o Everywhere Hospital com a punção de um novo AVP, nesse período, foi de US\$ 13860.00; dentre as 566 flebites, foram realizadas compressas quentes para a maioria ( $80 \%)$, com custo total mensal estimado em US\$ $18080.00^{100}$.

Nesta pesquisa, alguns pacientes foram submetidos a mais de um procedimento para o estabelecimento do AVP e continuidade da TIV, por isso os custos relacionados ao consumo de materiais e MOD foram mais elevados. Analisando-se o custo dos cateteres utilizados no HCE, verifica-se que o dispositivo intravascular íntima® tem impacto expressivo no CDM total do procedimento. Reconhece-se que os custos com esse procedimento são onerosos para os serviços de saúde e há que se considerar, além do desconforto para os pacientes relacionado ao número de tentativas de punção, que o CDM total será influenciado, especialmente, 
pelo tipo de dispositivo utilizado cujo custo estará diretamente relacionado à quantidade consumida.

O HCE adota estratégias e realiza investimentos para evitar que o paciente sofra com múltiplas tentativas de punções para o estabelecimento de AVP a fim de viabilizar a TIV. Os profissionais são orientados a realizar, no máximo, duas tentativas de punção e, caso não obtenham êxito ou em situações nas quais têm conhecimento prévio sobre a fragilidade vascular do paciente, a acionar a "brigada da punção". Esta é composta por um time de técnicos de enfermagem altamente qualificados e capacitados para atender a pacientes com dificuldades de estabelecimento de AVP. O HCE disponibiliza para todos os profissionais a possibilidade de uso de dois equipamentos (01 alocado no setor de pediatria e outro na unidade coronariana) que utilizam a luz infravermelha para criar uma imagem digital da veia do paciente projetada sobre a pele, direcionando a punção e contribuindo para o sucesso do procedimento. Após tais medidas, caso não tenha se obtido êxito no estabelecimento do AVP, há a orientação de que deve ser acionado o "grupo de enfermagem especializada em acessos vasculares". Este grupo é composto por enfermeiros que realizam passagem do CCIP e, com o apoio do aparelho de ultrassonografia, executam o procedimento de punção venosa. Dispor dessas estratégias no HCE traz conforto para o paciente, assegura a manutenção da sua integridade venosa e alivia o estresse do profissional pela dificuldade de punção. Dispor de medidas como essas contribuiu para o êxito na primeira tentativa de punção e, consequentemente, reduz o desperdício de recursos materiais e possibilita o incremento do tempo despendido por profissionais de enfermagem na prestação da assistência.

A instituição dispõe também de protocolos com orientações sobre como se realizar os procedimentos "instalação de acesso venoso periférico", "aplicação de compressas" e "aplicação de pomada de extrato de flor de camomila". Dispor de manuais com padronização dos procedimentos auxilia a equipe na tomada de decisão frente ao tratamento do EA flebite e também evita o desperdício de materiais, pois cada profissional sabe a quantidade exata do uso de materiais e soluções para o tratamento da flebite, consumindo os recursos disponíveis, de forma sustentável.

A falta de registro da equipe de enfermagem foi um fator limitante nesta pesquisa. A partir da análise dos 96 prontuários, observou-se que 64,6\% não continham informações sobre a "aplicação de compressas", 17,7\% estavam sem o 
registro da "aplicação de pomada de extrato de flor de camomila" e 17,7\% não continham qualquer registro sobre o procedimento para tratamento da flebite. Dessa forma, não foi possível comprovar se o paciente teve, de fato, a sua necessidade atendida para o manejo do dano causado pelo EA, além de se obter mais informações sobre o dispositivo que o paciente utilizava. O protocolo institucional orienta sobre o número de vezes em que a "aplicação de compressas" e "aplicação de pomada de extrato de flor de camomila" devem ser realizadas diariamente. Entretanto, não havia checagem e anotação da execução desses procedimentos, de forma sistemática, contrariando a experiência clínica da pesquisadora deste estudo que observa, na prática assistencial cotidiana, que os técnicos de enfermagem os realizam adequadamente, conforme preconizado pelo HCE.

Como o HCE se trata de um hospital privado, a ausência de registros dos procedimentos executados acarreta em não pagamento pelas operadoras de planos de saúde, pois procedimentos que não são checados e/ou documentados descritivamente no prontuário do paciente são glosados, nas respectivas contas hospitalares, gerando perdas financeiras. Pesquisa descritiva, transversal, com abordagem quantitativa identificou as glosas realizadas por operadora de plano de saúde em contas hospitalares na região norte do Paraná. Houve 36 mil itens glosados, especialmente pela falta de registros dos profissionais de enfermagem, visto que, se não há o registro, suspeita-se que o procedimento não tenha sido executado, influenciando, diretamente, no faturamento dos custos referentes ao tratamento realizado ${ }^{101}$.

Os Conselhos Federais de Enfermagem e de Medicina, nos respectivos Códigos de Ética Profissional, explicitam que os profissionais devem, a cada avaliação do paciente, documentar no prontuário as informações inerentes e indispensáveis ao processo de cuidar, de forma clara, legível, objetiva, completa, com data, hora, assinatura e número do seu registro profissional ${ }^{102-103}$.

O registro correto no prontuário do paciente respalda, ética e legalmente, a atuação dos profissionais e a instituição de saúde e subsidia o recebimento do pagamento da assistência prestada, evitando a ocorrência de glosas de itens constantes das contas hospitalares e a geração de prejuízos econômicos para a instituição de saúde ${ }^{104}$. 
A incompletude ou falta de registros dos cuidados prestados pode levar os auditores das operadoras de planos de saúde ao entendimento de que determinado procedimento não foi executado e, consequentemente, a glosarem os materiais utilizados no tratamento da flebite por falta de evidência do cuidado prestado. Os registros incompletos na maioria $(82,3 \%)$ dos prontuários analisado bem como a falta de registros $(17,7 \%)$ comprometeram a estimativa do CDM dos procedimentos realizados para o tratamento do EA flebite em pacientes da Unidade de Internação Clínica no ano de 2017, configurando-se como uma limitação do presente estudo.

Foram encontradas documentações relativas à realização de 656 procedimentos, a maioria para o tratamento da flebite graus 2 e 3 , sendo a estimativa do CDM equivalente a US\$ 866.18 ao ano e, tendo-se em conta as 107 notificações, pode ser estimado o CDM de US\$ 8.09 por flebite tratada. Cabe destacar, novamente, a expressividade dos custos associados ao procedimento "instalação de acesso venoso periférico" que teve variações no CDM devido ao custo unitário do dispositivo íntima ${ }^{\circledR}$. Contudo, vale destacar que, frente ao insucesso da punção para o estabelecimento de um AVP, os custos podem ser mais elevados.

Estudo conduzido em uma unidade pediátrica evidenciou que o elevado quantitativo de dispositivos consumidos (460 cateteres do tipo Jelco®) para o estabelecimento de AVP representou 31\% do valor repassado pelo SUS. Justificouse o quantitativo utilizado pela fragilidade vascular dos pacientes, ocorrência de flebite, infiltração e falta de habilidade do profissional executante, aumentando o consumo de materiais. Então, a equipe de enfermagem foi orientada a sempre registrar o número de cateteres utilizados, a cada tentativa de nova punção, para fundamentar o controle do consumo ${ }^{96}$.

Em um hospital de médio porte, realizou-se a análise econômica das punções mal sucedidas no período de um mês. Foram executadas 3.510 punções sem sucesso e, tendo-se em conta o custo estimado para cada procedimento de instalação de AVP de US\$35.00, o custo total correspondeu a US\$122.850101. Analisando-se o risco do insucesso da punção, os valores podem ser maiores ${ }^{100}$.

Os resultados obtidos no presente estudo indicam os benefícios de investimentos em estratégias preventivas ou de mitigação de riscos do EA flebite na Unidade de Internação Clínica: utilização da matriz de risco assistencial; orientação 
da equipe interdisciplinar para o reconhecimento dos sinais de flebite e intervenção imediata por meio da adoção de tratamento padronizado (descrição da técnica, dos materiais a serem utilizados e indicação do profissional responsável pela sua execução); reuniões sistemáticas entre as equipes assistencial interdisciplinar e de apoio ("pit stop"); estabelecimento das metas de cuidado individualizado ao paciente; compartilhamento das ações constantes do plano de cuidados com os pacientes e familiares visando à sua participação efetiva; suporte da "brigada da punção"; disponibilização de equipamentos de luz infravermelha (projeção de imagem digital da veia do paciente sobre a pele para facilitar a punção de rede venosa difícil); acionamento do "grupo de enfermagem especializada em acessos vasculares" em casos mais complexos. Tais investimentos, ao minimizarem a ocorrência de flebite ou constituírem barreiras que para que a flebite não evolua para um grau mais avançado, resultam em redução de custos com o tratamento desse EA para o HCE.

Porém, esses resultados também evidenciam a fragilidade documental decorrente da ausência de registros ou de registros incompletos, mesmo em campos específicos do prontuário eletrônico, causando riscos em relação ao cumprimento dos aspectos ético-legais e prejuízos no faturamento assistencial do HCE.

A literatura ainda é escassa em relação à produção de conhecimento sobre o custo com tratamento do EA flebite. Então, espera-se que este estudo, além de contribuir com o aprimoramento do conhecimento sobre a ocorrência e as causas da flebite, o CDM dos procedimentos realizados para o seu tratamento e a estimativa do CDM dos procedimentos realizados para o tratamento ao longo de um ano, forneça subsídios para a gerência da Unidade de Internação Clínica e verifique possibilidades de intervenções educativas junto aos profissionais visando à adequada documentação da assistência prestada. 
6 CONCLUSÃO 


\section{CONCLUSÃO}

A realização deste estudo na Unidade de Internação Clínica do HCE permitiu concluir que

$\checkmark$ em 2017, foram notificadas 107 flebites relativas a 96 pacientes, a maioria com registro da ocorrência de uma flebite $(91,7 \%)$, do sexo masculino $(53,1 \%)$, na faixa etária de 60 a 69 anos (23\%) e com tempo de permanência inferior a quatro dias $(30,2 \%)$. Em relação às doenças pré-existentes desses pacientes, destacaram-se hipertensão arterial sistêmica (22,9\%), diabetes mellitus (15,6\%) e dislipidemia (12,5\%); 68 pacientes apresentaram hipóteses diagnósticas médicas relativas a afecções infecciosas; 16 pacientes, a afecções do sistema nervoso central e periférico; nove pacientes, à categoria afecções do aparelho digestivo;

$\checkmark$ o quantitativo de notificações da ocorrência de flebites variou entre três e 14, sendo os meses de janeiro (13,1\%), junho (12,1\%), julho (10,3\%) e outubro (10,3\%) os de maior notificação. Os turnos da tarde e da manhã apresentaram o maior quantitativo de notificações (40,2\% e 38,3\%, respectivamente) e o enfermeiro correspondeu à categoria profissional que realizou a maioria das notificações $(68,2 \%)$ seguidas de 29,9\% de notificações anônimas;

houve predomínio da ocorrência de flebite em pacientes com AVP com cateter jelco® (56 - 52,3\%), do tempo de permanência do dispositivo de 24 h (41 - 38,3\%); da classificação em grau 2 (49 - 45,8\%); da infusão de antibióticos (50 - 46,7\%); da localização do leito distante do posto de enfermagem (56 - 52,3\%); e da presença de acompanhante (88 - 82,2\%);

$\checkmark$ quanto à distribuição do grau das 107 flebites notificadas e às variáveis sexo, faixa etária e tempo de permanência dos pacientes, não foi constatada diferença estatística significante;

$\checkmark$ houve diferença estatística significante da ocorrência de flebite grau 2, associada às doenças pré-existentes hipertensão arterial sistêmica $(p=0,020)$, transtornos mentais e comportamentais $(p=0,020)$ e neuropatia $(p=0,005)$. Os pacientes portadores de hipertensão arterial sistêmica apresentaram, na sua maioria, flebite grau $2(15$ - 68,2\%) e grau 3 (6 - 27,3\%). Três (75\%) pacientes com Insuficiência renal crônica e nove (75\%) com dislipidemia também apresentaram flebite grau 2 ; diabetes mellitus esteve associada ao maior número de pacientes com flebite grau 
$2(8-53,3 \%)$ e grau 3 (4 - 26,7\%). Três (60\%) pacientes com hipótese diagnóstica de sepse apresentaram flebite grau 3;

$\checkmark$ quando analisada a variável função do relator com o grau da flebite, houve relação estatística significante $(p=0,007)$ entre a flebite grau 2 e a notificação realizada pelo enfermeiro e a notificação de forma anônima;

$\checkmark$ vinte e um (42\%) pacientes que receberam antibioticoterapia apresentaram flebite grau 2 e 14 (28\%), flebite grau 3. Dentre os pacientes que utilizaram imunoglobulina (10 - 100\%), 50\% apresentaram flebite grau 3; 28 (50\%) pacientes que estavam distantes do posto de enfermagem apresentaram flebite grau 2;

$\checkmark$ considerando-se a documentação referente à classificação de risco para o desenvolvimento do EA flebite, 57 (47,7\%) pacientes foram classificados como de baixo risco, $23,4 \%$, de risco moderado, $22,4 \%$, de alto risco e $6,5 \%$, sem risco;

$\checkmark$ não se verificou diferença estatística significante entre o risco para desenvolvimento de flebite e as variáveis sexo, faixa etária, tempo de permanência dos pacientes, doenças pré-existentes e agrupamento das hipóteses diagnósticas médicas, mês da ocorrência, turno (manhã, tarde ou noite), categoria profissional do relator, tipo de dispositivo intravenoso, localização do leito em relação ao posto de enfermagem (próximo ou distante) e presença de acompanhante. Houve diferença estatística significante para o baixo risco de desenvolvimento de flebite associado ao uso de solução eletrolítica $(p=0,003)$ e antiviral $(p=0,018)$;

os registros da classificação de dano causado ao paciente pelo EA flebite indicaram que $93,5 \%$ dos pacientes sofreram dano leve, 4,7\%, dano moderado e 1,9\% não sofreu danos. Não houve registro de pacientes classificados como dano grave ou óbito;

$\checkmark$ não foi encontrada diferença estatística significante entre o dano causado pela flebite e as variáveis sexo, faixa etária, tempo de permanência dos pacientes, mês da ocorrência, turno e categoria profissional do relator, tipo de dispositivo intravenoso, tempo de permanência do dispositivo, classe do fármaco, localização do leito em relação ao posto de enfermagem e presença de acompanhante. Quanto à associação entre classificação de danos e os fármacos infundidos, apenas a Oxacilina $(p=0,007)$, pertencente à classe dos antibióticos, apresentou diferença estatística significante com o dano leve; 
houve diferença estatística significante do dano causado pela flebite associado às doenças pré-existentes transtorno mental e de comportamento $(p=0,014)$ e hipotireoidismo ( $p=0,042)$ e a hipótese diagnóstica médica de sepse $(p=0,023)$;

$\checkmark$ não houve diferença estatística significante entre o tempo de permanência do cateter e as variáveis grau da flebite, classificação do dano e avaliação de risco. $\mathrm{Na}$ ocorrência de flebite grau 1, o tempo de permanência do dispositivo foi de 2,5 dias com variação de dois a quatro dias; na flebite grau 2, de três dias com variação entre dois e cinco dias; na flebite grau 3 foi de três dias com variação de dois a 3,5 dias e na flebite grau 4, de seis dias com variação de três a nove dias. O tempo de permanência do dispositivo dos pacientes que apresentaram dano moderado foi de três dias com variação entre três e quatro dias;

$\checkmark$ para o tratamento dos diferentes graus de flebite, notificadas no ano de 2017, foram realizados três procedimentos: "aplicação de pomada de extrato de flor de camomila"; "aplicação de compressas" e "instalação de AVP";

$\checkmark$ o CDM total do procedimento "aplicação de pomada de extrato de flor de camomila" foi de US\$ $0.55(\mathrm{DP}=0.06)$, sendo US\$ 0.40 ( $\mathrm{DP}=0.06)$ correspondentes ao custo com a MOB de técnico de enfermagem e US\$ 0.15 (DP=0.00), ao custo com material;

$\checkmark$ o CDM total do procedimento "aplicação de compressas" foi de US $\$ 0.51$ $(\mathrm{DP}=0.00)$, sendo US\$ $0.36(\mathrm{DP}=0.00)$ correspondentes ao custo com a $\mathrm{MOB}$ de técnico de enfermagem e US\$ 0.15 ( $\mathrm{DP}=0.00)$, ao custo com material;

$\checkmark$ o CDM total do procedimento "instalação de AVP com cateter jelco®" foi de US\$ 3.85 ( $\mathrm{DP}=0.08)$, sendo US\$2.91 ( $\mathrm{DP}=0.00$ ) correspondentes ao custo do material, cuja composição foi impactada pelo custo unitário dos itens: película transparente com fenda $(7 \mathrm{~cm} \times 7 \mathrm{~cm})$ - US $\$ 1.01$, conector de sistema fechado (US\$0.53) e cateter jelco® (US\$0.32) e US\$0.94 (DP=0.08) ao custo com a MOB de técnico de enfermagem;

$\checkmark$ o CDM total do procedimento "instalação de AVP com cateter íntima®" foi de US\$ 8.90 ( $\mathrm{DP}=0.06)$, sendo US\$ 7.94 ( $\mathrm{DP}=0.00$ ) correspondentes ao custo do material, cuja composição foi impactada pelo custo unitário dos itens cateter íntima® (US\$4.82), película transparente com fenda $(7 \mathrm{~cm} \times 7 \mathrm{~cm})$ - US\$1.01 e conector de sistema fechado (US\$0.53), e US\$ $0.96(\mathrm{DP}=0.06)$, ao custo com a MOB de técnico de enfermagem; 
$\checkmark$ a análise dos prontuários dos 96 pacientes da Unidade de Internação Clínica, referente aos procedimentos realizados para o tratamento de flebite em 2017, evidenciou que $62(64,6 \%)$ não continham o registro da "aplicação de compressas"; $17(17,7 \%)$ estavam sem o registro da "aplicação de pomada de extrato de flor de camomila"; e 17 (17,7\%) sem qualquer registro de procedimento padronizado no HCE para o tratamento da flebite. Dentre os $17,7 \%$ prontuários sem nenhum registro, $11,2 \%$ eram de pacientes portadores de flebite grau 1 e $5.6 \%$, de pacientes com flebite grau 2;

$\checkmark$ verificou-se o registro da realização de 656 (100\%) procedimentos, sendo a maioria (326 - 49,7\%) para o tratamento de flebite grau 2 e para a flebite grau 3 (172 $26,2 \%$ ), e os procedimentos mais realizados foram "aplicação da pomada de extrato de flor de camomila" (473 - 72,1\%) e "aplicação de compressas" (93 - 14,1\%);

$\checkmark$ a estimativa do CDM total dos 656 (100\%) procedimentos, realizados em 2017, para o tratamento do EA flebite, correspondeu a US\$ 866.18, com forte impacto do CDM do quantitativo da "instalação de acesso venoso periférico com cateter íntima $₫$ " (42 procedimentos - 6,4\%), com CDM estimado em US\$373.80, e da "aplicação de pomada de extrato de flor de camomila" (473 procedimentos - $72.1 \%$ ), CDM estimado em US\$ 260.15. A "instalação de AVP", considerando-se a somatória dos custos com cateter jelco $\AA^{\circledR}$ e cateter íntima ${ }^{\circledR}$, foi o procedimento com a estimativa de CDM mais elevado (US\$ 558,60 - 90 procedimentos), correspondendo a $64.5 \%$ do CDM total;

$\checkmark$ o manejo da flebite grau 2 apresentou o maior quantitativo de procedimentos documentados em 2017 (326/ano) e o CDM total mais elevado (US\$ 395.43 $45,7 \%$ ), seguido da flebite grau 1, com 141 procedimentos registrados ao ano e CDM total de US\$260.01 (30,0\%). 


\section{REFERÊNCIAS}

1. Zheng GH, Yang L, Chen HY, Chu JF, Mei L. Aloe vera for prevention and treatment of infusion phlebitis. Cochrane Data base Syst Rev. [Internet] 2014 [citado 2017 out 16];4(6):CD009162. Disponível em: https://www.ncbi.nlm.nih.gov/pubmed/24895299. 10.1002/14651858.CD009162.pub2.

2. Danski MTR, Oliveira GLR, Johann DA, Pedrolo E, Vayego AS. Incidence of local complications in peripheral venous catheters and associated risk factors. Acta paul. enferm. [Internet]. 2015 Dec [citado 2017 Oct 14]; 28(6): 517-23. Disponível em: $\quad$ http://www.scielo.br/scielo.php?script=sci_arttext\&pid=S0103$21002015000600517 \&$ Ing=en. http://dx.doi.org/10.1590/1982-0194201500087.

3. Alexander M. Infusion Nursing: Standards of Practice-Infusion. J Infus Nurs [Internet]. $2011 \quad$ [citado 2017 Set 01]34(1). Disponível em: http://engage.ahima.org/HigherLogic/System/DownloadDocumentFile.ashx?Docu mentFileKey=2238ee0a-c2df-4d1a-affa-f69f2ce41856

4. Abdul-Hak CK, Barros AF The incidence of phlebitis in a Medical Clinical Unit. Texto contexto - enferm. [Internet]. 2014 Sep [citado 2017 set 28]; 23(3): 633-8. Disponível em: http://www.scielo.br/scielo.php?script=sci_arttext\&pid=S010407072014000300633\&lng=en. $\underline{07072014000900013}$.

http://dx.doi.org/10.1590/0104-

5. Rufino GP, Gurgel MG, Pontes TC, Freire E. Avaliação de fatores determinantes do tempo de internação em clínica médica. Rev Bras Clin Med [internet]. 2012 [citado 2017 set 28] jul-ago;10(4):291-7. Disponível em: http://files.bvs.br/upload/S/1679-1010/2012/v10n4/a3043.pdf.

6. Slawomirski L, Auraaen A, Klazinga N. The economics of patient safety Strengthening a value-based approach to reducing patient harm at national level. Organisation for Economic Co-operation and Development - OECD. March 2017.

7. Castilho V, Lima AFC, Fugulin FMT. Gerenciamento de Custos nos Serviços de Enfermagem. In: Paulina Kurcgant, organizadora. Gerenciamento em Enfermagem. Rio de Janeiro: Guanabara Koogan, 2016. p. 171-83.

8. Brasil. Conselho Nacional de Secretários de Saúde. SUS: avanços e desafios. / Conselho Nacional de Secretários de Saúde. Brasília: CONASS; 2006, 164 p.

9. Francisco IMF, Castilho V. A enfermagem e o gerenciamento de custos. Rev Esc Enferm USP 2002; 36(3): 240-4. 
10. Fugulin FMT, Lima AFC, Castilho V, Guimarães CP, Carvalho A, Gaidzinskin RR. Nursing staff in the internal medicine and surgical units of teaching hospitals: composition and cost. Rev. esc. enferm. USP [Internet]. 2015 Dec [citado 2017 Out 09]; 49(spe2): 48-54. Disponível em: http://www.scielo.br/scielo.php?script=sci_arttext\&pid=S0080-

62342015000800048\&lng=en. http://dx.doi.org/10.1590/S0080623420150000800007.

11. Castilho V, Castro LC, Couto AT, Maia FOM, Sasaki NY, Nomura FH et al. Survey of the major sources of waste in the health care units of a teaching hospital. Rev. esc. enferm. USP [Internet]. 2011 Dec [citado 2017 set 25]; 45( spe ): 1613-20. Disponível em: http://www.scielo.br/scielo.php?script=sci_arttext\&pid=S0080$62342011000700012 \&$ lng =en. $\underline{62342011000700012 .}$

12. La Forgia GM, Couttolenc BF. Desempenho hospitalar no Brasil: em busca da excelência. São Paulo: Singular; 2009.

13. Oliveira WT, Rodrigues AVD, Haddad MCL, Vannuch MTO, Taldivo MA. Conceptions of nurses from a public university hospital regarding the cost management report. Rev. esc. enferm. USP [Internet]. 2012 [citado 2017 set 30]; 46(5): 1184-1191. Disponível em: http://www.scielo.br/scielo.php?script=sci_arttext\&pid=S0080-

$62342012000500021 \&$ lng =en.

http://dx.doi.org/10.1590/S0080$\underline{62342012000500021 .}$.

14. Ministério da Saúde e Organização Pan-Americana de Saúde. Introdução à gestão de custos em saúde. 2013. [citado 2017 set 29] Disponível em: http://bvsms.saude.gov.br/bvs/publicacoes/introducao gestao custos saude.pdf

15. Lima AFC, Castilho V. Gerenciamento de custos em UTI. In: Padilha KG, Vattimo MFF, Silva SC, Kimura M, Watanabe M, organizadores. Enfermagem em UTI: cuidando do paciente crítico. $2^{\underline{a}}$ Ed. ampliada e atualizada. São Paulo: Manole; 2016. p.1317-332.

16. Lima AFC, Castilho V, Baptista CMC, Rogenski NMB, Rogenski KE. Direct cost of dressings for pressure ulcers in hospitalized patients. Rev Bras Enferm [Internet]. 2016 [citado 2017 out 08];69(2):269-75. Disponível em: http://www.scielo.br/pdf/reben/v69n2/0034-7167-reben-69-02-0290.pdf http://dx.doi.org/10.1590/0034-7167.2016690212i

17. Cicolini G, Manzoli L, Simonetti V, Flacco ME, Comparcini D, Capasso L, Di Baldassar REA. Elaji EG. Phlebitis risk varies by peripheral venous catheter site and increases after 96 hours: a large multi-center prospective study. J Adv Nurs [Internet]. 2014 Nov [citado 2017 out 22];70(11):2539-49. Disponível em: https://www.ncbi.nlm.nih.gov/pubmed/24684163 doi: 10.1111/jan.12403. 
18. Brennan TA, Leape LL, Laird NM, et al. Incidence of Adverse Events and Negligence in Hospitalized Patients - Results of the Harvard Medical Practice Study I. N Engl J Med [internet] 1991; [citado 2017 jun 15] 324:370-6. Disponível em: http://www.nejm.org/doi/full/10.1056/NEJM199102073240604\#t=article DOI: 10.1056/NEJM199102073240604.

19. Kohn LT,Corrigan JM, Donaldson MC, editors; Institute of Medicine. To Err Human: building a safer health system. Washington: National Academy Press; 1999.

20. World Health Organization (WHO). World Alliance for Patient Safety: Forward Programme [Internet]. Genebra; 2004 [citado 2017 set 15]. Disponível em: http://www.who.int/patientsafety/en/brochure final.pdf.

21. Brasil. Ministério da Saúde, Programa Nacional de Segurança do Paciente. [Internet]. Brasília; 2017 [atualizado 2017; citado 2017 set. 16]. Disponível em: http://portalsaude.saude.gov.br/index.php/oministerio/principal/secretarias/sas/dahu/seguranca-do-paciente.

22. Brasil. Ministério da Saúde, Fundação Oswaldo Cruz, Agência Nacional de Vigilância Sanitária. Documento de referência para o Programa Nacional de Segurança do Paciente. Brasília; 2014.

23. Tartaglia CR, Martins M, Laguardia J. A segurança do paciente como dimensão da qualidade do cuidado de saúde: um olhar sobre a literatura. Ciênc. saúde coletiva [Internet]. 2013 [citado 2017 set 14];18(7): 2029-36. Disponível em: http://www.scielo.br/scielo.php?script=sci_arttext\&pid=S1413-

81232013000700018\&lng=en. http://dx.doi.org/10.1590/S141381232013000700018.

24. World Health Organization. Patient Safety [Internet]. Genebra; 2004 [citado 2017 set 15]. Disponível em: http://www.who.int/patientsafety/about/en/.

25. Runciman W, Hibbert $P$, Thomson R., Schaaf TV, Sherman H., LewalleP. Towards an International Classification for Patient Safety: key concepts and terms. Int $\mathrm{J}$ Qual Health Care. 2009;21(1):18-26.

26. Proqualis/lcict/Fiocruz. Taxonomia - Classificação Internacional para a Segurança do Paciente (ICPS). Centro Colaborador para a Qualidade do Cuidado e a Segurança do Paciente [Internet]. Rio de Janeiro; Disponível em: http://proqualis.net/

27. Brasil. Ministério da Saúde. Portaria GM n. 529, de 1 de abril de 2013. Institui o Programa Nacional de Segurança do Paciente (PNSP). Brasília; 2013 [acesso 2017 Set 18]. Disponível em: http://bvsms.saude.gov.br/bvs/saudelegis/gm/2013/prt0529_01_04_2013.html 
28. Agência Nacional de Vigilância Sanitária. Resolução de Diretoria Colegiada 36/2013. Institui ações para a segurança do paciente em serviços de saúde e dá outras providências. In: Diário Oficial da União. Brasília; 2013, n.143. [acesso 2017 Set 18]. Disponível em: http://portal.anvisa.gov.br/documents/10181/2871504/RDC 362013 COMP.pdf /36d809a4-e5ed-4835-a375-3b3e93d74d5e.

29. Brasil. Ministério da Saúde. Portaria GM n. 1.377, de 9 de julho de 2013. Aprova os Protocolos de Segurança do Paciente. [online]. Brasília; 2013 [acesso 2017 Set 18]. http://bvsms.saude.gov.br/bvs/saudelegis/gm/2013/prt1377_09_07_2013.html

30. Brasil. Ministério da Saúde. Portaria GM n. 2.095, de 24 de setembro de 2013. Aprova os Protocolos de Segurança do Paciente. [online]. Brasília; 2013 [acesso 2017 Set 18]. Disponível em: http://bvsms.saude.gov.br/bvs/saudelegis/gm/2013/prt2095 2409 2013.html

31. World Health Organization (WHO). Patient Safety: Making health care safer e [Internet]. Geneva; 2017. [citado 2017 set 10]; Disponível em: http://apps.who.int/iris/bitstream/10665/255507/1/WHO-HIS-SDS-2017.11eng.pdf.

32. Duarte SCM, Stipp MAC, Silva MM, Oliveira FT. Adverse events and safety in nursing care. Rev. Bras. Enferm. [Internet]. 2015 Feb [citado 2017 Sep 14]; 68(1): 144-54. Disponível

em: http://www.scielo.br/scielo.php?script=sci_arttext\&pid=S0034$71672015000100144 \&$ Ing=en. 7167.2015680120p.

http://dx.doi.org/10.1590/0034-

33. Porto S, Martins M, Mendes W, Travesssos C. A magnitude financeira dos eventos adversos em hospitais no Brasil. Rev Port Saude Publica [Internet]. 2010; [citado 2017 set 14]; Vol Temat(10):74-80. Disponível em: http://www.elsevier.pt/pt/revistas/revista-portuguesa-saude-publica-323/artigo/amagnitude-financeira-dos-eventos-adversos-em-hospitais-X0870902510898606.

34. Taofikat BA, Lietz M, Mira JJ, Warner B. A literature-based economic evaluation of healthcare preventable adverse events in Europe. Int $\mathrm{J}$ Qual Health Care [internet]. 2017 [citado 2017 out 10]; 29(1), 9-18. Disponível em: https://www.ncbi.nlm.nih.gov/pubmed/28003370. doi: 10.1093/intqhc/mzw14.

35. Sousa, P; Uva. A; Serraheira, F; Nunes, C; Leite, E. Estimating the incidence of adverse events in Portuguese hospitals: a contribution to improving quality and patient safety. BMC Health Services [internet] 2014 Jul [citado 2017 out 10]; 14 (311). Disponível em: https://www.ncbi.nlm.nih.gov/pubmed/25034870. doi:10.1186/1472-6963-14-311.

36. Couto RC, Pedrosa TMG, Rosa MB. Erros acontecem a força da transparência para o enfrentamento dos eventos adversos assistenciais em pacientes 
hospitalizados - construindo um sistema de saúde mais seguro. Instituto de estudos de saúde suplementar. Belo Horizonte, 2016. Disponível em: http://documents.scribd.com.s3.amazonaws.com/docs/5x5i1j985c5jwcsp.pdf.

37. Rafter N, Hickey A, Conroy RM, et al. The Irish National Adverse Events Study (INAES): the frequency and nature of adverse events in Irish hospitals - a retrospective record review study. BMJ Qual Saf [Internet] 2017 Feb [citado 2017 set 25];26(2):111-9. Disponível em: https://www.ncbi.nlm.nih.gov/pubmed/26862223 doi: 10.1136/bmjqs-2015004828.

38. Mendes W, Pavão ANB, Martins M, Mourac MLO, Travessos C. Características de eventos adversos evitáveis em hospitais do Rio de Janeiro Rev. Assoc. Med. Bras. [Internet]. 2013 [citado 2017 ago 29]; 59(5): 421-8. Disponível em: http://www.scielo.br/scielo.php?script=sci arttext\&amp;pid=S0104$\underline{42302013000500006 \& a m p ; I n g=e n}$. http://dx.doi.org/10.1016/j.ramb.2013.03.002.

39. Costa NN, Silva AEBC, Lima JC, et al. O retrato dos eventos adversos em uma clínica médica: análise de uma década. Cogitare Enferm [internet]. 2016; [citado 2017 ago 18]; 21 (esp): 01-10. Disponível em: revistas.ufpr.br/cogitare/article/view/45661.

http://dx.doi.org/10.5380/ce.v21i5.45661.

40. 40 Paiva MCMS, Melleiro MMM, Tronchin DMR, Lima SAM, Juliani CMC. The reasons of de nursing staff to notify adverse events. Rev. Latino-Am. Enfermagem [internet] set.-out. 2014; [citado 2017 set 15] 22(5):747-54. Disponível em: http://www.scielo.br/pdf/rlae/v22n5/pt 0104-1169-rlae-22-05-00747.pdf. DOI: 10.1590/0104-1169.3556.2476.

41. Brasil. Agência Nacional de Vigilância Sanitária. Assistência Segura: Uma Reflexão Teórica Aplicada à Prática [Internet]. Brasília; 2017. [citado 2017 set]; Disponível em: https://www20.anvisa.gov.br/segurancadopaciente/images/documentos/ivros/Liv ro1-Assistencia_Segura.pdf.

42. Levinson DR. Hospital Incident Reporting Systems Do Not Capture Most Patient Harm. Departament of Health and Human Services, Office of Inspection General, United State of America; 2012. Disponível em: https://oig.hhs.gov/oei/reports/oei06-09-00091.asp

43. Paiva MCMS, Paiva SAR, Berti HW. Adverse events: analysis of a notification instrument used in nursing management. Rev Esc Enferm USP [internet] 2010; [citado 2017 set 14] 44(2):287-94. Disponível em: http://www.scielo.br/pdf/reeusp/v44n2/07.pdf.

DOI: http://dx.doi.org/10.1590/S0080-62342010000200007.

44. Reason J. Safety in the operating theatre - Part 2: Human error and organisational failure. Qual Saf Health Care [internet] 2005; [citado 2017 ago 18] 14(1): 56-60. 
Disponível em: https://www.ncbi.nlm.nih.gov/pmc/articles/PMC1743973/.

45. Reason J, Carthey J, de Leval MR. Diagnosing vulnerable system syndrome: an essential pre requesite to effective risk management. Qual Health Care [Internet] 2001; [citado 2017 ago 18] 10(2):21-5.Disponível em:https://www.ncbi.nlm.nih.gov/pmc/articles/PMC1765747/

doi:10.1136/qhc.0100021.

46. Oliveira AC, Garcia PC, Nogueira LS. Nursing workload and occurrence of adverse events in intensive care: a systematic review. Rev. esc. enferm. USP [Internet]. 2016; [citado 2017 Ago 10]; 50(4): 683-94. Disponível em: http://www.scielo.br/scielo.php?script=sci_arttext\&pid=S0080-

$62342016000400683 \&$ Ing $=$ en.

http://dx.doi.org/10.1590/S0080-

$\underline{623420160000500020 .}$

47. Gonçalves LA, Andolhe R, Oliveira EMO, et al. Nursing allocation and adverse events/incidents in Intensive Care Unit. Rev. esc. enferm. USP [Internet]. 2012 [citado 2017 Set 21]; 46(esp): 71-7. Disponível em: http://www.scielo.br/scielo.php?script=sci_arttext\&pid=S0080$62342012000700011 \&$ Ing=en. http://dx.doi.org/10.1590/S0080$\underline{62342012000700011}$

48. World Health Organization (WHO). Quality of care: patient safety. Fifty-Fifth World Health Assembly Provisional [Internet]. 2002. [acessado 2017 ago 15]. Disponível em: http://www.who.int/patientsafety/worldalliance/ea5513.pdf

49. Conselho Regional de Enfermagem de São Paulo [internet]. São Paulo; Disponível em: http://www.coren-sp.gov.br.

50. Johann DA, Danski MTR, Vayego AS, Barbosa DA, Lind J. Risk factors for complications in peripheral intravenous catheters in adults: secondary analysis of a randomized controlled trial. Rev. Latino-Am. Enferm [Internet]. 2016 [citado 2017 Out 20]; 24 (e2833). Disponível em: http://www.scielo.br/scielo.php?script=sci_arttext\&pid=S010411692016000100435\&lng=en. http://dx.doi.org/10.1590/1518-8345.1457.2833.

51. Brasil. Agência Nacional de Vigilância Sanitária. Medidas de Prevenção de Infecção Relacionada à Assistência à Saúde [Internet]. Brasília; 2017. [citado 2017 set]; Disponível em: https://www20.anvisa.gov.br/segurancadopaciente/index.php/publicacoes/item $/ \mathrm{m}$ edidas-de-prevencao-de-infeccao-relacionada-a-assistencia-a-saude-3

52. Milutinović D, Simin D, Zec D. Risk factor for phlebitis: a questionnaire study of nurses' perception. Rev. Latino-Am. Enfermagem [Internet]. 2015 Aug [citado 2017 Set 22]; 23(4): 677-84. Disponível em: http://www.scielo.br/scielo.php?script=sci_arttext\&pid=S010411692015000400677\&lng=en. http://dx.doi.org/10.1590/0104-1169.0192.2603. 
53. Agencia Nacional de Vigilância Sanitária. Boletim Segurança do Paciente e Qualidade em Serviços de Saúde - Incidentes Relacionados à Assistência à Saúde - 2015. Gerência Geral de Tecnologia em Serviços de Saúde - Brasília, 2016.

54. Yassuko ACM, Silva VGLG, Aparecido BLJ, Camboin MV, Willamowius VD, Misue ML. Avaliação de cuidados na terapia intravenosa: desafio para a qualidade na enfermagem. Esc. Anna Nery [Internet]. 2013 Mar [citado 2017 out 16]; 17(1): 116. Disponível em: http://www.scielo.br/scielo.php?script=sci_arttext\&pid=S1414$81452013000100002 \&$ lng $=$ en. http://dx.doi.org/10.1590/S141481452013000100002.

55. Yin RK. Estudo de caso: Planejamento e método. 5ª ed. Porto Alegre: Bookman; 2015.

56. Sampieri RH, Collado CF, Lucio MPB. Metodologia de Pesquisa. Porto Alegre: Penso, 2013. Definição do alcance da pesquisa a ser realizada: exploratória, descritiva, correlacional ou explicativa; p. 99-110.

57. Jericó MC. Aplicação do custeio baseado em atividades em um centro de material esterilizado [tese]. São Paulo: Escola de Enfermagem; 2008 [citado 2017 ago 08]. Disponível em: http://www.teses.usp.br/teses/disponiveis/7/7136/tde-17042008$\underline{103258 / .}$.

58. Martins E. Contabilidade de custos. São Paulo: Atlas; 2010.

59. Lima AFC. Direct costs of integrated procedures of conventional hemodialysis performed by nursing professionals. Rev. Latino-Am. Enfermagem. [Internet]. 2017[cited 2018 Feb, 06]; 70(2):357-63. Available from: http://dx.doi.org/10.1590/0034-7167-2016-0447

60. Conselho Nacional de Saúde (Brasil). Resolução $n^{\circ} 466$, de 12 de dezembro de 2012. Brasília, 2012 [citado 16 outubro 2016]. Disponível em: http://www.conselho.saude.gov.br/web comissoes/conep/index.htm

61. Beccaria LM, Contrin LM, Werneck AL, Machado BD, Sanches EB. Incidente of phlebitis in adult patients. Rev enferm UFPE on line., Recife, 12(3):745-52, mar., 2018[citado 2019 jan 28]. Available from: https://doi.org/10.5205/1981-8963v12i3a230454p745-752-2018

62. Ferreira LR, Pedreira MLG, Diccini S. Flebite no pré e pós-operatório de pacientes neurocirúrgicos. Acta paul. enferm. [online]. 2007 [citado 2019 jan 28], vol.20, n.1, pp.30-36. ISSN 0103-2100. Available from: http://dx.doi.org/10.1590/S010321002007000100006. 
63. Teixeira CC, Bezerra ALQ, Paranaguá TTB, Pagotto V. Factors related to the occurrence of adverse events in hospitalized elderly patients. Rev baiana enferm (2018) [citado 2019 jan 28]; 32:e25772. DOI 10.18471/rbe.v32.25772

64. Urbanetto JS, Peixoto CG, May TA. Incidence of phlebitis associated with the use of peripheral IV catheter and following catheter removal. Rev. Latino-Am. Enfermagem. 2016;24:e2746. [cited 2019 fev 10]; Available in: http://www.scielo.br/pdf/rlae/v24/pt_0104-1169-rlae-24-02746.pdf. DOI: http://dx.doi.org/10.1590/1518-8345.0604.2746.

65. Tertuliano AC, Borges JLS, Fortunato RAS, Poveda VB, Oliveira AL. Flebite em acessos venosos periféricos de pacientes internados em um hospital do Vale do Paraíba. Rev min enferm. 2014 [citado 2019 fev 28] abr/jun; 18(2):334-45. 339. DOI: $10.5935 / 1415-2762.20140026$

66. Souza AEBR, Oliveira JLC, Dias DC, Nicola AL. Prevalência de flebites em pacientes adultos internados em hospital universitário. Revista da Rede de Enfermagem do Nordeste [Internet]. 2015[citado 2019 fev 28];16(1):114-122. Disponível em: https://www.redalyc.org/articulo.oa?id=324036185014.

67. Nyika ML, Mukona D, Zvinavashe M. Factors Contributing to Phlebitis Among Adult Patients Admitted in the Medical-Surgical Units of a Central Hospital in Harare, Zimbabwe. J Infus Nurs. 2018 [citado 2019 mar 28] Mar/Apr;41(2):96-102. doi: 10.1097/NAN.0000000000000265.

68. Göttems LBD, Santos MLG, Carvalho PA, Amorim FF. A study of cases reported as incidents in a public hospital from 2011 to 2014. Rev Esc Enferm USP. 2016[citado 2019 mar 28];50(5):861-867. DOI: http://dx.doi.org/10.1590/S0080$623420160000600021)$

69. Instituto Brasileiro de Geografia e Estatística [homepage na internet]. Projeção da população do Brasil e das Unidades da Federação. [acesso em 28 dez 2018]. Disponível em https://brasilemsintese.ibge.gov.br/populacao/distribuicao-dapopulacao-por-sexo.html.

70. Miranda GMD, Mendes ACG, Silva ALA. Population aging in Brazil: current and future social challenges and consequences. Rev. bras. geriatr. gerontol. [Internet]. 2016 June [cited 2019 Jan 02]; 19( 3 ): 507-519. Available from: http://www.scielo.br/scielo.php?script=sci_arttext\&pid=S1809-

98232016000300507\&lng=en.

http://dx.doi.org/10.1590/1809-

98232016019.150140

71. Dragana M, Dragana S, Davor Z. Risk factor for phlebitis: a questionnaire study of nurses' perception. Rev Lat Am Enfermagem. 2015[citado 2019 mar 28]; 23(4):677-84. Available from: http://www.scielo.br/scielo.php?script=sci_arttext\&pid=S010411692015000400677 
72. Danski MTR, Johann DA, Vayego SA, Oliveira GRL, Lind J. Complicações relacionadas ao uso do cateter venoso periférico: ensaio clínico randomizado. Acta paul. enferm. [Internet]. 2016 Feb [cited 2018 Nov 06]; 29( 1 ): 84-92. Available from: http://www.scielo.br/scielo.php?script=sci_arttext\&pid=S0103$21002016000100084 \&$ Ing=en. http://dx.doi.org/10.1590/1982-0194201600012.

73. Braga LM, Parreira PM, Oliveira ASS, Mónico LSM, Arreguy-Sena C, Henriques MA. Phlebitis and infiltration: vascular trauma associated with the peripheral venous catheter. Rev. Latino-Am. Enfermagem. 2018;26:e3002. [cited 2018 nov 06]; Available in: http://www.scielo.br/pdf/rlae/v26/0104-1169-rlae-26-e3002.pdf. DOI: http://dx.doi.org/10.1590/1518-8345.2377.3002.

74. Enes SMS, opitz SP, faro ARMc, Pedreira MLG. Phlebitis associated with peripheral intravenous catheters in adults admitted to hospital in the Western brazilian Amazon. Rev Esc Enferm USP. 2016 . [cited 2018 nov 06];50(2):261269. Doi: http://dx.doi.org/10.1590/S0080-623420160000200012

75. Brasil. Ministério da Saúde. Secretaria de Vigilância em Saúde. Departamento de Análise de Situação de Saúde. Plano de ações estratégicas para o enfrentamento das doenças crônicas não transmissíveis (DCNT) no Brasil 2011-2022 / Ministério da Saúde. Secretaria de Vigilância em Saúde. Departamento de Análise de Situação de Saúde. - Brasília : Ministério da Saúde, 2011. 160 p. : il. - (Série B. Textos Básicos de Saúde).

76. Do Rego Furtado LC. Incidence and predisposing factors of phlebitis in a surgery department. Br J Nurs. 2011;20(14 suppl):S16-S25.). [cited 2019 feb 10]; Available in: https://www.ncbi.nlm.nih.gov/pubmed/21841668

77. Silva LA, Terra FS, Macedo FRM, Santos SVM, Maia LG, Batista MHJ. Notification of adverse events: characterization of events occurred in a hospital institution. Rev enferm UFPE on line., Recife, 8(9):3015-23, set., 2014 . [cited 2019 mar 06]. Available from: https://periodicos.ufpe.br/revistas/revistaenfermagem/article/view/10020

78. Furini ACA, Nunes AA, Dallora MELV. Notificação de eventos adversos: caracterização dos eventos ocorridos em um complexo hospitalar Rev Gaúcha Enferm. 2019 . [cited 2019 mar 06];40(esp):e20180317 doi: https://doi.org/10.1590/1983-1447.2019.20180317.

79. Paranaguá TTB, Bezerra ALQ, Silva AEBC, Azevedo FFM. Prevalência de incidentes sem dano e eventos adversos em uma clínica cirúrgica. Acta paul. enferm. [Internet]. 2013 [citado 2019 Mar 10]; 26( 3 ): 256-262. Disponível em: http://dx.doi.org/10.1590/S0103-21002013000300009

80. Agência Nacional de Vigilância Sanitária (BR). Relatório Brasil e Estado de São Paulo - 2018. Brasília: Anvisa; 2018 [citado 2019 fev 28]. 
81. Pasalioglu KB, Kaya $\mathrm{H}$. Catheter indwell time and phlebitis development during peripheral intravenous catheter administration. Pak J Med Sci 2014. [cited 2019 mar 06].;30(4):725-730. doi: http://dx.doi.org/10.12669/pjms.304.5067.

82. ECS Oliveira, APB Oliveira, RC Oliveira. Characterization of phlebitis notifications to risk management in hospital sentinel network. Revista Baiana de Enfermagem, Salvador, p. 1-9, abr./jun. 2016. [cited 2019 mar 06]. DOI: 10.18471/rbe.v30i2.1536.

83. Rossini FP, Andrade D, Santos LCS, Ferreira AM, Tieppo C, Watanabe E. Microbiological testing of devices used in maintaining peripheral venous catheters. Rev. Latino-Am. Enfermagem. 2017;25:e2887. [cited 08 mar 2019]; Available from: http://www.scielo.br/pdf/rlae/v25/pt_0104-1169-rlae-25-e2887.pdf. DOI: http://dx.doi.org/10.1590/1518-8345.1528.2887.

84. Rickard CM, Webster J, Wallis MC, Marsh N, McGrail MR, French V, et al. Routine versus clinically indicated replacement of peripheral intravenous catheters: a randomised controlled equivalence trial. Lancet [Internet]. 2012 [citado 2019 mar 4];380(9847):1066-74.

Disponível

em: http://www.thelancet.com/journals/lancet/article/PIIS0140-6736(12)610824/abstract.

85. Salgueiro $A O$, Parreira $P$, Veiga $P$. Incidence of phlebitis in patients with peripheral intravenous catheters: The influence of some risk factors. Australian Journal of Advanced Nursing, 30(2) (Dec 2012-Feb 2013). [cited 2019 mar 16]. Disponível em:

https://search.informit.com.au/documentSummary;dn=089105424571588;res=iel apa.

86. Alves JL, Rodrigues CM, Antunes AV. Prevalence of Phlebitis in a Clinical Inpatient Unit of a High-complexity Brazilian University Hospital. R bras ci Saúde 22(3):231236, 2016. [cited 2019 mar 26]. Disponível em: http://www.periodicos.ufpb.br/ojs/index.php/rbcs/article/view/27078/19855.

87. Urbanetto JS, Freitas APC, Oliveira APR, Santos JCR, Muniz FOM, Silva RM, et al. Fatores de risco para o desenvolvimento da flebite: revisão integrativa da literatura. Rev Gaúcha Enferm. 2017. [cited 2019 mar 26].;38(4):e57489. doi: http://dx.doi.org/10.1590/19831447.2017.04.57489

88. Agência Nacional de Vigilância Sanitária. Pacientes pela segurança do paciente em serviços de saúde: Como posso contribuir para aumentar a segurança do paciente? Orientações aos pacientes, familiares e acompanhantes/ Agência Nacional de Vigilância Sanitária. Brasília: Anvisa, 2017. Disponível em: http://portal.anvisa.gov.br/documents/33852/3507912/Como+posso+contribu ir+para+aumentar+a+seguran\%C3\%A7a+do+paciente/52efbd76-b692-4b0e8b70-6567e532a716

89. Wegner W, EVA NRP. Patient safety in care circumstances: prevention of adverse 
events in the hospitalization of children. Rev. Latino-Am. Enfermagem 20(3):[8 telas] maio-jun. 2012 www.eerp.usp.br/rlae

90. Sousa FCP, Montenegro LC, Goveia VR, Corrêa ARe, Rocha PK, Manzo BF. Family participation in patient safety in neonatal units from the nursing perspective. Texto contexto - enferm. [Internet]. 2017 [cited 2019 Mar 01]; 26( 3): e1180016. Available from: http://www.scielo.br/scielo.php?script=sci_arttext\&pid=S010407072017000300314\&lng=en. Epub Aug 17, 2017. http://dx.doi.org/10.1590/0104-07072017001180016

91. Melo TO, Lima AFC. Cost of nursing most frequent procedures performed on severely burned patients Revista Brasileira de Enfermagem, vol. 70, núm. 3, mayo-junio, 2017, [cited 2019 Apr 01] pp. 481-488 Associação Brasileira de Enfermagem Brasília, Brasil. Available from: https://www.redalyc.org/pdf/2670/267051078006 5.pdf

92. Andrade CCD, Almeida CFSC, Pereira WE, Alemão MM, Brandão CMaRuas, Borges EL. Custos do tratamento tópico de pacientes com úlcera por pressão. Rev. esc. enferm. USP [Internet]. 2016 Apr [cited 2019 Apr 04] ; 50( 2 ): 295301. Available from: http://www.scielo.br/scielo.php?script=sci_arttext\&pid=S008062342016000200295\&lng=en. http://dx.doi.org/10.1590/S0080$\underline{623420160000200016}$

93. Gouvêa AL, Lima AFC. Direct cost of connecting, maintaining and disconnecting patient-controlled analgesia pump. Rev. esc. enferm. USP [Internet]. 2014 Feb [cited 2019 Apr 02] ; 48(1): 104-109. Available from: http://www.scielo.br/scielo.php?script=sci_arttext\&pid=S0080-

62342014000100104\&lng=en. http://dx.doi.org/10.1590/S0080$\underline{623420140000100013}$.

94. Stevens C, Milner KA, Trudeau J. Routine Versus Clinically Indicated Short Peripheral Catheter Replacement: An Evidence-based Practice Project. J Infus Nurs 2018 May/Jun;41(3):198-204. doi: 10.1097/NAN.0000000000000281.

95. Tuffaha HW, Rickard CM, Inwood S, Gordon L, Scuffham P The epic3 recommendation that clinically indicated replacement of peripheral venous catheters is safe and cost-saving: how much would the NHS save? Send to J Hosp Infect. 2014 Jul;87(3):183-4. doi: 10.1016/j.jhin.2014.04.004. Epub 2014 May 6.Disponível em: https://www.ncbi.nlm.nih.gov/pubmed/24928785.

96. Martins TSS, Silvino ZR. Survey of the costs of Peripheral the Intravascular Device in the composition of the values of the internment in a pediatric unit - quantitative study. Rev enferm UFPE on line. 2008 out./dez.; 2(4):492-94. Disponível em: https://www.ufpe.br/revistaenfermagem/index.php/revista/article/view/735/pdf 45

97. Reichert MCF, Lozovoi TG, D'Innocenzo M. O desperdício de materiais assistenciais percebido por graduandos de enfermagem. Rev. Eletr. Enf. 
[Internet]. 2017 [acesso em: 02 mar 2019];19:a27. Disponível em: http://dx.doi.org/10.5216/ree.v19.42243.

98. Albano TC,Freitas JB. Nurse's effective participation in planning: focus on costs. Rev Bras Enferm; 66(3): 372-7, 2013 [acesso em: 02 mar 2019]; May-Jun. Disponível em: http://www.scielo.br/pdf/reben/v66n3/a11v66n3.pdf.

99. Castilho V, Mira VL, Lima AFC. Gerenciamento de Recursos materiais. In: Paulina Kurcgant, organizadora. Gerenciamento em Enfermagem. Rio de Janeiro: Guanabara Koogan, 2016. p.-145-157.

100. Jones RK Short Peripheral Catheter Quality and Economics: The Intravenous Quotient. J Infus Nurs. 2018 Nov/Dec;41(6):365-371. doi: 10.1097/NAN.0000000000000303. disponível em: https://www.ncbi.nlm.nih.gov/pubmed/30399072

101. Rodrigues JARM, Cunha ICKO, Vannuchi MTO, Haddad MCFL. Glosas em contas hospitalares: um desafio à gestão. Rev. Bras. Enferm. [Internet]. 2018 Out [citado 2019 Abr 01] ; 71(5): 2511-18. Disponível em: http://www.scielo.br/scielo.php?script=sci_arttext\&pid=S0034-

71672018000502511\&Ing=pt. http://dx.doi.org/10.1590/0034-7167-2016-0667

102. Conselho Federal de Medicina. Resolução CFM no 193/2009. Código de Ética Médica. Capítulo X - Documentos médicos. In: Diário Oficial da União. Brasília; 17 set 2009.

103. Conselho Federal de Enfermagem. Resolução COFEN no 311/2007. Código de Ética dos Profissionais de Enfermagem. In: Diário Oficial da União. Brasília; 13 fev 2007.

104. Setz VG, D'Innocenzo M. Avaliação da qualidade dos registros de enfermagem no prontuário por meio da auditoria. Acta Paul. Enferm. 2009; 22 (3): 313-7. Disponível em: http://www.scielo.br/scielo.php?script=sci_arttext\&pid=S0103$21002009000300012 \& \operatorname{lng}=$ en. http://dx.doi.org/10.1590/S010321002009000300012 . 


\section{APÊNDICE A}

\section{Instrumento para coleta de dados}

Autor da notificação:

( ) Enfermeiro ( ) Técnico de enfermagem ( ) Anônimo ( ) Outro:

1. Unidade da ocorrência:

( ) Unidade de Internação Clínica 1 ( ) Unidade de Internação Clínica 2

2. Número do atendimento:

3. Número do SAME:

4. Data da ocorrência:

5. Idade do paciente:

6. Sexo do paciente: ( ) masculino ( ) feminino

7. Período da ocorrência: ( ) manhã ( ) tarde ( ) noite

8. Grau de flebite:

( ) grau 1: hiperemia ( ) grau 2: hiperemia + dor local

( ) grau 3: hiperemia + dor local + cordão palpável

( ) grau 4: hiperemia + dor local + cordão palpável e drenagem purulenta

9. Nome do fármaco envolvido:

10. Tempo de permanência do cateter:

( ) 1 dia ( ) 2 dias ( ) 3 dias ( ) 4 dias ( ) 5 dias

( ) 6 dias ( ) 7 dias ( ) pós retirada

11. Classificação do dano:

( ) grave ( ) moderado ( ) leve ( ) nenhum

12. Avaliação do risco para o desenvolvimento de flebite:

( ) alto ( ) moderado ( ) baixo ( ) sem risco

Observações: 


\section{APÊNDICE B}

\section{Instrumento para coleta de dados}

Procedimento: Punção de acesso venoso periférico

Data

Duração

Turno da coleta

MATERIAL UTILIZADO

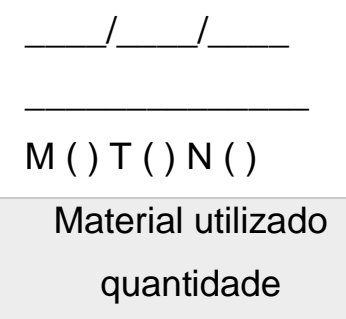

quantidade

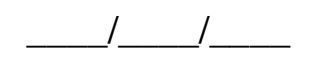

$\mathrm{M}($ ) T ( ) N ( )

Material utilizado

quantidade

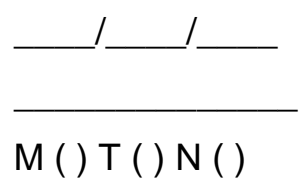

Material utilizado

quantidade

Luvas de procedimento

Máscara cirúrgica

Seringas de $10 \mathrm{~mL}$ com SF

0,9\% (PosiFlush $\circledast$ )

Película transparente $(7 \mathrm{~cm}$

$x 8,5 \mathrm{~cm}$ ) com fenda

Conector de sistema

fechado

Garrote

Swab de álcool a $70 \%$

Cateter periférico com dispositivo de segurança jelco® ( ) íntima® ( ) 


\section{APÊNDICE C}

\section{Instrumento para coleta de dados}

Procedimento: Aplicação de compressas

Data

Duração

Turno da coleta

MATERIAL UTILIZADO

uvas de procedimento

Bolsa gel

Sontara $\AA^{(c o m p r e s s a)}$

Gaze 


\section{APÊNDICE D}

\section{Instrumento para coleta de dados}

\section{Procedimento: Aplicação de pomada tópica}

Data

Duração

Turno da coleta

MATERIAL UTILIZADO

Luvas de procedimento

Pomada de extrato de flor

de camomila

Outra pomada:

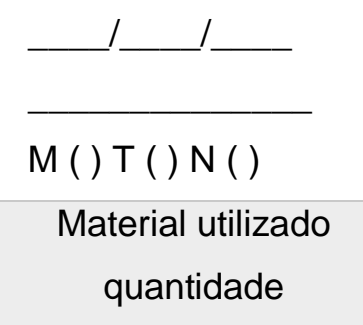$$
\text { M }
$$$$
\mathrm{M}(\text { ) } \mathrm{T}(\mathrm{)} \mathrm{N}(\text { ) }
$$

Material utilizado

quantidade

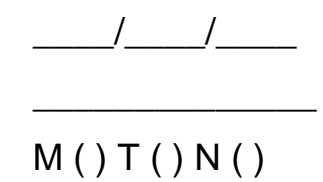

Material utilizado quantidade 


\section{APÊNDICE E}

\section{Solicitação de autorização para pesquisa em banco de dados}

Eu, Maryana da Silva Furlan, mestranda do Programa de Pós-graduação em Gerenciamento em Enfermagem da Escola de Enfermagem da Universidade de São Paulo (EEUSP), estou desenvolvendo o projeto de pesquisa "Custo direto da ocorrência do evento adverso flebite (EA) em uma Unidade de Internação Clínica", sob orientação do Professor Doutor Antônio Fernandes Costa Lima.

O conhecimento das causas e do impacto financeiro da ocorrência de flebite constitui uma importante fonte de informação visando a melhoria dos processos, assistenciais e gerenciais, com repercussões favoráveis na qualidade do cuidado e na segurança do paciente. Nesta perspectiva, esta pesquisa tem como objetivos analisar a ocorrência do EA flebite em pacientes da Unidade de Internação Clínica de um hospital privado no município de São Paulo e estimar o custo direto médio dos procedimentos decorrentes do referido EA. Para o alcance destes objetivos, solicitamos a autorização para a coleta de dados, constantes dos formulários de notificação de eventos adversos e prontuários dos pacientes, relativos aos procedimentos decorrentes do EA flebite em pacientes da Unidade de Internação Clínica no período de janeiro a dezembro de 2017.

Esclarecemos que a pesquisa somente será realizada após a anuência do hospital campo de estudo (HCE) e aprovação do Comitê de Ética em Pesquisa do HCE. Os dados obtidos serão tratados de forma anônima, sendo preservadas as identidades dos pacientes, dos profissionais envolvidos e do HCE.

Contando com a autorização desta conceituada instituição, colocamo-nos à disposição para quaisquer esclarecimentos.

São Paulo, de de 2018.

Maryana da Silva Furlan / RG

7.576.534-7
Prof. Dr. Antônio Fernandes Costa

Lima / RG: 20.289.732-1 


\section{APÊNDICE F Termo de Consentimento Livre e Esclarecido (Profissional)}

Convido o(a) Sr(a) para participar da pesquisa intitulada "Custo direto da ocorrência do evento adverso e flebite em uma Unidade de Internação Clínica" desenvolvida por Maryana da Silva Furlan, sob orientação do Professor Doutor Antônio Fernandes Costa Lima.

Justifica-se a sua realização visto que o conhecimento das causas e do impacto financeiro da ocorrência de flebite pode ser considerado uma importante fonte de informação visando a melhoria dos processos, assistenciais e gerenciais, com repercussões favoráveis na qualidade do cuidado e na segurança do paciente. Nesta perspectiva, a pesquisa tem como objetivos analisar a ocorrência do evento adverso flebite em pacientes da Unidade de Internação Clínica de um hospital privado no município de São Paulo e estimar o custo direto médio dos procedimentos decorrentes da ocorrência deste evento adverso.

Caso aceite participar, solicitamos a sua autorização para observá-la (o) durante a realização dos procedimentos decorrentes da ocorrência de flebite em pacientes da Unidade de Internação Clínica, a fim de documentar o tempo despendido e o material consumido. Sua participação pode ser classificada como de risco mínimo associado ao desconforto de ser observado durante a execução dessas procedimentos. A observação não ocasionará alterações na condução das suas atividades e poderá ser interrompida a qualquer momento, mediante sua solicitação, sem prejuízo pessoal ou profissional. Asseguro-lhe o anonimato e a garantia de que os resultados desta pesquisa serão utilizados e divulgados com finalidade única de contribuir para o conhecimento científico, sem qualquer ganho pessoal ou econômico para o pesquisador.

Não há despesas pessoais ou compensação financeira relacionada à sua participação. Você poderá requerer indenização caso haja algum dano decorrente da condução da pesquisa. O projeto de pesquisa em questão foi aprovado pelo Comitê de Ética em Pesquisa do Hospital campo de estudo (HCE).

Caso você tenha alguma consideração ou dúvida sobre a ética da pesquisa, entre em contato com o Comitê de Ética em Pesquisa do HCE: Rua Peixoto Gomide, 316 - 7ํandar - tel: (11) 3394-0200 ou (11) 3394 5701; e-mail: cepesq@hsl.org.br.

Este Termo deverá ser assinado em duas vias, uma pertence a você e a outra será arquivada pelo pesquisador.

A pesquisadora principal pode ser encontrada na Avenida Nove de Julho, 1952 apartamento 301, ou contatada por meio do telefone: (11) 987561710, ou pelo e-mail: maryana.silvafurlan@gmail.com. 
Esta pesquisa atende todas as especificações da resolução 466, de 12 de dezembro de 2012, que aprova as diretrizes e normas regulamentadoras de pesquisas envolvendo seres humanos.

São Paulo, __ de____ de 2018. 


\section{APÊNDICE G \\ Termo de Consentimento Livre e Esclarecido (Paciente)}

Convido o(a) $\mathrm{Sr}($ a) para participar da pesquisa intitulada "Custo direto da ocorrência do evento adverso flebite em uma Unidade de Internação Clínica" desenvolvida por Maryana da Silva Furlan sob orientação do Professor Doutor Antônio Fernandes Costa Lima.

Justifica-se a sua realização visto que o conhecimento das causas e do impacto financeiro da ocorrência de flebite (inflamação da parede das veias) pode ser considerado uma importante fonte de informação visando a melhoria dos processos, assistenciais e gerenciais, com repercussões favoráveis na qualidade do cuidado e na segurança do paciente. Nesta perspectiva, a pesquisa tem como objetivos analisar a ocorrência do evento adverso flebite em pacientes da Unidade de Internação Clínica de um hospital privado no município de São Paulo e estimar o custo direto médio dos procedimentos decorrentes da ocorrência deste evento adverso.

Caso aceite participar solicito a sua autorização para observar o(a) profissional de enfermagem durante a execução de cuidados para o tratamento de flebite. Sua participação pode ser classificada como de risco mínimo associado ao possível desconforto de ser observado. A observação não ocasionará nenhuma alteração na realização desses cuidados. Esclarece-se que a observação poderá ser interrompida, a qualquer momento, por sua solicitação ou solicitação do(a) profissional executante do procedimento sem qualquer prejuízo ao seu atendimento. Asseguro-lhe o anonimato e a garantia de que os resultados desta pesquisa serão utilizados e divulgados com finalidade única de contribuir para o conhecimento científico, sem qualquer ganho pessoal ou econômico para o pesquisador.

Não há despesas pessoais ou compensação financeira relacionada à sua participação. Você poderá requerer indenização caso haja algum dano decorrente da condução da pesquisa. $O$ projeto de pesquisa em questão foi aprovado pelo Comitê de Ética em Pesquisa do Hospital campo de estudo (HCE).

Caso você tenha alguma consideração ou dúvida sobre a ética da pesquisa, entre em contato com o Comitê de Ética em Pesquisa do HCE: Rua Peixoto Gomide, 316 - $7^{\circ}$ andar - tel: (11) 3394-0200 ou (11) 3394 5701; e-mail: cepesq@hsl.org.br.

Este Termo deverá ser assinado em duas vias, uma pertence a você e a outra será arquivada pelo pesquisador.

A pesquisadora principal pode ser encontrada na Avenida Nove de Julho, 1952 apartamento 301, ou contatada por meio do telefone: (11) 987561710, ou pelo e-mail: maryana.silvafurlan@gmail.com. 
Esta pesquisa atende todas as especificações da resolução 466, de 12 de dezembro de 2012, que aprova as diretrizes e normas regulamentadoras de pesquisas envolvendo seres humanos.

São Paulo,__ de___ de 2018. 


\section{APENDICE H}

Grupos Patológicos

Patologias

\begin{tabular}{|c|c|}
\hline AFECÇÕES CARDÍACAS & $\begin{array}{l}\text { Crise hipertensiva } \\
\text { Insuficiência Cardíaca Congestiva descompensada }\end{array}$ \\
\hline AFECÇÕES REUMÁTICA & Espondilite \\
\hline AFECÇÕES GENÉTICAS & Febre familiar do mediterrâneo \\
\hline AFECÇÕES INFECCIOSAS & $\begin{array}{l}\text { Broncopneumonia } \\
\text { Celulite em perna direita } \\
\text { Histoplasmose ganglionar fistulizado } \\
\text { Tuberculose pulmonar } \\
\text { Erisipela em membro inferior esquerdo } \\
\text { Celulite periorbitária } \\
\text { celulite em punho direito } \\
\text { Insuficiência respiratório por traqueobronquite } \\
\text { Primoinfecção herpética } \\
\text { Colite pseudomembranosa } \\
\text { Diarreia aguda infecciosa } \\
\text { Pielonefrite } \\
\text { Pneumonia } \\
\text { Celulite em membro inferior direito } \\
\text { Úlcera crônica infectada } \\
\text { Síndrome viral aguda } \\
\text { Bacteremia } \\
\text { Celulite em glúteo } \\
\text { Doença de Lyme } \\
\text { Herpes zoster } \\
\text { Prostatite bacteriana } \\
\text { Infecção do trato urinário } \\
\text { Toxoplasmose aguda } \\
\text { Abcesso sub-hepático } \\
\text { Meningite por varicela } \\
\text { Gastrenterocolite infecciosa } \\
\text { Meningite } \\
\text { Hematoma glúteo infectado } \\
\text { Linfadenite supurativa } \\
\text { Gastrenterocolite por rotavírus } \\
\text { ald }\end{array}$ \\
\hline
\end{tabular}


Grupos patológicos

Patologias

\begin{tabular}{|c|c|}
\hline $\begin{array}{l}\text { AFECÇÕES DO SISTEMA } \\
\text { NERVOSO CENTRAL E } \\
\text { PERIFÉRICO }\end{array}$ & $\begin{array}{l}\text { Polirradiculoneurite aguda } \\
\text { Crise miastênica } \\
\text { Ataque isquêmico transitório } \\
\text { Mielite } \\
\text { Polirradiculoneurite axonal crônica } \\
\text { Polineuropatia } \\
\text { Polineuropatia sensitivo-motora em membros } \\
\text { inferiores } \\
\text { Crise convulsiva } \\
\text { Síndrome de Guillain Barré }\end{array}$ \\
\hline $\begin{array}{l}\text { AFECÇÕES DO APARELHO } \\
\text { DIGESTIVO }\end{array}$ & $\begin{array}{l}\text { Constipação intestinal } \\
\text { Pancreatite aguda } \\
\text { Adenocarcinoma de colón } \\
\text { Síndrome do intestino curto } \\
\text { Abdome obstrutivo com volvo gástrico } \\
\text { Gastrite aguda enantematosa } \\
\text { Diverticulite } \\
\text { Obstrução Intestinal por bridas } \\
\text { Hipertensão portal } \\
\text { Doença do refluxo gastresofágico } \\
\text { Constipação intestinal } \\
\text { Pancreatite aguda } \\
\text { Adenocarcinoma de colón } \\
\text { Síndrome do intestino curto } \\
\text { Abdome obstrutivo com volvo gástrico } \\
\text { Gastrite aguda enantematosa } \\
\text { Diverticulite } \\
\text { Obstrução intestinal por bridas }\end{array}$ \\
\hline AFECÇÕES ENDÓCRINAS & Diabetes mellitus descompensada \\
\hline SEPSE & $\begin{array}{l}\text { Sepse de foco cutâneo } \\
\text { Sepse por abcesso hipofisário } \\
\text { Sepse de foco a esclarecer }\end{array}$ \\
\hline $\begin{array}{l}\text { AFECÇÕES DO SISTEMA } \\
\text { RESPIRATÓRIO }\end{array}$ & Carcinoma de pulmão \\
\hline
\end{tabular}

